NBER WORKING PAPER SERIES

\title{
INTANGIBLES, MARKUPS, AND THE MEASUREMENT OF PRODUCTIVITY GROWTH
}

\author{
Nicolas Crouzet \\ Janice C. Eberly \\ Working Paper 29109 \\ http://www.nber.org/papers/w29109
NATIONAL BUREAU OF ECONOMIC RESEARCH
1050 Massachusetts Avenue
Cambridge, MA 02138 \\ July 2021
}

This paper was prepared for the 2020 JME-SNB-SCG conference, held on October 15, 2020. We thank Susanto Basu, Antonio Ciccone and John Fernald, our formal discussants, Ricardo Reis, our editor, seminar participants at the 2021 SI Conference on Research in Income and Wealth, and an anonymous referee for comments that greatly helped improve the paper. The views expressed herein are those of the authors and do not necessarily reflect the views of the National Bureau of Economic Research.

NBER working papers are circulated for discussion and comment purposes. They have not been peerreviewed or been subject to the review by the NBER Board of Directors that accompanies official NBER publications.

(C) 2021 by Nicolas Crouzet and Janice C. Eberly. All rights reserved. Short sections of text, not to exceed two paragraphs, may be quoted without explicit permission provided that full credit, including (c) notice, is given to the source. 
Intangibles, Markups, and the Measurement of Productivity Growth

Nicolas Crouzet and Janice C. Eberly

NBER Working Paper No. 29109

July 2021

JEL No. D24,D4,E01,E22,G31

\begin{abstract}
In recent years, measured TFP growth in the US has declined. We argue that two forces contributed to this decline: the mismeasurement of intangible capital, and rising markups. Markups affect input shares, while intangibles omitted from measures of investment affect measured capital growth, each potentially generating downward bias in measured TFP growth. Most importantly, when both forces are simultaneously present, their effects reinforce each other and amplify the downward bias in measured TFP growth. Using input-output data, we estimate that this mechanism could account for one-third to two-thirds of the decline in measured TFP growth.
\end{abstract}

\author{
Nicolas Crouzet \\ Finance Department \\ Kellogg School of Management \\ Northwestern University \\ 2211 Campus Drive \\ Evanston, IL 60208 \\ n-crouzet@kellogg.northwestern.edu \\ Janice C. Eberly \\ Department of Finance \\ Kellogg School of Management \\ Northwestern University \\ 2211 Campus Drive \\ Evanston, IL 60208 \\ and NBER \\ eberly@kellogg.northwestern.edu
}




\section{Introduction}

Productivity is an enduring challenge in the U.S. economy and its measurement. Postfinancial crisis, slow growth was initially put down to scarring or the aftermath of the crisis itself. But later work traces the explanation to weak productivity (Fernald et al., 2017). Moreover, they and others date weak productivity earlier than the financial crisis. That is, the weak growth in the U.S. economy following the financial crisis has its roots in a much earlier productivity slowdown. In this paper, we show how the presence of intangible capital and market power, which have also grown over this time period, leads to underestimates of productivity growth. The effect of either alone is relatively small, but together - as in Crouzet and Eberly (2020) — their effect is magnified. Empirically reasonable values of markups and unmeasured capital can account for about half of the measured productivity slowdown in the 2000s.

The US productivity slowdown has been extensively debated and researched, focusing on whether it is a measurement problem or a real phenomenon, and if it is real, what has caused productivity to decline - especially when innovation seems so prevalent. While there are many reasons for productivity to be mismeasured, especially given the methodological and data challenges, most candidate explanations cannot generate the sustained magnitudes seen in the data. For example, Byrne et al. (2016) take into account mismeasured IT capital and nonmarket consumption (among other factors). These factors have an effect on measured productivity by changing the level of output, but they cannot account for more than a tiny fraction of the magnitude of slowing productivity growth over time.

Research has instead focused on how productivity growth can be so low in the face of apparently enormous innovation in digital technologies and the internet. Prominent among this work is Robert Gordon's research and book (Gordon, 2017) on "The Rise and Fall of American Growth," arguing that recent innovation has not had the productivity enhancing impact of historical breakthroughs. Impact on the scale of penicillin, he argues, for example, has not occurred in the era of digital innovation. 
Concurrent with this work on low productivity, research has expanded into explaining related aspects of the puzzle, such as the low level of investment in the US economy. Low capital investment is consistent with low productivity, but not consistent with observed high firm valuations and profitability, which would instead suggest that the returns to capital investment are high. A growing literature on the growth of market power in the U.S. economy (De Loecker et al., 2020) offers one explanation, since firms have less incentive to expand capacity when they have market power (Gutiérrez and Philippon, 2017).

At the same time that productivity has fallen and market power appears to have risen, intangible capital has also become a larger share of firms' capital stocks while physical capital investment has declined (Alexander and Eberly, 2018). Crouzet and Eberly (2019) show that intangibles can explain 30 to 60 percent of the decline, when looking at firmlevel and industry-level data, respectively. These explanations are not mutually exclusive and actually reinforce each other, as in Crouzet and Eberly (2020), and the interaction of intangible capital with markups from market power can explain much the decline in observed investment in the U.S.

This paper brings market power and intangible capital together to examine the puzzle of low US productivity. Both phenomena violate the standard assumptions of productivity measurement.

We first show, in Section 2, how market power and omitted intangible capital would appear in an extension of a standard and general productivity measurement framework. We allow for purchases of some capital goods to be incorrectly classified as intermediates in the national accounts, instead of being treated as final spending and accordingly capitalized. Omitted intangible investment is one example, but our treatment is more general.

In this framework, markups alone generate a downward bias in TFP growth. They imply that the measured labor share is an overestimate of the true elasticity of output with respect to labor. When capital is growing faster than labor, this biases downward measures of TFP growth. However, this bias is not quantitatively large, even in extreme cases. 
Omitted intangibles alone could also bias measured TFP growth: if the true stock of unmeasured capital is growing more slowly than the measured stock, measured TFP growth will be biased downward. In addition, omitting intangible investment makes the level of GDP too low, relative to true GDP; therefore, the measured labor share is higher than the elasticity of output to labor. This upward bias in the measured labor share can be large and increases with the amount of intangible investment omitted from GDP calculations. However, an upward bias in the labor share seems surprising empirically, since the measured labor share has been declining since at least the late 1990s.

Combining markups with omitted intangibles offsets this labor share effect, while preserving the potential for a negative bias in productivity growth. As discussed above, markups tend to make the measured labor share lower. Sufficiently high markups can then allow the framework to be consistent with both a large and growing amount of omitted intangible investment and a low measured labor share - potentially lower than the true elasticity of output to labor, thus adding to the overall TFP bias.

Aside from these two sources of measurement bias - the capital growth bias, and the labor share bias -, a third source of bias is that GDP growth itself might be mismeasured. This is the bias emphasized by many previous studies. To the extent that omitted intangible investment is growing faster than measured GDP, the true growth rate of GDP might be higher than its measured counterpart, leading to underestimates of true TFP growth.

In Section 2, we therefore develop further results using the balanced-growth version of a model to quantify the effects of the two main mechanisms that we are interested in: markups and omitted intangible capital.

This specialized framework has two key insights. First, while in the model, the level of output is mismeasured - it is too low -, its growth rate is correctly measured, because omitted and measured investment, in nominal terms, grow at the same rate on the balanced growth path. Thus, in our framework, mismeasurement of GDP growth is not a source of bias in productivity growth by construction, whereas it is the focus of much previous work. 
Second, and most important, the model helps clarify under what conditions mismeasurement in the growth rate of capital may lead to underestimating TFP growth. Specifically, we show that this will occur when the price of unmeasured investment grows sufficiently quickly relative to the price of measured capital. This mechanism, on its own, can lead to a substantial downward bias in measured TFP growth, which we characterize analytically.

In Section 3, we then use data on omitted intangibles, in the balanced growth framework, to quantify the size of the combined biases in measured TFP growth. We use the annual Input-Output tables for the 1997-2018 period to measure annual expenditures on 61 commodities or services that are treated as intermediate purchases in national accounting. We then examine those for which reclassifying intermediate purchases as final expenditure on capital goods would have the largest impact on GDP.

Several service groups stand out. Professional, Scientific and Technical services, Administrative and Support services, and Management services, lead to large upward adjustments in measured GDP. We argue that purchases of these services could plausibly represent investment in what the literature has called organization capital (Atkeson and Kehoe, 2005; Eisfeldt and Papanikolaou, 2013): expenditures on workforce human capital, distribution systems and logistics, product design, and customer and brand capital. Importantly, since 1997, the price of these services rose faster than the deflator for personal consumption expenditures, consistent with the necessary condition, implied by the model, under which unmeasured capital would lead to a downward bias in TFP growth.

Using these data and our balanced growth model, we then estimate that the combination of markups and omitted intangibles can explain between one-third and two-thirds of the decline in U.S. productivity from the pre-1997 to the post-1997 period. Table 1 shows that productivity growth measured using the standard Solow residual, declined by 49bps, from $1.11 \%$ to $0.62 \%$ per year. $^{1}$ Our corrected measure of TFP growth, which adjusts for both intangibles and markups, instead declines from $1.11 \%$ to $0.95 \%$, or only about one-third as

\footnotetext{
${ }^{1}$ Appendix A.2.1 provides more details on the construction of these figures.
} 
much. Importantly, we also show that measurement bias was likely much smaller in the 1947-1996 period, a period which pre-dates the rise in both intangibles and in markups. ${ }^{2}$

Our results thus suggest that the decline in TFP growth was, at least in part, the reflection of growing mismeasurement driven by structural changes in the economy - the rise in markups, and the increasing importance of intangibles. Because total GDP growth, in our framework, is not mismeasured, this result has implications for understanding sources of GDP growth. For example, since our adjusted measures suggest that more of total GDP growth since the 2000s was driven by TFP growth, investment-specific technical change might have contributed less to GDP growth than previously thought.

The rest of the paper is organized as follows. Section 2 analyzes theoretically the biases that omitted intangibles and markups case generate in the measurement of GDP growth, starting with a general growth accounting framework, and then specializing the analysis to a balanced growth model. Section 3 applies this framework to the data, using measures of intermediate expenditures that should potentially be reclassified as intangible investment. Section 4 concludes.

Related research and contribution Our work first relates to the literature on the measurement of productivity growth (Solow, 1957; Jorgenson and Griliches, 1967; Hall, 1968; Basu and Fernald, 2001). The closest papers in this literature study the rise in intangible capital. In particular, Corrado et al. (2009) also study how including omitted intangibles affects measures of GDP growth, labor productivity, and TFP growth. Our work complements theirs by first providing a general framework for describing biases in measured TFP growth, allowing in particular for markups; and, empirically, we focus on organization cap-

\footnotetext{
${ }^{2}$ Because our goal is to study the impact of misclassification of intangibles on TFP growth, we use a sample split coinciding with a breakpoint for the trend in misclassified intangible investment relative to GDP. We use the year 1997 because the ratio of unadjusted GDP to GDP adjusted for omitted intangibles stabilized around that year, after a long period of decline, as highlighted in the top panel of Figure 3. In Section 3.4 and Appendix A.2.4, we discuss how our results change if we use different breakpoints. We generally find positive but smaller effects for later breakpoints; for instance, with a breakpoint in 2000, markups and intangibles explain one-half of the observed decline in TFP growth, instead of two-thirds with the 1997 breakpoint.
} 
ital (Atkeson and Kehoe, 2005; Eisfeldt and Papanikolaou, 2013), whereas Corrado et al. (2009) primarily focus on R\&D capital. Heterogeneous price trends between these two types of intangible capital largely explain why we reach different conclusions on the sign of the bias in measured TFP growth created by intangibles. Our paper also closely relates to Basu et al. (2003), who study how unmeasured investments in capital that is complementary to information technology (IT) capital could affect TFP growth. We discuss the differences with that paper in more detail in Section 2.2.2.

As mentioned in the introduction, there is a recent literature focusing on the decline in measured TFP growth (Cette et al., 2016; Fernald et al., 2017; Byrne et al., 2016). We contribute to this literature by arguing that growing mismeasurement due to intangibles and markups can explain a sizable fraction of this decline. In particular, Byrne et al. (2016) also re-estimate productivity growth for the US after 2005 including mismeasured intangibles. They find a relatively small effect. Our approaches differ in three main ways. First, they do not allow for markups, whereas our analysis shows that including them substantially increases the impact of mismeasured capital on TFP growth. Second, their measures of intangibles are drawn from Corrado et al. (2016), who rely on data beyond the use tables (including compensation of non-production workers) to estimate intangible investment. By contrast, we focus on the use tables to measure intangible investment, but also leverage the corresponding price indices for services and commodities. These price indices have been rising faster than those of measured capital goods, which contributes to the downward bias in TFP growth. Finally, their analysis is off the balanced growth path and allows for mismeasurement of GDP growth, whereas we focus on a balanced growth path where output growth (in consumption units) is correctly measured.

As noted above, our work also relates to the literature on investment-specific technical change, and in particular, to papers in this literature focusing on its impact on long-run growth (Greenwood et al. 1997). As noted, our results indicate that omitting some intangibles from measures of the capital stock can lead to overestimates of the contribution of 
investment-specific technical change to GDP growth — and, as a result, to underestimates of the contribution of TFP growth. Ongoing work by Gourio and Rognlie (2020) also argues that existing measures may overstate the trend decline in the relative price of investment goods, but they highlight issues of aggregation across existing measures of heterogeneous capital goods, while we explore the possibility that investment in certain types of capital is not well measured.

Our results also connect with the recent literature on the implications of rising rents. Consistent with our findings, this literature documents a significant rise in the pure profit share and in markups, especially after 2000 (Barkai, 2020). We show that rising markups also have quantitatively sizable implications for measuring of TFP growth.

Finally, recent work has highlighted how, when intermediate input use is not symmetric across industries or firms and firms have markups, aggregate TFP may also include terms reflecting allocative (in)efficiencies. This is highlighted, in particular, by Basu and Fernald (2001) and Baqaee and Farhi (2020). In our framework, aggregate TFP, absent markups and absent the measurement issues we highlight, is equal to aggregate technology, so there is no scope for allocative inefficiency. These asymmetries could augment our mechanism by providing a separate way in which factor use may depress measured TFP. Relatedly, Bils et al. (2020) study how mismeasurement in revenue and inputs can affect the allocative efficiency component of TFP. Our analysis differs from theirs in several dimensions. First, their focus is on the misallocation component of TFP, and how it compares across countries. In our paper, we do not study the contribution of misallocation to aggregate TFP, in the sense that there is no wedge between the marginal revenue product of inputs and their marginal cost. Second, their focus is on differences in the level of sectoral TFP; instead, our focus is on the growth rate of aggregate TFP. Finally, while they consider mismeasurement that is random (and similar to classical measurement error), in our paper, mismeasurement is due to investment expenditures being misclassified as intermediate purchases. This is important because in our case, mismeasurement can be addressed by reclassifying intermediate expenditures. 


\section{Theory}

This section studies conditions under which Solow residuals can be biased downward relative to true TFP growth. We focus on markups, omitted intangibles, or the combination of the two, as a source of such bias. Throughout the paper, we use a value added production function. Appendix A.1.2 shows that our results on the value added Solow residuals hold in a model where the underlying production function uses intermediate inputs. ${ }^{3}$

\subsection{General results}

We start by deriving results on measurement bias that rely on minimal assumptions.

\subsubsection{The standard methodology}

The Solow residual (Jorgenson and Griliches, 1967; Basu and Fernald, 2001) is defined as:

$$
\frac{d \hat{Z}_{t}}{\hat{Z}_{t}}=\frac{d \hat{Y}_{t}}{\hat{Y}_{t}}-\hat{s}_{L, t} \frac{d \hat{L}_{t}}{\hat{L}_{t}}-\left(1-\hat{s}_{L, t}\right) \frac{d \hat{K}_{t}}{\hat{K}_{t}}
$$

where $d \hat{Y}_{t} / \hat{Y}_{t}$ growth rate of real output, $d \hat{L}_{t} / \hat{L}_{t}$ and $d \hat{K}_{t} / \hat{K}_{t}$ are the growth rates of real capital and labor inputs, and $\hat{s}_{L, t}=\frac{\hat{W}_{t} \hat{L}_{t}}{\hat{N}_{t}}$ is the labor share of value added, with $\hat{N}_{t}=\hat{P}_{t} \hat{Y}_{t}$ denoting nominal value added. ${ }^{4}$ In words, measured TFP growth is the gap between the growth rate of real output, and a weighted sum of the growth rates of capital and labor inputs. ${ }^{5}$ The input weights are payments to each input relative to total value added, with the

\footnotetext{
${ }^{3}$ The Appendix also explores the link between TFP growth and the gross output Solow residual.

${ }^{4}$ Throughout the paper, we use the hat notation in reference to measured variables. This helps distinguish them from their unbiased values, which we denote without the hat. Additionally, we use the notation $d X_{t} / X_{t}$ for the continuous-time growth rate $\dot{X}_{t} / X_{t}=\lim _{d t \rightarrow 0}(1 / d t)\left(X_{t+d t}-X_{t}\right) / X_{t}$. In discrete-time data, we approximate it using the $\log$-growth $\operatorname{rates} \log \left(X_{t+d t} / X_{t}\right)$.

${ }^{5}$ Throughout, we express output in units of consumption, so that $P_{t}$ represents the price of consumption goods. We follow this convention in order to be consistent with the model we study later in this section. Correspondingly, in all our empirical measures of Solow residuals, output is expressed in consumption units. We provide details on measures of output growth in consumption units, and a comparison with chained GDP growth, in Appendix A.2.1; the two measures imply similar declines in Solow residuals after 1997, as shown in Appendix Table A2. Appendix A.1.1.3 discusses the biases which using chained GDP growth would add to our basic exercise. See also Oulton (2007) for a discussion of chained GDP Solow residuals in models where the price of investment relative to consumption goods is not 1 .
} 
labor share $s_{L, t}$ measured directly from payments to labor, and the capital share computed as a residual. Such a measure produces an unbiased estimate of TFP growth under four assumptions:

A1: Production follows $Y_{t}=Z_{t} F\left(K_{t}, L_{t}\right)$, where $F$ is homogeneous of degree 1 .

A2: Labor input is given by: $L_{t}=\arg \min _{\tilde{L}_{t}} W_{t} \tilde{L}_{t}$ s.t. $Z_{t} F\left(K_{t}, \tilde{L}_{t}\right) \geq Y_{t}$.

A3: The price of output is equal to its marginal cost: $P_{t}=M C_{t}$, where $M C_{t}$ is the Lagrange multiplier on the output constraint $Z_{t} F\left(K_{t}, \tilde{L}_{t}\right) \geq Y_{t}$.

A4: There is no measurement error in growth rates for inputs and output, $d \hat{X}_{t} / \hat{X}_{t}=d X_{t} / X_{t}$ for $X \in\{Y, K, L\}$, and there is no measurement error in levels for the labor income share: $\hat{s}_{L, t}=s_{L, t}$.

Under A1, growth in total factor productivity is given by:

$$
\frac{d Z_{t}}{Z_{t}}=\frac{d Y_{t}}{Y_{t}}-\left(1-\epsilon_{L, t}\right) \frac{d K_{t}}{K_{t}}-\epsilon_{L, t} \frac{d L_{t}}{L_{t}}
$$

where $\epsilon_{L, t}$ is the elasticity of output with respect to labor. Under A2, $\epsilon_{L, t}$ is related to the labor cost share by:

$$
\epsilon_{L, t}=\frac{F_{L}\left(K_{t}, L_{t}\right) L_{t}}{F\left(K_{t}, L_{t}\right)}=\frac{W_{t} L_{t}}{M C_{t} Y_{t}}
$$

Under A3, the labor cost share is equal to its income share:

$$
\epsilon_{L, t}=\frac{W_{t} L_{t}}{M C_{t} Y_{t}}=\frac{W_{t} L_{t}}{P_{t} Y_{t}}=\hat{s}_{L, t} .
$$

Therefore, the elasticities in Equation (2) can be derived from the labor income share. ${ }^{6}$ Finally, under A4, all the variables involved in the right-hand side of Equation (2) are correctly measured, so that the resulting TFP growth measure is unbiased.

\footnotetext{
${ }^{6}$ An alternative approach is to directly measure cost shares, which are correct measures of output elasticities even with markups, but this requires proxies for the (generally unobservable) user costs of capital.
} 


\subsubsection{Bias due to markups}

Assume that $\mathrm{A} 3$ is relaxed, and let: $\mu_{t}=\frac{P_{t}}{M C_{t}}$. We will consider the situation where the price-cost markup is larger than 1 , so there may be pure profits: $\mu_{t} \geq 1 .^{7}$ In this case, the measured labor share is an underestimate of the output elasticity of labor: $\hat{s}_{L, t} \leq \mu_{t} \hat{s}_{L, t}=\epsilon_{L, t}$. Additionally, A1 implies that $\epsilon_{L, t} \leq 1 ; \mu_{t} \leq \hat{s}_{L, t}^{-1}$. We then have the following result.

Result 1. When $\mu_{t} \geq 1$, the bias in measured TFP growth is given by:

$$
\frac{d \hat{Z}_{t}}{\hat{Z}_{t}}-\frac{d Z_{t}}{Z_{t}} \equiv \Delta_{t}=-\hat{s}_{L, t}\left(\mu_{t}-1\right)\left(\frac{d K_{t}}{K_{t}}-\frac{d L_{t}}{L_{t}}\right)
$$

Moreover, when $d K_{t} / K_{t}>d L_{t} / L_{t}, \Delta_{t} \leq 0$, and the bias is bounded (in absolute value) by $\left|\Delta_{t}\right| \leq\left(1-\hat{s}_{L, t}\right)\left(\frac{d K_{t}}{K_{t}}-\frac{d L_{t}}{L_{t}}\right)$, with the upper bound reached when $\epsilon_{L, t}=1$, i.e. only labor is used in production.

With markups, the true elasticity of output to labor, $\epsilon_{L, t}$, is higher than the measured labor income share $\hat{s}_{L, t}$. As a result, the true elasticity of output to capital, $1-\epsilon_{L, t}$, is lower than $1-\hat{s}_{L, t}$, the (residual) capital income share. When capital grows faster than labor (the empirically relevant case, as indicated by Table 1), the latter effect dominates, and the Solow residual is biased downward.

Figure 1 reports time series for measured and adjusted TFP growth, and Appendix Table A1 reports estimates of the size of this bias. First, we assume that the true elasticity of output to labor is 1 , so that the bias is at its upper bound. In this case, measured TFP growth is approximately $\bar{\Delta}_{t}=0.80 \%$ lower than true TFP growth. However, this gap is roughly the same in the pre- and post-1997 periods and cannot explain a substantial decline in estimated TFP growth. Using a more plausible Cobb-Douglas labor share, so when $\epsilon_{L, t}=\overline{\hat{s}}_{L, t}=0.68$, the pre-1997 average of the labor income share, the bias is only $\bar{\Delta}_{t}=0.09 \%$ on average in that case. Moreover, the increase in $\bar{\Delta}_{t}$ from pre- to post-1997 is positive but small — less than $1 / 5$ th of the observed decline in measured TFP growth.

\footnotetext{
${ }^{7}$ Note that $\mu_{t}$ a value-added markup, as $M C_{t}$ is the marginal cost of value added.
} 


\subsubsection{Bias due to omitted intangibles}

Assume now that A3 holds, but A4 is relaxed: there is measurement error in input and output quantities because of omitted intangible capital. Let $B_{t}$ denote nominal investment expenditures contributing to the growth of the stock of unmeasured intangible capital. In national accounts, these investment expenditures will be recorded, but treated as intermediate goods purchases, as opposed to purchases of final investment goods. Therefore, measured output $\hat{Y}_{t}$ and actual output $Y_{t}$ will be related through:

$$
\hat{N}_{t}=P_{t} \hat{Y}_{t}=P_{t} Y_{t}-B_{t}
$$

where recall that $P_{t}$ is the price of consumption goods, and $Y_{t}$ is assumed to be expressed in units of the consumption good, so that $P_{t} \hat{Y}_{t}$ is measured total nominal output.

The omission of intangibles, both as a stock and a flow, impacts measured TFP growth in three ways. First, the growth rate of output might be mis-measured; namely:

$$
\frac{d \hat{Y}_{t}}{\hat{Y}_{t}}=\frac{d Y_{t}}{Y_{t}}+\left(\frac{1}{b_{t}}-1\right)\left(\frac{d Y_{t}}{Y_{t}}-\frac{d \tilde{B}_{t}}{\tilde{B}_{t}}\right)
$$

where: $b_{t} \equiv \frac{P_{t} \hat{Y}_{t}}{P_{t} Y_{t}} \leq 1$ is the ratio of measured (or unadjusted) to actual (or adjusted) output, and $\tilde{B}_{t}=B_{t} / P_{t}$. Second, because the level of output is mismeasured, the labor share might be mismeasured. Specifically, the measured labor share of income is always an overestimate of the elasticity of output with respect to labor: $\hat{s}_{L, t}=\frac{W_{t} L_{t}}{P_{t} \hat{Y}_{t}}=\frac{W_{t} L_{t}}{P_{t} Y_{t}} \frac{1}{b_{t}}=\frac{\epsilon_{L, t}}{b_{t}}>\epsilon_{L, t}$. A3 holds, so the true labor income share $W_{t} L_{t} / P_{t} Y_{t}$ is equal to the elasticity of output to labor. However, because of omitted intangible investment, which biases measured output downward, the measured labor income share $W_{t} L_{t} /\left(P_{t} \hat{Y}_{t}\right)$ is higher than the true labor income share. Note that this is the opposite effect from markups. Third, the measured growth rate of capital might be incorrect: $\frac{d \hat{K}_{t}}{\hat{K}_{t}} \gtrless \frac{d K_{t}}{K_{t}}$. The following result summarizes these different sources of bias. 
Result 2. When intangibles are omitted $\left(b_{t}<1\right)$, the bias in measured TFP growth is:

$$
\begin{array}{rlr}
\Delta_{t} & =\Delta_{t}^{(1)}+\Delta_{t}^{(2)}+\Delta_{t}^{(3)} & \\
\Delta_{t}^{(1)} & \equiv\left(\frac{1}{b_{t}}-1\right)\left(\frac{d Y_{t}}{Y_{t}}-\frac{d \tilde{B}_{t}}{\tilde{B}_{t}}\right) & \text { (output growth bias) } \\
\Delta_{t}^{(2)} & \equiv \hat{s}_{L, t}\left(1-b_{t}\right)\left(\frac{d \hat{K}_{t}}{\hat{K}_{t}}-\frac{d L_{t}}{L_{t}}\right) & \text { (labor share bias) } \\
\Delta_{t}^{(3)} & \equiv\left(1-\epsilon_{L, t}\right)\left(\frac{d K_{t}}{K_{t}}-\frac{d \hat{K}_{t}}{\hat{K}_{t}}\right) & \text { (capital growth bias). }
\end{array}
$$

Three points stand out. First, the sign of the bias introduced by capital growth is ambiguous in general: it depends on the growth rate of the measured capital stock relative to the growth rate of the true capital stock. Nevertheless, when measured (real) capital input $\hat{K}_{t}$ is growing faster than actual (real) capital input, the simple Solow residual will tend to underestimate true output growth.

Second, and most important, as noted above, there is mismeasurement in the elasticity of output with respect to labor, as in the case of markups; but it has the opposite sign as with markups. Intuitively, this is because measured output is too low, so that the measured labor share is too high relative to the elasticity of output with respect to labor, or equivalently, the measured capital share is too low relative to the elasticity of output with respect to capital. When capital is growing faster than labor, this biases measured TFP upward.

A third and equally important point is that, since the measured labor income share is $\hat{s}_{L, t}=\epsilon_{L, t} / b_{t}$, if the elasticity of output with respect to labor is constant, $\epsilon_{L, t}=\epsilon_{L}$, but there is a growing amount of omitted intangible investment, so that $b_{t}$ is falling, then the measured labor income share should rise. By contrast, the measured labor share of income has declined since at least the late 1990s. Thus, on its own, a rising amount of omitted intangible capital, even if produces downward bias in the Solow residual, would likely have counterfactual implications for the measured labor share. 


\subsubsection{Bias with both markups and intangibles}

The previous discussion shows that markups alone imply that the simple Solow residual underestimates true TFP growth, by making the measured labor income share lower than the elasticity of output with respect to labor. The magnitude of the bias in measured TFP growth, however, appears to be relatively small. On the other hand, omitted intangibles could also generate a downward bias in measured TFP growth, if their omission makes the growth rate of capital inputs too high. But omitting intangibles makes the labor income share higher than the elasticity of output with respect to labor, potentially offsetting some of the downward bias. Thus, alone, neither mechanism appears to be sufficient to generate a negative and large bias in measured TFP growth. Because they work through different channels, however, combining the two is potentially more powerful than either alone.

Result 3. With omitted intangibles $\left(b_{t}<1\right)$ and markups $\left(\mu_{t}>1\right)$, the bias in measured TFP growth can again be decomposed as:

$$
\Delta_{t}=\Delta_{t}^{(1)}+\Delta_{t}^{(2)}+\Delta_{t}^{(3)}
$$

The output growth bias $\Delta_{t}^{(1)}$ and the capital growth bias $\Delta_{t}^{(3)}$ have the same expression as in Result 2, and the labor share bias $\Delta_{t}^{(2)}$ is given by:

$$
\Delta_{t}^{(2)}=-\hat{s}_{L, t}\left(\mu_{t} b_{t}-1\right)\left(\frac{d \hat{K}_{t}}{\hat{K}_{t}}-\frac{d L_{t}}{L_{t}}\right)
$$

This result has two implications. First, the measured labor share is given by $\hat{s}_{L, t}=$ $\frac{\epsilon_{L, t}}{\mu_{t} b_{t}} \gtrless \epsilon_{L, t}$. With both markups and intangibles, the measured labor share need not be an upper bound for the elasticity of output with respect to labor, so that rising intangibles need not lead to a rising labor share. Second, all three sources of bias described in Result 3 could now potentially be negative and contribute to measured TFP growth being lower than actual TFP growth. To determine their signs, we next turn to a more specialized model. 


\subsection{Results in a balanced growth model}

We next derive expressions for the measurement biases in the context of a balanced growth model where we allow for both markups and mismeasured capital.

\subsubsection{Model elements}

Description Here, we briefly summarize key model elements; Appendix A.1.1 provides details. A representative firm chooses inputs in order to minimize total production costs. There are three inputs: labor $L_{t}$, and two types of capital: $K_{1, t}$ (which represents measured capital), and $K_{2, t}$ (which represents omitted intangibles). The production function is:

$$
Y_{t}=Z_{t}\left(K_{1, t}^{1-\eta} K_{2, t}^{\eta}\right)^{1-\alpha} L_{t}^{\alpha}
$$

where $1-\alpha$ is the elasticity of output with respect to labor, and $\eta$ is the Cobb-Douglas share of omitted intangibles in total capital, with $\eta=0$ corresponding to no omitted intangibles.

Capital and labor are rented by the firm on perfectly competitive markets from a representative household that owns them. The household's budget constraint is:

$$
R_{1, t} K_{1, t}+R_{2, t} K_{2, t}+W_{t} L_{t}+\Pi_{t}=P_{t} C_{t}+Q_{1, t} I_{1, t}+Q_{2, t} I_{2, t}
$$

where $R_{n, t}$ is the user cost of capital of type $n, W_{t}$ is the wage rate, $\Pi_{t}$ are profits rebated by the firm to the household, $C_{t}$ is consumption, $P_{t}$ is the price of consumption goods, $I_{n, t}$ is investment in capital of type $n$, and $Q_{n, t}$ is price of capital of type $n$. The model is set in continuous time; labor and the prices of capital goods evolve exogenously and deterministically, according to $d L_{t}=g_{L} L_{t} d t$ and $d Q_{n, t}=g_{Q_{n}} Q_{n, t} d t, n=1,2$, and the law of motion for each capital type is given by $d K_{n, t}=\left(I_{n, t}-\delta_{n} K_{n, t}\right) d t, n=1,2$, where $\delta_{n}$ are

capital-specific depreciation rates. The household's objective is $U=\int_{t \geq 0} e^{-\rho d t} \frac{C_{t}^{1-\sigma}}{1-\sigma} d t$, with $\rho>0$ and $\sigma \geq 1$. Finally, we allow for a constant wedge between the price of consumption 
goods, $P_{t}$, and their marginal cost of production, $M C_{t}: P_{t}=\mu M C_{t}, \quad \mu \geq 1$. Pure profits are then $\Pi_{t}=(\mu-1) M C_{t} Y_{t}$. In equilibrium, we will normalize $P_{t}=1$, so that prices and quantities will be expressed relative to consumption. ${ }^{8}$ Thus, this setup satisfies assumptions A1 (constant returns) and A2 (cost minimization), and violates assumption A3 when $\mu>1$, and assumption A4 when $\eta>0$.

Balanced growth path Along the unique balanced growth path of the model, output growth $d Y_{t} / Y_{t}$ is constant, and given by:

$$
g=g_{L}+\frac{1}{1-\alpha} g_{Z}-\frac{\alpha}{1-\alpha} g_{Q}
$$

where $g_{Q}$ is a weighted average of the growth rate of the prices of the two types of capital goods, $g_{Q}=(1-\eta) g_{Q_{1}}+\eta g_{Q_{2}}$. Each capital stock $K_{n, t}$ grows at rate $g_{K_{n}}=g-g_{Q_{n}}$, while the growth rate of the total capital stock $K_{t}=K_{1, t}^{1-\eta} K_{2, t}^{\eta}$ is $g_{K}=g-g_{Q}$. Additionally, the riskfree rate along the balanced growth path is given by $r=\rho+\sigma g$. A complete characterization of the balanced growth path is reported in Appendix A.1.1.

\subsubsection{An analytical characterization of the bias}

We assume that labor $L_{t}$ and payments to labor $W_{t} L_{t}$ are correctly measured, but that intangible investment - that is, investment in $K_{2, t}$ - is treated as intermediate expenditure in the expenditure-side measure of output, so that: $\hat{Y}_{t}=Y_{t}-Q_{2, t} I_{2, t}$ and $\hat{K}_{t}=K_{1, t} \cdot{ }^{9}$ Mirroring the discussion in Section 2.1, the balanced growth path has three key features that affect the measurement of TFP growth.

First, output growth is measured accurately. Recall that measured and actual output differ because investment in capital of type 2 is treated as an intermediate expenditure, and

\footnotetext{
${ }^{8}$ In particular, output $Y_{t}$ is expressed in consumption units. Appendix A.1.1.3 discusses how $d Y_{t} / Y_{t}$ relates, in the model, to chained GDP growth as defined in national accounts.

${ }^{9}$ Output in the income approach would also be underestimated, as measured gross operating surplus of firms would be $Y_{t}-Q_{2, t} I_{2, t}-W_{t} L_{t}$ instead of $Y_{t}-W_{t} L_{t}$.
} 
not a purchase of final product: $\hat{Y}_{t}=Y_{t}-Q_{2, t} I_{2, t}$. However, along the balanced growth path, expenditures on all final products - including expenditure on intangibles, $Q_{2, t} I_{2, t}$ - grow at rate $g$. Therefore, there is no bias in the measured growth rate of output by construction. ${ }^{10}$

Second, there is bias in the level of measured output. This, in turn, affects the measured labor share. Specifically, the ratio of measured to actual output is constant along the balanced growth path, and given by:

$$
b_{t}=b=\frac{\hat{Y}_{t}}{Y_{t}}=1-\frac{\alpha \eta}{\mu} \frac{g+\delta_{2}-g_{Q_{2}}}{r+\delta_{2}-g_{Q_{2}}} .
$$

As a result, the measured labor share is:

$$
s_{L}=\frac{W_{t} L_{t}}{P_{t} \hat{Y}_{t}}=\frac{1-\alpha}{b \mu} \gtrless 1-\alpha=\epsilon_{L} .
$$

Third, the growth rate of capital is mis-measured, because only the stock of capital of type $1, K_{1, t}$ is measured, and it may not grow at the same rate as omitted capital $K_{2, t}$ :

$$
\frac{d K_{t}}{K_{t}}-\frac{d \hat{K}_{t}}{\hat{K}_{t}}=\eta\left(g_{Q_{2}}-g_{Q_{1}}\right)
$$

that is, measured capital growth is higher than actual capital growth, if an only if, prices of omitted intangibles are growing faster than prices of measured capital.

Result 4. The bias in measured TFP growth along the balanced growth path is constant:

$$
\Delta_{t}=\Delta=\Delta^{(1)}+\Delta^{(2)}+\Delta^{(3)}
$$

\footnotetext{
${ }^{10}$ Outside of the balanced growth path, the growth rate of measured output could differ from the true growth rate of output. This assumption could be relaxed, for instance by studying transitional dynamics between steady-state. It is likely that accumulation of intangibles along the transition of the model from low- to high- $\eta$ steady states (steady-states with low and high levels of the omitted capital) would further exacerbate the negative bias in measured TFP growth, as investment in omitted intangibles would be high along that transition path.
} 
where:

$$
\begin{array}{lll}
\Delta^{(1)}=\alpha \eta \frac{g+\delta_{2}-g_{Q_{2}}}{\mu(r-g)+(\mu-\alpha \eta)\left(g+\delta_{2}-g_{Q_{2}}\right)}(g-g)=0 & \text { (output growth bias) } \\
\Delta^{(2)}=\frac{-(\mu-1)\left(r+\delta_{2}-g_{Q_{2}}\right)+\alpha \eta\left(g+\delta_{2}-g_{Q_{2}}\right)}{\mu(r-g)+(\mu-\alpha \eta)\left(g+\delta_{2}-g_{Q_{2}}\right)}\left(g_{Z}-g_{Q_{1}}-\alpha \eta\left(g_{Q_{2}}-g_{Q_{1}}\right)\right) & \text { (labor share bias) } \\
\Delta^{(3)}=-\alpha \eta\left(g_{Q_{2}}-g_{Q_{1}}\right) & \text { (capital growth bias) }
\end{array}
$$

In balanced growth, there is no bias due to mismeasurement of output growth: $\Delta^{(1)}=0$; so the bias is the sum of the labor share and the capital biases $\Delta=\Delta^{(2)}+\Delta^{(3)}$.

Two limiting cases are useful to consider. First, assume that there are no omitted intangibles: $\eta=0$, but markups are positive, $\mu>1$. Then, the capital growth bias is zero; all mismeasurement comes from the downward bias that markups create in the labor share. The value of the bias is given by $\Delta^{(2)}=-\frac{\mu-1}{\mu}\left(g_{Z}-g_{Q}\right)$, reflecting the fact that it depends on the growth rate of the capital-to-labor ratio, which is given by $\left(g_{Z}-g_{Q}\right) /(1-\alpha)$. The bias is positive whenever capital grows faster than labor, or $g_{Z}>g_{Q}$ in the model.

The other limiting case is $\eta>0$ (omitted intangibles) but $\mu=1$ (no markups). In Appendix A.1.1.4, Result 5, we show analytically that the measurement bias will be negative, if and only if, the relative price of omitted capital is growing sufficiently fast, i.e. $g_{Q_{2}}$ is sufficiently large. The reason for this is simple: a higher growth rate of intangible capital prices implies a lower growth rate of the stock of omitted intangibles, $K_{2, t}$, and therefore, a lower growth rate of the true stock of capital $K_{t}$, relative to the measured stock, $\hat{K}_{t}=K_{1, t}{ }^{11}$

These results relate to Basu et al. (2003), who study a model with unmeasured investment in capital that is complementary with IT capital. They show that in balanced growth, the bias in measured TFP growth must be positive. By contrast with our model, they do not allow for markups, and assume that the price of unmeasured capital and output are constant and equal to one another. This corresponds to $g_{Q_{1}}=g_{Q_{2}}=0$ and $\mu=1$ in our model. In

\footnotetext{
${ }^{11}$ Note, however, that along the balanced growth path, expenditures on intangible capital goods $Q_{2, t} I_{2, t}$, or the value of the intangible capital stock in consumption units, $Q_{2, t} K_{2, t}$, are growing at the same rate as measured capital; so, this mechanism does not require a shrinking ratio of intangible capital (at cost) to measured capital (at cost).
} 
this case, using Result 4, the measurement bias in TFP growth boils down to the labor share bias: $\Delta^{(2)}=\alpha \eta\left(g+\delta_{2}\right) /\left(r-g+(1-\alpha \eta)\left(g+\delta_{2}\right)\right) g_{Z}$, which is strictly positive in the balanced growth path, consistent with their result.

\subsubsection{How large can the bias be?}

Beyond the cases $\eta=0$ and $\mu=1$, it is not possible to characterize the sign of the bias analytically, so we provide a numerical illustration. First, we set $\rho=0.04, \sigma=1, \delta_{2}=0.20{ }^{12}$ Second, for different values of $\eta$ and $\alpha$, we compute productivity growth $g_{Z}$ required to match the post-1997 values of output growth, labor growth, capital growth, and the measured labor share. Finally, we construct the implied markup and ratio of measured to actual GDP. ${ }^{13}$

The results are reported in Figure 2; the top panel focuses on results when the CobbDouglas capital share is $\alpha=0.32$, consistent with the pre-1997 value of the measured labor share. ${ }^{14}$ The left graph on the top panel indicates that, with $\eta=0.5$ and $g_{Q_{2}}=2 \%$, the balanced growth model can fit the post-1997 data on output growth, input growth, and the labor share - and thus on measured TFP growth - , without requiring a decline in true TFP growth relative to the pre-1997 period.

In order to do this, the model requires two additional forces. First, omitted investment in intangibles must represent approximately $11 \%$ of measured GDP. Second, the markup must be substantially above 1 . Why is this? We fixed the Cobb-Douglas share of labor to $1-\alpha=0.68$, but the post-1997 data, the measured labor income share is, on average, lower: $\hat{s}_{L}=0.64$. Imagine that there were no markups: $\mu=1$. The model-implied measured labor share would then be given by $(1-\alpha) / b$. If $b<1$ (that is, with omitted intangibles), this value would be larger than 0.68 , and thus larger than the measured labor share. Thus, markups are required in order to offset the upward bias of the measured labor income share.

\footnotetext{
${ }^{12}$ See, for instance, Li and Hall (2020) for evidence on the high depreciation rates of intangibles.

${ }^{13}$ The corresponding values are given by: $g_{Z}=\hat{g}-(1-\alpha) \hat{g}_{L}-\alpha \hat{g}_{K}+\alpha \eta\left(g_{Q_{2}}-\left(\hat{g}-\hat{g}_{K}\right)\right), \mu=\frac{1-\alpha}{\hat{s}_{L}}+$ $\alpha \eta \frac{\hat{g}+\delta_{2}-g_{Q_{2}}}{\rho+\hat{g}+\delta_{2}-g_{Q_{2}}}$ and $b=1-\frac{\alpha \eta}{\mu} \frac{\rho+\hat{g}+\delta_{2}-g_{Q_{2}}}{\hat{g}+\delta_{2}-g_{Q_{2}}}$.

${ }^{14}$ The middle and bottom panel report results for higher values of $\alpha$; these imply somewhat smaller values for true TFP growth, but also somewhat lower markup values.
} 


\section{Empirics}

This section assesses, empirically, whether the combined effect of omitted intangible investment and markups creates a large negative bias in measured TFP growth.

\subsection{Methodology}

We use two approaches, meant to answer different questions. The first approach provides an estimate of the rate of relative price growth of omitted intangibles, $g_{Q_{2}}$, necessary to explain a given gap between true and measured TFP. The second approach instead uses empirical proxies for $g_{Q_{2}}$ to estimate this gap directly. Since the first approach only uses data on expenditures on omitted intangibles, and not on prices, it can be applied more broadly.

First approach: computing required relative price growth Given measured expenditures $M$ on a particular type of intermediate commodity or service, we construct:

$$
\hat{b}=\frac{\text { Measured GDP }}{\text { Adjusted GDP }}=\frac{P Y}{P Y+M} .
$$

This ratio captures mismeasurement in the level of GDP if recorded intermediate expenditures on the commodity or service were in fact (misclassified) intangible investment. Using the model, we then solve for the price growth rate $g_{Q_{2}}$, such that for any $\tilde{g}_{Z}$ :

(1) true TFP growth in the model, $g_{Z}$, is given by $g_{Z}=\tilde{g}_{Z}$;

(2) the ratio of measured to adjusted GDP in the model, $b$ is given by $b=\hat{b}$;

(3) the model matches measured values of output growth $\hat{g}$, labor growth $\hat{g}_{L}$, capital growth $\hat{g}_{K}$, and the labor share $\hat{s}_{L}$, and therefore of the Solow residual $\hat{g}_{Z}$.

Intuitively, this approach produces the growth rate $g_{Q_{2}}$, such that all of the gap between true TFP growth $\tilde{g}_{Z}$ and the Solow residual $\hat{g}_{Z}$ is due to mismeasurement. Appendix A.2.2 shows that there is a unique such value for $g_{Q_{2}}$. 
In the application below, for true TFP growth $\tilde{g}_{Z}$, we use the pre-1997 empirical average of the Solow residual, while we use post-1997 averages of other measured variables. Thus, this approach will produce the value of $g_{Q_{2}}$ necessary for measurement error to entirely account for the observed decline in TFP growth from pre- to post-1997 (assuming that the Solow residual properly measures TFP growth before 1997). Finally, this approach requires calibrating certain parameters; as in the previous section, we use $\sigma=1, \rho=0.04$, and $\delta_{2}=0.20$. Moreover, we set $\alpha=0.32$, the measured capital share before 1997 .

Second approach: adjusting Solow residuals First, given a measure of expenditures $M$ on a particular intermediate commodity or service, we again define $\hat{b}$ as in Equation (18). Next, we obtain an empirical proxy for $\hat{g}_{Q_{2}}$. Finally, we use the relationships implied by the balanced growth model in order to compute the value of $\eta$, the Cobb-Douglas intangible share, $\mu$, the markup, and $g_{Z}$, true TFP growth, that are consistent with measured values of output growth $\hat{g}$, labor growth $\hat{g}_{L}$, capital growth $\hat{g}_{K}$, and the labor share $\hat{s}_{L} \cdot{ }^{15}$ Intuitively, this approach computes an "adjusted" Solow residual that correctly measures TFP growth in the model, while also ensuring that the model matches the empirical value of the simple Solow residual $\hat{g}_{Z}$. We can then assess whether the "adjusted" Solow residual, $g_{Z}$, fell less than the simple Solow residual $\hat{g}_{Z}$ after 1997. The difference is a measure of the bias introduced by intangibles and markups in the measurement of TFP growth. ${ }^{16}$

\subsection{Data sources}

Our data comes from two main sources. First, we use the benchmark Input-Output accounts (Lawson et al., 2002) to measure intermediate expenditures of different types of commodities and services. ${ }^{17}$. This data covers the $1997-2018$ period. We use more specifically the Com-

\footnotetext{
${ }^{15}$ These are given by $\eta=\frac{1-\hat{b}}{\hat{b}} \frac{1-\alpha}{\hat{s}_{L}} \frac{1}{\alpha} \frac{\hat{r}+\delta_{2}-\hat{g}_{Q_{2}}}{\hat{g}+\delta_{2}-\hat{g}_{Q_{2}}}, \mu=\frac{1-\alpha}{\hat{b} \hat{s}_{L}}$, and $g_{Z}=\hat{g}-(1-\alpha) \hat{g}_{L}-\alpha \hat{g}_{K}+$ $\alpha \eta\left(\hat{g}_{Q_{2}}-\left(\hat{g}-\hat{g}_{\hat{K}}\right)\right)$.

${ }^{16}$ As for the first methodology, this approach requires calibrating the values of $\left(\sigma, \rho, \delta_{2}, \alpha\right)$; we use the same values as reported above.

${ }^{17}$ The data are available at apps.bea.gov/industry/iTables $\% 20$ Static $\% 20 \mathrm{Files} / \mathrm{AllTablesSUP}$. zip These data were produced following the 2018 comprehensive update of the Industry Economic accounts
} 
modity Use tables, aggregated at the Summary level, which provides detail for 61 different commodities and services, after excluding non-comparable imports, used and second-hand goods, and government-provided services and commodities. In each year and for each commodity or service, we collapse the amount used as intermediate input (as opposed to final product) across all industries. This provides a measure of $M$; we then compute the associated ratio of measured to adjusted GDP, $\hat{b}$, as in Equation (18)..$^{18}$

Second, we obtain information on prices from the GDP-by-industry tables. ${ }^{19}$ These data provide annual measures of gross output, intermediate input use, and value added, at the industry level, for the period 1997-2018, along with associated price deflators. Industries in this data follow an identical classification as the 61 groups of commodities and services described in the Input-Output tables, so that industry price deflators can be merged to the Input-Output account data on commodities and services. ${ }^{20}$ For each commodity and service, we then compute $\hat{g}_{Q_{2}}=\hat{g}_{Q_{2}^{n o m}}-\hat{g}_{P C E}$, where $\hat{g}_{P C E}$ is the annual change in the implicit deflator for personal consumption expenditure. ${ }^{21}$

The data sources on expenditures and prices overlap on both their time and commodity/service coverage, but they are limited to the 1997-2018 period. In Section 3.3.3 below, we extend our analysis to the pre-1997 period, using the historical Input-Output accounts for the 1947-1962 and 1962-1996 periods. Other data sources are described in Appendix A.2.3.

\subsection{Results}

This section discusses the results from our two empirical approaches.

(Howells et al., 2018).

${ }^{18}$ We adjust our basic output measure, total final product use across all commodities, by subtracting imports from the Commodity Supply tables at the same level of disaggregation; the resulting measure matches, by construction, total value added.

${ }^{19}$ The data are available at apps.bea.gov//industry/iTables\%20Static\%20Files/AllTables.zip.

${ }^{20}$ The tables provide price indices for more a disaggregated industry classification, but we only use the data at the same level of aggregation as the Input-Output accounts.

${ }^{21}$ The GDP-by-industry tables also provide price deflators for gross output, which have similar signs, on average, than value added deflators, but are somewhat smaller in magnitude. From the standpoint of the model, value added deflators should be used, and so we focus on this measure for the remainder of the results. 


\subsubsection{First approach: computing required relative price growth}

The magnitude of GDP adjustments Table 2 reports the time-series averages of the ratios of unadjusted to adjusted GDP, $\hat{b}$, defined as in Equation (18). The averages reported are computed when intermediate use of a single commodity or service group (among the 61 reported in the Use table) is reclassified as intangible investment in isolation. Among the groups with the 10 largest adjustments, 3 service groups are of particular interest.

The largest adjustment is associated with the Professional, Scientific and Technical Services (PSTS) group. Reclassifying intermediate expenditures on these services as intangible investment implies that actual GDP is approximately $6 \%$ larger than measured GDP. This group comprises service activities that can be purchased externally by firms, such as accounting, consulting, design, or computer services. The two other service groups of interest are Administrative and Support Services, and Management of Companies and Enterprises. The former group measures the use of outsourced business support services (such as personnel administration and training). The latter group measures the service output of establishments that administer other establishments in a company. ${ }^{22}$

Our core argument is that intermediate expenditures on these types of services could in fact represent purchases of investment goods by firms, which would then be misclassified in national accounts. The type of capital created by these purchases is intangible, in that it does not have a physical presence. Indeed, these purchases could lead to the accumulation of various forms of organization capital (through consulting, advertising, design, management and personnel-related services), none of which are embodied in physical assets. These expenditures lead to capital accumulation to the extent that the corresponding inputs are not used up in production entirely within the year of their purchase.

Taken together, omitting these forms of investment could have large effects on GDP. The first column of Table 3 shows that reclassifying the three service groups mentioned above

\footnotetext{
${ }^{22}$ These establishments are likely to be headquarters or core firm locations where organization and strategic planning services are produced. The output of these establishments is reported in isolation in the benchmark IO accounts.
} 
leads to a cumulative adjustment in the level of GDP in the order of $11 \%$. Accordingly, investment rates adjusted for these omissions are higher than, and diverging from, measured investment rates. Figure 3 reports the time series for both the ratio of unadjusted to adjusted GDP, and for the implied ratio of nominal investment to GDP after adjusting for omitted intangibles. For instance, adjusting for Professional Services leads to an upward revision of approximately $5 \%$ in the ratio of nominal investment to nominal GDP. ${ }^{23}$

For reference, Table 2 also reports the adjustment factor $\hat{b}$ implied by reclassifying seven other commodities and service groups (those remaining among the 10 groups with the largest GDP adjustments). However, it is difficult to argue that these inputs represent misclassified investment; Chemical Products, for instance, tend to be used up in production within the year of their purchase. Hence, not all intermediates are candidates to be capitalized, in particular if they are clearly used as materials inputs.

Finally, own-account investment in organization capital, for instance through worker training, or branding and marketing expenses, could also contribute to the stock of organization capital. The distinction between externally purchased and own-account intangible investment is moot in our model because we assume away internal capital adjustment costs. However, in the Use tables, only externally purchased intangibles will be captured. (This is with the exception of one important component of own-account spending on organization capital, managerial compensation, which is isolated in the Use table as intermediate inputs purchased from the Management of Companies and Enterprises sector, and will therefore be captured by our baseline approach.) In Section 3.4 and Appendix A.2.4, we use firmlevel data on organization capital spending that includes own-account investment, and show that the magnitudes we obtain for the adjustments to GDP are in the upper range of those implied by the Use tables.

\footnotetext{
${ }^{23}$ In anticipation of the analysis of Section 3.3.3, this figure reports the times series for these ratios for the entire postwar era, 1947-2018. The ratios of unadjusted to adjusted GDP reported in the top panel of Figure 3 differ somewhat from those used in this section because the industry classification of the Input-Output accounts changed in 1963 and 1997, as explained in Section 3.3.3. Appendix Figure A2 reports the time series for the same moments from 1997-2018 only, using definitions of the omitted intangibles based on the more granular classifications of the post-1997 IO tables.
} 
Results Using these GDP adjustments, Table 3 then reports the values of relative price growth of omitted capital, $g_{Q_{2}}$, that would be required to explain the entirety of the decline in measured TFP growth from bias generated by intangibles and markups. The implied relative price growth ranges from 0.6 to $2.1 \%$ p.a., with lower estimates corresponding to more intermediate expenditures being reclassified as investment.

Two points are worth noting. First, the required relative price growth is positive; that is, the price of omitted capital must be rising, relative to the price of final goods, in order for the bias to be positive, as discussed in Section 2. In Section 3.3.1, we argue that, for the three service groups we focus on, this is empirically plausible. Second, these adjustment lead to high markups. For instance, when adjusting for the PSTS group, the implied valueadded markup corresponds to a pure profit share of value added in the order of $11.5 \%$. As highlighted in the previous section, in order to simultaneously accommodate a low labor share $\hat{s}_{L}$ and a substantial underestimation of GDP, markups must be elevated.

\subsubsection{Second approach: adjusting Solow residuals}

Relative price growth in the data Are relative price growth rates for omitted intangibles in the order of $0.6 \%$ to $2.1 \%$ realistic? The second column of Table 2 reports average price growth rates for the 10 commodities or service groups with the 10 largest GDP adjustments. For the three key service groups discussed above and highlighted in Table 2, our empirical proxies for $\hat{g}_{Q_{2}}$ are all positive. However, their magnitudes are not as large as the values discussed in the previous section: the highest rate of relative price increase is $1.5 \%$ per year, for Management Services. Thus the bias generated will not be sufficient to fully explain the decline in measured TFP growth. So we next discuss how much of this decline our mechanism can account for, given these proxies for $\hat{g}_{Q_{2}}$.

Results Figure 4 reports the implied rate of growth of TFP (as well as a red line indicating the average simple Solow residual $\hat{g}_{Z}$ the post-1997 sample) when adjusting for the 61 
commodity and service groups individually. Adjustments of individual service or commodities groups have a positive, though relatively small overall effect on measured TFP growth. Among the largest adjustments is obtained for the PSTS group; alone, it adds approximately $0.1 \%$ to overall TFP growth, or 1/5th of the gap between pre- and post- 1997 TFP growth. ${ }^{24}$

Table 4 reports the implied growth rates, Cobb-Douglas intangible shares, and markups, when adjusting for the three key groups of services highlighted earlier in the discussion. The first two lines report the unadjusted Solow residual for the pre- and post-1997 periods; as highlighted in the introduction, it declines by $49 \mathrm{bps}$, from $1.11 \%$ to $0.62 \%$ per year.

The third line reports the average growth rate of TFP obtained when adjusting only for markups, but not for omitted intangibles. The adjustment for markups alone raises measured TFP growth by approximately $9 \mathrm{bps}$, or one-fifth of the decline. The remaining lines report TFP growth in the post-1997 sample when adjusted for both markups and omitted intangibles. Altogether, the decline is 33bps (or 67\%) smaller after adjusting for both markups and intangibles produced by all three key sectors highlighted above. Thus markups and intangibles together can account for $2 / 3$ of the observed decline in TFP growth. ${ }^{25}$ Adjusting only for professional services, or for professional services plus management, yields somewhat lower effects - from one-third to one-half of the total decline in measured TFP growth.

\subsubsection{Comparing pre- and post-1997 data}

The previous section shows that measurement bias from markups and intangible capital can explain up to two thirds of the decline in the Solow residual. It is however possible that the Solow residual before 1997 also requires upward adjustments because of markups and intan-

\footnotetext{
${ }^{24}$ In Figure 4, it is also worth briefly highlighting the Petroleum and Coal Products commodity group. As a widely used intermediate input, it has a low value of $\hat{b}$. Additionally, as indicated by Table 2 , this group experienced a high rate of relative price increase over the period. As result, reclassifying intermediate expenditures on this group as purchases of capital goods would lead to a large upward adjustment to TFP growth. However, as argued before, these are typically used up in production within the year, which rules out reclassifying them as omitted capital goods.

${ }^{25}$ Appendix Figure A3 reports the annual time-series underlying the averages of Table 4 . These timeseries show that the adjustment for omitted intangibles produces a sizable upward revision of TFP growth in two periods: the early 2000's, and the Great Recession. In particular, during the Great Recession, the difference between measured and adjusted TFP growth is almost a full percentage point.
} 
gibles. More generally, since the rise in intangible capital and markups are thought to have accelerated after the 1990s, comparing the pre- to post-1997 data provides a "placebo" test for our hypothesis that both trends have contributed to an increase in the mismeasurement of TFP growth.

The first empirical challenge in doing so is that the service and commodity groups used in the Input-Output tables change twice before 1997. More specifically, the 1947-1962 InputOutput tables have a substantially coarser definition of service and commodity groups. ${ }^{26}$ Given this limitation, we aggregate up service and commodity groups in the 1963-1996 and 1997-2018 data so that they match the 43 groups of the 1947-1962 data. Table 5 then reports the magnitude of these GDP adjustments, both before and after 1997.

The top panel of Table 5 shows that omitted intangibles would have led to adjustments to the level of GDP even before $1997 .{ }^{27}$ However, the adjustment is substantially larger in the post-1997 period. The last two columns of the top panel of Table 5 report the change in $\hat{b}$ for each group; it is generally negative, with $t$-tests confirming that the drop is statistically significant. The bottom panel of Table 5 repeats these computations, using aggregates of the three service groups most likely to represent misclassified intangible investment and discussed in the previous section. Taken together, the ratio of unadjusted to adjusted GDP for these three service groups is 0.92 pre-1997, but falls to 0.87, after 1997.

Nevertheless, the fact that $\hat{b}<1$ even before 1997 means that one should, in principle, adjust the Solow residual also before 1997. In order to do so, as discussed in the previous section, data on the growth rate of relative prices of omitted intangibles is required. However, the second empirical challenge is that there are, to our knowledge, no price deflators available,

\footnotetext{
${ }^{26}$ There are 43 groups in the 1947-1962 tables, instead of 60 in the 1963-1996 tables and 61 in the 1997-2018 tables. The historical Input-Output tables we use in the analysis are available at https://apps.bea.gov/industry/xls/io-annual/IOUse_Before_Redefinitions_ PRO_1947-1962_Summary.xlsx and http://https://apps.bea.gov/industry/xls/io-annual/IOUse_ Before_Redefinitions_PRO_1963-1996_Summary.xlsx, respectively. In particular, the service groups most likely to include omitted intangible investment after 1997 are not consistently defined across periods. For instance, prior to 1997, the Administrative and Support Services group is included in a larger group, which also contains Waste Management services.

${ }^{27}$ The GDP adjustments in this exercise after 1997 are mechanically large than in our previous exercise, because of the coarser definitions of commodity and service groups which we are constrained to use.
} 
at the required level of aggregation, for the 1947-1996 period. ${ }^{28}$ We therefore assume that relative price growth is the same as in the post-1997 period.

The adjusted Solow residuals which we obtain are reported in Table 6. With all three key service sectors accounted for, the pre-1997 Solow residual is $1.21 \%$ p.a., versus $1.11 \%$ in the baseline. Crucially, this upward adjustment is smaller than the upward adjustment for the post-1997 sample. ${ }^{29}$ Thus after adjusting for markups and intangibles in both the pre- and post-1997 periods, the Solow residual only fell by approximately 21bps after 1997, instead of an unadjusted decline of 49bps, confirming our baseline findings.

\subsection{Robustness}

Appendix A.2.4 reports results from four robustness checks. First, our results also hold using BLS price data. Second, the magnitude of the adjustments for omitted intangibles obtained from firm data (potentially including own-account intangible investment) is similar to that obtained from the Input-Output tables. Third, later breakpoints weaken our results somewhat, because the price of omitted intangibles grew more slowly (relative to the PCE deflator) in the 2004-2007 period. However, even with a 2004 breakpoint, our mechanism still explains one-third of the decline in the Solow residual. Finally, our results are robust to using alternative values for the depreciation rate of omitted intangibles, $\delta_{2}$.

\section{Conclusion}

A recent literature has argued that the recent decline in the rate of economic growth in the US is attributable to a decline in TFP growth (Cette et al., 2016; Gordon, 2017; Fernald

\footnotetext{
${ }^{28}$ The historical GDP by industry tables, available at https ://apps . bea.gov/industry/xls/GDPbyInd_ VA_SIC.xls, do not include price deflators. The Gross Output by industry tables, available at https: //apps.bea.gov/industry/xls/GDPbyInd_GO_SIC.xls, report price deflators, but only for the 1977-1997 period, and with a different industry classification (that does not adequately cover service groups) relative to the input-output accounts.

${ }^{29}$ Adjusted TFP growth for the post-1997 sample is, itself, higher than in Table 3, because the estimates of $\hat{b}$ obtained using the coarser industry classification are higher than in our baseline analysis.
} 
et al., 2017). In this paper, we have studied whether this decline in measured TFP growth could reflect measurement bias caused by a simultaneous rise in rents (Barkai, 2020) and a rise in the importance of firms' use of intangible capital, which may not be properly measured (Corrado et al., 2009; Crouzet and Eberly, 2020).

If the price of omitted intangible capital is rising sufficiently fast, an upward bias in measured capital growth (and therefore, a downward bias in measured TFP growth) can occur. However, such mismeasurement would also imply that the level of measured GDP is biased downward, by an amount equal to the flow of intangible investment. This, in turn, would tend to generate a rising measured labor share, at odds with the data. Rising markups, in tandem with rising intangibles, can offset this force and allow simultaneously for a downward bias in measured TFP growth and a declining labor share. We articulated this argument more precisely in balanced growth model featuring both intangibles and markups, and showed, using the input-output tables, that this mechanism could plausibly account for one to two-thirds of the decline in measured TFP growth.

Our results do not imply that the rate of growth of output is mismeasured. Rather, they attribute some of this decline to rising relative prices of certain forms of intangible capital. A difficult but worthwhile question is why these forms of intangible capital have become relatively more expensive. Additionally, outside of the balanced growth path, omitted intangibles may bias the measured growth rate of GDP, further exacerbating TFP growth biases. Finally, our balanced growth analysis assumes Cobb-Douglas substitutability between labor and capital, but deviations from this assumption may accentuate the wedge between the measured labor share and the output elasticity of labor, and amplifying measurement bias. We leave these questions to future research.

\section{References}

Alexander, L. and J. Eberly (2018). Investment hollowing out. IMF Economic Review 66(1), 5-30.

Atkeson, A. and P. J. Kehoe (2005). Modeling and measuring organization capital. Journal of political 
Economy 113(5), 1026-1053.

Baqaee, D. R. and E. Farhi (2020). Productivity and misallocation in general equilibrium. The Quarterly Journal of Economics 135(1), 105-163.

Barkai, S. (2020). Declining labor and capital shares. The Journal of Finance.

Basu, S. and J. Fernald (2001). Why is productivity procyclical? Why do we care? In New developments in productivity analysis, pp. 225-302. University of Chicago Press.

Basu, S., J. G. Fernald, N. Oulton, and S. Srinivasan (2003). The case of the missing productivity growth. NBER macroeconomics annual 18, 9-63.

Bils, M., P. Klenow, and C. Ruane (2020). Misallocation or mismeasurement? NBER working paper.

Byrne, D. M., J. G. Fernald, and M. B. Reinsdorf (2016). Does the United States have a productivity slowdown or a measurement problem? Brookings Papers on Economic Activity 2016(1), 109-182.

Cette, G., J. Fernald, and B. Mojon (2016). The pre-great recession slowdown in productivity. European Economic Review 88, 3-20.

Corrado, C., J. Haskel, C. Jona-Lasinio, and M. Iommi (2016). Intangible investment in the EU and US before and since the Great Recession and its contribution to productivity growth. Technical report, EIB Working Papers.

Corrado, C., C. Hulten, and D. Sichel (2009). Intangible capital and US economic growth. Review of income and wealth 55(3), 661-685.

Crouzet, N. and J. Eberly (2020). Rents and Intangibles: a Q+ Framework. Working paper, Northwestern University.

Crouzet, N. and J. C. Eberly (2019). Understanding weak capital investment: The role of market concentration and intangibles. Technical report, National Bureau of Economic Research.

De Loecker, J., J. Eeckhout, and G. Unger (2020). The rise of market power and the macroeconomic implications. The Quarterly Journal of Economics 135(2), 561-644.

Eisfeldt, A. L. and D. Papanikolaou (2013). Organization capital and the cross-section of expected returns. The Journal of Finance 68(4), 1365-1406. 
Fernald, J. (2014). A quarterly, utilization-adjusted series on total factor productivity. Federal Reserve Bank of San Francisco.

Fernald, J. G., R. E. Hall, J. H. Stock, and M. W. Watson (2017). The disappointing recovery of output after 2009. Technical report, National Bureau of Economic Research.

Gordon, R. J. (2017). The rise and fall of American growth: The US standard of living since the civil war, Volume 70. Princeton University Press.

Gourio, F. and M. Rognlie (2020). Capital heterogeneity and investment prices: how much are investment prices declining?

Greenwood, J., Z. Hercowitz, and P. Krusell (1997). Long-run implications of investment-specific technological change. The American economic review, 342-362.

Gutiérrez, G. and T. Philippon (2017). Declining Competition and Investment in the US. Technical report, National Bureau of Economic Research.

Hall, R. E. (1968). Technical change and capital from the point of view of the dual. The Review of Economic Studies 35(1), 35-46.

Howells, T., E. Morgan, and C. Ross (2018). Improved estimates of the industry economic accounts. In Survey of Current Business, Volume 98. Bureau of Economic Analysis.

Jorgenson, D. W. and Z. Griliches (1967). The explanation of productivity change. The review of economic studies $34(3), 249-283$.

Lawson, A. M., K. S. Bersani, M. Fahim-Nader, and J. Guo (2002). Benchmark input-output accounts of the United States. Survey of Current Business 82, 19-108.

Li, W. C. and B. H. Hall (2020). Depreciation of business R\&D capital. Review of Income and Wealth 66(1), $161-180$.

Oulton, N. (2007). Investment-specific technological change and growth accounting. Journal of Monetary Economics 54(4), 1290-1299.

Solow, R. M. (1957). Technical change and the aggregate production function. The review of Economics and Statistics, 312-320. 
1947-1996 1997-2018 Change

\begin{tabular}{llll}
\hline GDP growth (p.p.) & 3.36 & 2.44 & -0.92 \\
Labor growth (p.p.) & 1.52 & 0.98 & -0.54 \\
Capital growth (p.p.) & 3.80 & 3.32 & -0.48 \\
Labor share of income & 0.68 & 0.64 & -0.04 \\
\hline TFP growth (p.p.) & 1.11 & 0.62 & -0.49 \\
\hline TFP growth (utilization-adjusted; p.p.) & 1.13 & 0.66 & -0.47 \\
\hline
\end{tabular}

Table 1: Solow residuals before and after 1997. The Solow residual is constructed as $\hat{g}_{Z}=$ $\hat{g}-\hat{s}_{L} \hat{g}_{L}-\left(1-\hat{s}_{L}\right) \hat{g}_{K}$, where $\hat{g}$ is the average growth rate of output in consumption units (defined as nominal business value added divided by the deflator for personal consumption expenditures), $\hat{s}_{L}$ is the average measured labor income share, $\hat{g}_{L}$ is the average growth rate of labor input, and $\hat{g}_{K}$ is the average growth rate of capital input. Utilization-adjusted TFP growth is constructed as $\hat{g}_{Z}=\hat{g}-\hat{s}_{L} \hat{g}_{L}-\left(1-\hat{s}_{L}\right) \hat{g}_{K}-\hat{g}_{u}$, where $\hat{g}_{u}$ is the average growth rate of utilization. Input and utilization data are from the Fernald (2014) quarterly dataset; more detail on the measurement of the growth rate of output in consumption units is reported in Appendix A.2.1. 
$\hat{b} \quad \hat{g}_{Q_{2}(\%)} \quad \begin{gathered}\text { GDP } \\ \text { share }(\%)\end{gathered}$

Services

Professional, scientific, and technical services $\quad \begin{array}{lll}0.940 & 0.59 & 3.63\end{array}$

Other real estate

$0.952 \quad-1.75 \quad 0.77$

Administrative and support services

$\begin{array}{lll}0.964 & 0.20 \quad 0.31\end{array}$

Insurance carriers and related activities

$0.972 \quad-0.21$

1.84

Credit intermediation and related activities

$0.973 \quad 1.06$

1.42

Management of companies and enterprises

0.974

1.54

0.02

\section{Commodities}

Chemical products

0.962

1.31

2.67

Oil and gas extraction

0.972

2.09

$-1.25$

Petroleum and coal products

0.973

3.78

1.89

Food and beverage and tobacco products

0.976

1.12

5.55

Table 2: Intermediate commodities or services producing the largest GDP adjustments. The table reports the 10 commodity or service groups with the smallest value of unadjusted GDP to adjusted GDP, where the latter is computed using data from the Use tables of the benchmark Input-Output accounts. For each commodity or service, the first column is the average value of $\hat{b}_{t}=P_{t} Y_{t} /\left(P_{t} Y_{t}+M_{t}\right)$, where $P_{t} Y_{t}$ is total GDP at producer prices, and $M_{t}$ is the nominal value of intermediate input use of the commodity or service. The average is computed over the 19972018 period, for each commodity or service group. The second column reports average values for the relative price growth of omitted capital, computed using price deflators from the GDPby-industry tables, as described in Section 3.2. The third column is the share of the commodity or service in total GDP. We compute the contribution of each commodity to GDP by using the final expenditure data by commodity provided in the Use tables, and subtracting imports of the commodity or service, the latter obtained from the Supply tables. Total GDP is the sum of GDP across all goods and services. The contribution of oil and gas extraction is negative because in many sample years, imports are larger than total domestic use for that commodity. The top panel reports services, while the bottom panel reports commodities. Intermediate services the purchases of which plausibly represents omitted intangible investment are highlighted in bold. 


\begin{tabular}{lcccc}
\hline & \multicolumn{4}{c}{ Average, 1997-2018 } \\
Service groups included & $\hat{b}$ & $g_{Q_{2}}(\%)$ & $\eta$ & $\mu$ \\
\hline Professional serv. & 0.94 & 2.08 & 0.25 & 1.13 \\
Professional serv. + Management & 0.92 & 1.21 & 0.36 & 1.15 \\
Professional serv. + Management + Administrative serv. & 0.89 & 0.60 & 0.50 & 1.19 \\
\hline Organization Capital (Compustat) & 0.91 & 1.05 & 0.39 & 1.16 \\
\hline
\end{tabular}

Table 3: Required rate of growth of relative prices, $g_{Q_{2}}$, in order to fully account for the post-1997 decline in measured TFP growth. These results are constructed using the first approach described in Section 3.1, which only uses data on intermediate expenditures on commodities or services. The first column reports the average ratio of unadjusted GDP to GDP adjusted for omitted intangible investment, $\hat{b}$, defined as in Equation (18). The second column reports the rate of relative price growth $g_{Q_{2}}$ which would be necessary for measurement bias to account for the entirety of the decline in measured TFP growth after 1997, while the third and fourth columns report the CobbDouglas share of omitted intangible capital $\eta$ and the implied level of markups $\mu$. Each line reports the results when a different set of intermediate service expenditures are reclassified as intangible investment. See Section 3.1 for more details on the methodology used to construct $g_{Q_{2}}, \eta$ and $\mu$. 


\begin{tabular}{lccccc} 
& $\hat{b}$ & $\hat{g}_{Q_{2}}(\%)$ & $g_{Z}(\%)$ & $\mu$ & $\eta$ \\
\hline $\mathbf{1 9 4 7 - 1 9 9 6}$ & 0 & 0 & 1.11 & 1.00 & 0 \\
\hline $\mathbf{1 9 9 7 - 2 0 1 8}$ & & & & & \\
$\quad$ No adjustment, no markups & 0 & 0 & 0.62 & 1.00 & 0 \\
$\quad$ No adjustment, markups & 0 & 0 & 0.71 & 1.06 & 0 \\
Adjusted for Prof. services & 0.94 & 0.59 & 0.83 & 1.13 & 0.25 \\
Adjusted for Prof. services + Manag. & 0.92 & 0.78 & 0.90 & 1.15 & 0.35 \\
Adjusted for Prof. services + Manag. + Admin. & 0.89 & 0.65 & 0.95 & 1.19 & 0.50 \\
Adjusted for Organization capital (Compustat) & 0.91 & 0.78 & 0.91 & 1.16 & 0.38 \\
\hline
\end{tabular}

Table 4: TFP growth, after adjusting for omitted intangibles and for markups. The first line reports TFP growth estimated using a model without markups and without omitted capital on the 1947-1996 data; the simple Solow residual is, in that case, a correct measure of GDP. The second line reports the simple Solow residual in the post-1997 sample. The third line reports TFP growth adjusted for markups, and the third to sixth lines report measured TFP growth after adjusting for both markups and omitted intangibles. The adjustments are made following the second of the two approaches described in Section 3.1, which uses data on both expenditures and prices. GDP adjustments, $\hat{b}$, are reported in the first column, and relative price growth rates, $g_{Q_{2}}$, are reported in the third column. 


\begin{tabular}{lcccr} 
& \multicolumn{2}{c}{$\hat{b}$ (average) } & & \\
& $\mathbf{1 9 4 7 - 1 9 9 6}$ & $\mathbf{1 9 9 7 - 2 0 1 8}$ & $\Delta \hat{b}$ & $t$-stat \\
\hline Services & & & & \\
Prof., scient. \& techn. services & 0.955 & 0.921 & $-0.033^{* * *}$ & -15.40 \\
Finance and Insurance & 0.957 & 0.929 & $-0.028^{* * *}$ & -13.72 \\
Real estate & 0.973 & 0.952 & $-0.021^{* * *}$ & -13.15 \\
Admin. and waste services & 0.984 & 0.959 & $-0.025^{* * *}$ & -13.84 \\
Information & 0.979 & 0.967 & $-0.013^{* * *}$ & -9.89 \\
Management of companies & 0.981 & 0.974 & $-0.007^{* * *}$ & -17.60 \\
\hline Commodities & & & & \\
Chemical products & 0.966 & 0.962 & $-0.004^{* * *}$ & -9.89 \\
Oil and gas extraction & 0.978 & 0.972 & $-0.007^{* *}$ & -2.78 \\
Petroleum and coal products & 0.980 & 0.973 & $-0.007^{* * *}$ & -3.48 \\
Food, beverage, tobacco & 0.956 & 0.976 & $0.020^{* * *}$ & 6.07 \\
\hline All commodities and services & 0.982 & 0.983 & 0.001 & 1.25 \\
\hline
\end{tabular}

$*: p<0.05, * *: p<0.01, * * *: p<0.001$.

(a) Individual commodity and service groups

\begin{tabular}{lcccr} 
& \multicolumn{6}{c}{ (average) } & & \\
& $\mathbf{1 9 4 7 - 1 9 9 6}$ & $\mathbf{1 9 9 7 - 2 0 1 8}$ & $\Delta \hat{b}$ & $t$-stat \\
\hline Prof. services & 0.955 & 0.921 & $-0.033^{* * *}$ & -15.40 \\
Prof. services + Manag. & 0.937 & 0.899 & $-0.038^{* * *}$ & -18.11 \\
Prof. services + Manag. + Admin. & 0.924 & 0.866 & $-0.057^{* * *}$ & -16.23 \\
\hline
\end{tabular}

$*: p<0.05, * *: p<0.01, * * *: p<0.001$.

(b) Aggregated service groups

Table 5: Change in GDP adjustment between 1947-1996 and 1997-2018, for the 10 commodity and service groups with the largest GDP adjustments after 1997. The top panel of the table reports the 10 commodity of service groups with the smallest value of unadjusted GDP to adjusted GDP for the 1997-2018 period. The data are from the Use tables of the benchmark Input-Output accounts. For each period and each commodity or service, the first column is the average value of $\hat{b}_{t}=P_{t} Y_{t} /\left(P_{t} Y_{t}+M_{t}\right)$, where $P_{t} Y_{t}$ is nominal GDP, and $M_{t}$ is the nominal value of intermediate input use of the commodity or service. Averages are computed over the 1947-1996 and 19972018 periods, respectively. The definition of the groups differs from Table 2 because the industry classification of the Input-Output accounts changed in 1963 and in 1997; see main text for details. The last column of the table reports the change in the adjustment ratio $\hat{b}$ across periods, and the t-statistic for the one-sided t-test on the difference of means across the two samples. The bottom panel of the table reports similar moments, computed for the aggregated service sectors highlighted in the top panel of the table, and where purchases of intangible capital goods is most likely to be misclassified as expenditure on intermediate inputs. 


\begin{tabular}{l|cccc|cccc|c} 
& \multicolumn{5}{|c|}{$\mathbf{1 9 9 7 - 2 0 1 8}$} & \multicolumn{5}{|c|}{$\mathbf{1 9 4 7 - 1 9 9 6}$} & \multicolumn{1}{c}{} \\
& $\hat{g}_{Q_{2}}(\%)$ & $g_{Z}(\%)$ & $\mu$ & $\eta$ & $\hat{g}_{Q_{2}}(\%)$ & $g_{Z}(\%)$ & $\mu$ & $\eta$ & $\Delta g_{Z}(\%)$ \\
\hline No adj., no markups & 0 & 0.620 & 1.00 & 0 & 0 & 1.107 & 1.00 & 0.00 & -0.487 \\
No adj., markups & 0 & 0.708 & 1.06 & 0 & 0 & 1.106 & 1.00 & 0.00 & -0.398 \\
Prof. serv. & 0.59 & 0.866 & 1.15 & 0.33 & 0.59 & 1.164 & 1.05 & 0.17 & -0.298 \\
Prof. serv.+Manag. & 0.78 & 0.942 & 1.18 & 0.44 & 0.78 & 1.202 & 1.07 & 0.25 & -0.261 \\
Prof. serv.+Manag.+Admin. & 0.65 & 1.004 & 1.22 & 0.60 & 0.65 & 1.212 & 1.08 & 0.30 & -0.208 \\
\hline
\end{tabular}

Table 6: Change in implied moments, between 1947-1996 and 1997-2018, after adjusting for the bias induced by markups and omitted intangible investment. The columns marked "1947-1996" report adjusted moments for the 1947-1996 period, while the columns marked "1997-2018" report adjusted moments for the 1997-2018 period. The last column reports the implied change in the rate of growth of TFP. The line marked "No adjustment, no markup" uses a model with no markups and no intangibles; the line marked "No adjustment, markup" uses a model with no intangibles but positive markups; and the remaining lines adjust for both omitted intangibles and markups, using different service groups to measure omitted intangible investment. 


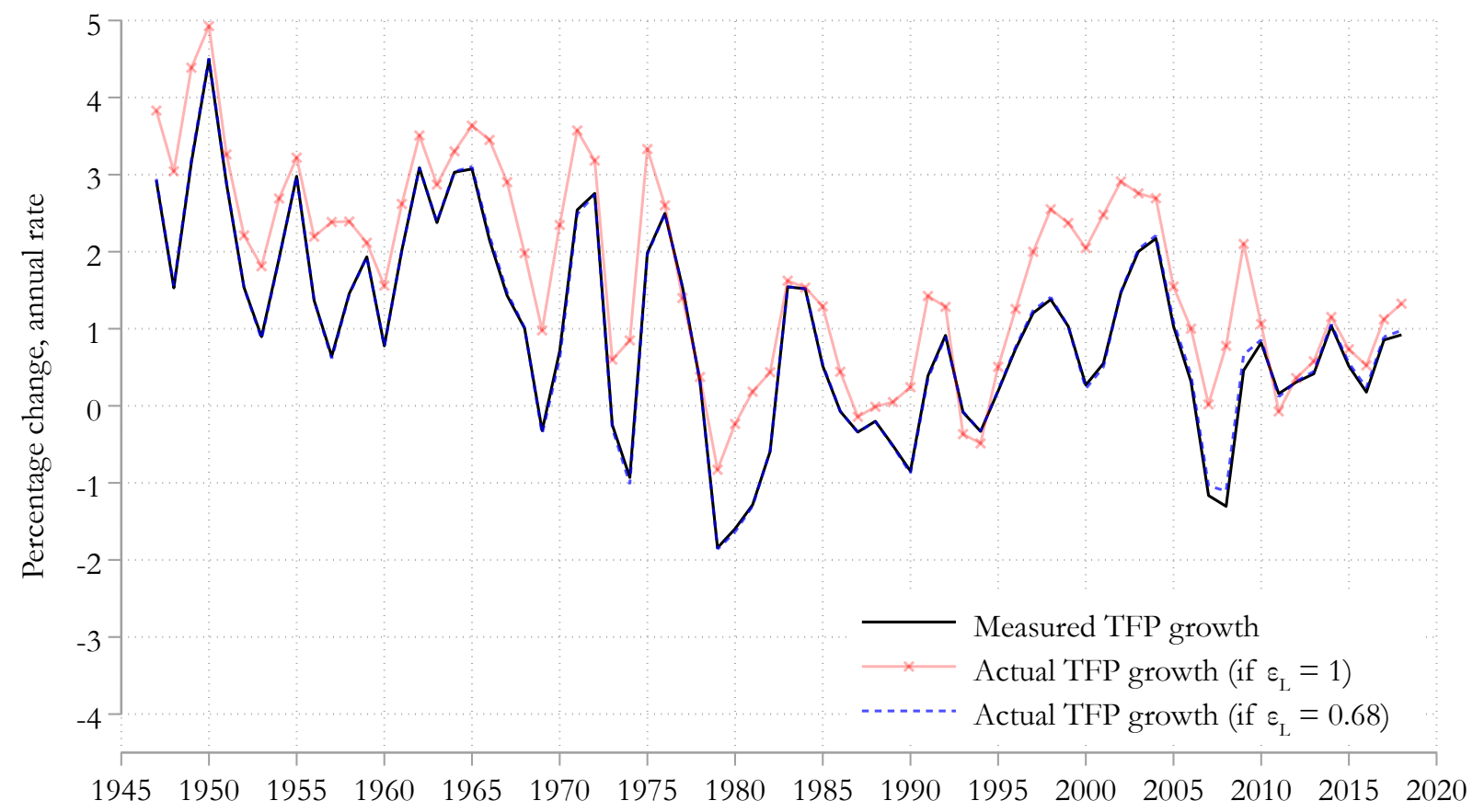

Figure 1: Measured TFP growth, unadjusted and adjusted for markups. The solid black line is annual TFP growth, constructed as $d \hat{Z}_{t} / \hat{Z}_{t}=d \hat{Y}_{t} / \hat{Y}_{t}-\hat{s}_{L, t} d \hat{L}_{t} / \hat{L}_{t}-\left(1-\hat{s}_{L, t}\right) d \hat{K}_{t} / \hat{K}_{t}$, where $d \hat{Y}_{t} / \hat{Y}_{t}$ is output growth, $\hat{s}_{L, t}$ is the measured labor share of income, $d \hat{L}_{t} / \hat{L}_{t}$ is labor input growth, and $d \hat{K}_{t} / \hat{K}_{t}$ is capital input growth, all obtained as annual average from the quarterly data of Fernald (2014). The solid red line is TFP growth adjusted for markups, assuming that $\epsilon_{L, t}=1$ : $\left(d \hat{Z}_{t} / \hat{Z}_{t}\right)^{(a d j)}=d \hat{Z}_{t} / \hat{Z}_{t}+\left(1-\hat{s}_{L, t}\right)\left(d \hat{K}_{t} / \hat{K}_{t}-d \hat{L}_{t} / \hat{L}_{t}\right)$ i.e. the upper bound (in absolute value) for the bias in measured TFP growth. The dashed blue line TFP growth adjusted for markups, when the output elasticity of labor is assumed to be given by the sample average of the labor income share prior to 1995: $\left(d \hat{Z}_{t} / \hat{Z}_{t}\right)^{(a d j)}=d \hat{Z}_{t} / \hat{Z}_{t}+\left(\overline{\hat{s}}_{L, t}-\hat{s}_{L, t}\right)\left(d \hat{K}_{t} / \hat{K}_{t}-d \hat{L}_{t} / \hat{L}_{t}\right)$, with $\overline{\hat{s}}_{L, t}=0.68$. 
Implied moments for $\alpha=0.32$
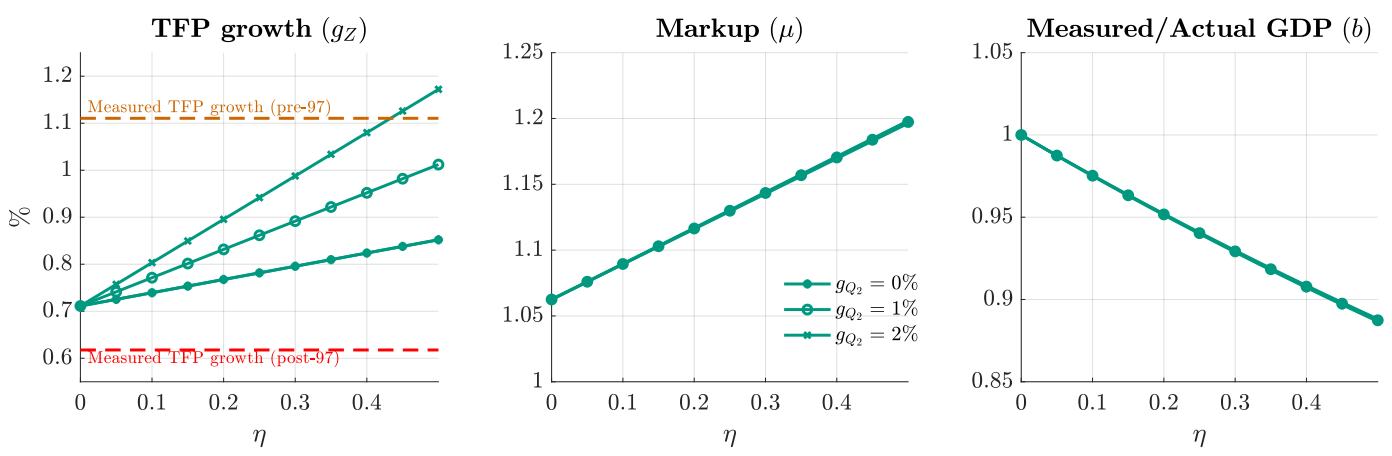

Implied moments for $\alpha=0.34$
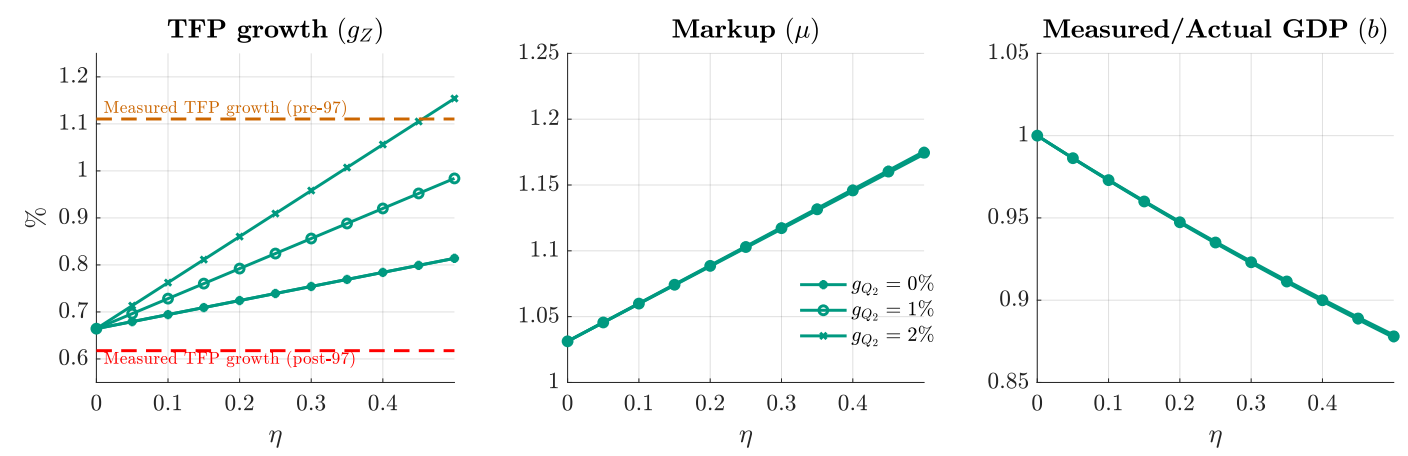

Implied moments for $\alpha=0.36$
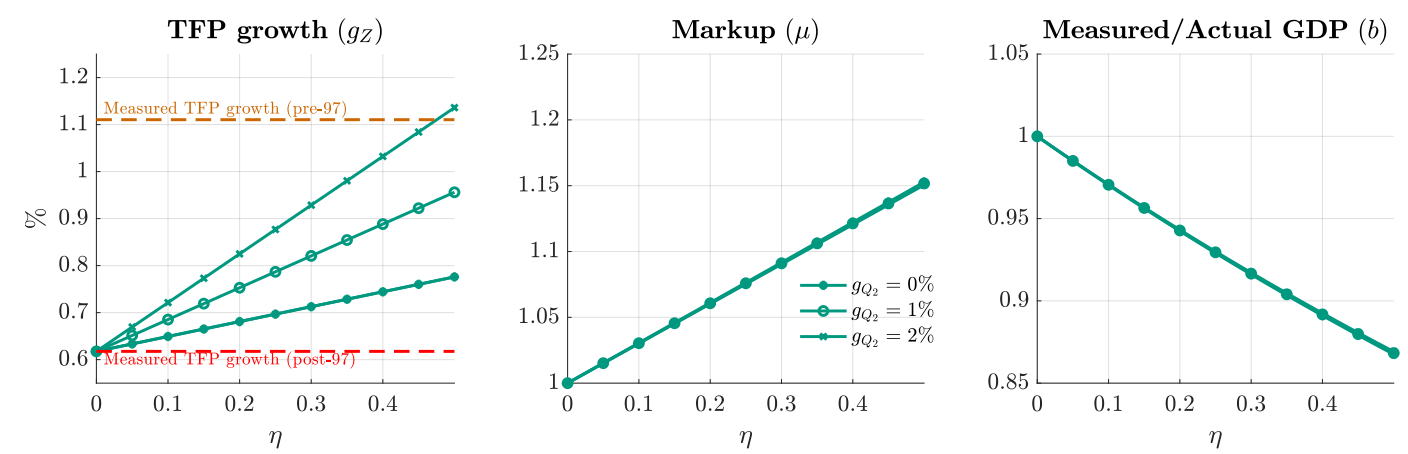

Figure 2: Numerical examples from the balanced growth model. The top panel corresponds to a calibration with $\alpha=0.32$, while the middle and bottom panels correspond to $\alpha=0.34$ and $\alpha=0.36$, respectively. In each panel, the left graph reports the true value of productivity growth $g_{Z}$ required for the balanced growth model to match measured average values of output growth $\hat{g}$, labor growth $\hat{g}_{L}$, measured capital growth $\hat{g}_{\hat{K}}$, and the labor share $\hat{s}_{L}$, in the post-97 sample, as a function of $\eta$, the Cobb-Douglas share of omitted intangibles. Implied TFP growth $g_{Z}$ is reported for different values of the growth rate of omitted capital prices, $g_{Q_{2}}$ (the different green lines). The dashed red line is the average simple Solow residual post-97, while the dashed orange line is the average simple Solow residual pre-97. The middle and right graphs of each panel report the implied markups $\mu$ and share of measured to actual capital $b$. In these latter two graphs, the three distinct lines, corresponding to the different levels of $g_{Q_{2}}$, are not visible because they overlap. 

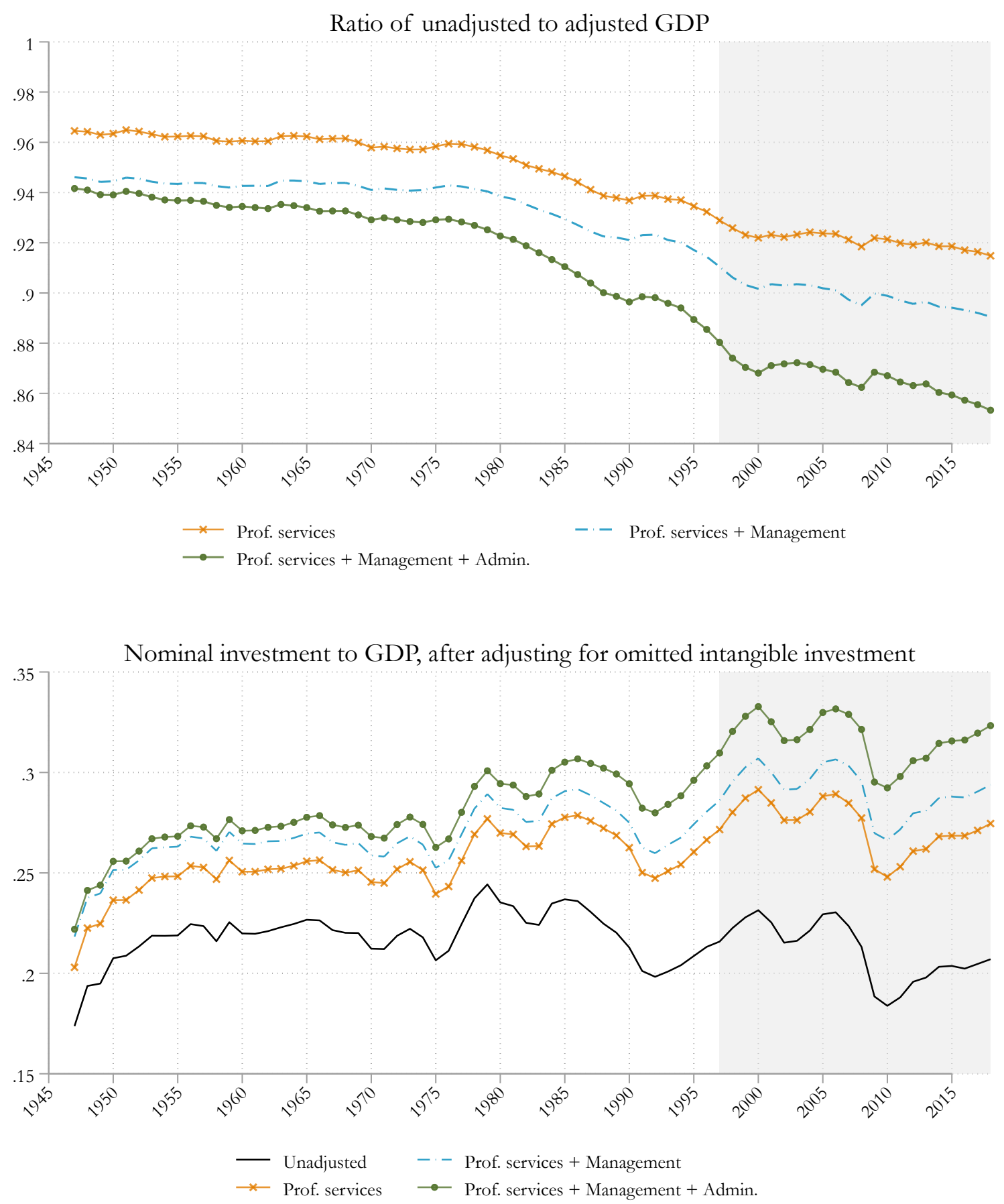

Figure 3: Time series for the ratio of unadjusted GDP to GDP adjusted for omitted intangibles (top panel), and for the ratio of investment to GDP without and with adjustments for omitted intangibles (bottom panel), for the 1947-2018 period. The 1997-2018 period is highlighted in grey. The top panel reports the time series for $\hat{b}_{t}=P_{t} Y_{t} /\left(P_{t} Y_{t}+M_{t}\right)$, where $P_{t} Y_{t}$ is nominal GDP, and $M_{t}$ is the nominal value of intermediate input use of a group of services, where the latter is obtained from the Use tables of the benchmark Input-Output accounts. Each line corresponds to the ratio obtained when treating a different group of services as misclassified intangible investment. The bottom panel reports the time series $\iota_{t}=\left(Q_{t} I_{t}+M_{t}\right) /\left(P_{t} Y_{t}+M_{t}\right)$, where $Q_{t} I_{t}$ is measured aggregate spending on investment goods, also obtained from the Input-Output accounts. Appendix Figure A2 reports the time series for the same moments from 1997-2018 only, using definitions of the omitted intangibles based on the more granular classifications of the post-1997 input/output tables. 
Adjusted Solow residual $g_{\mathrm{Z}, \mathrm{j}}(\%)$
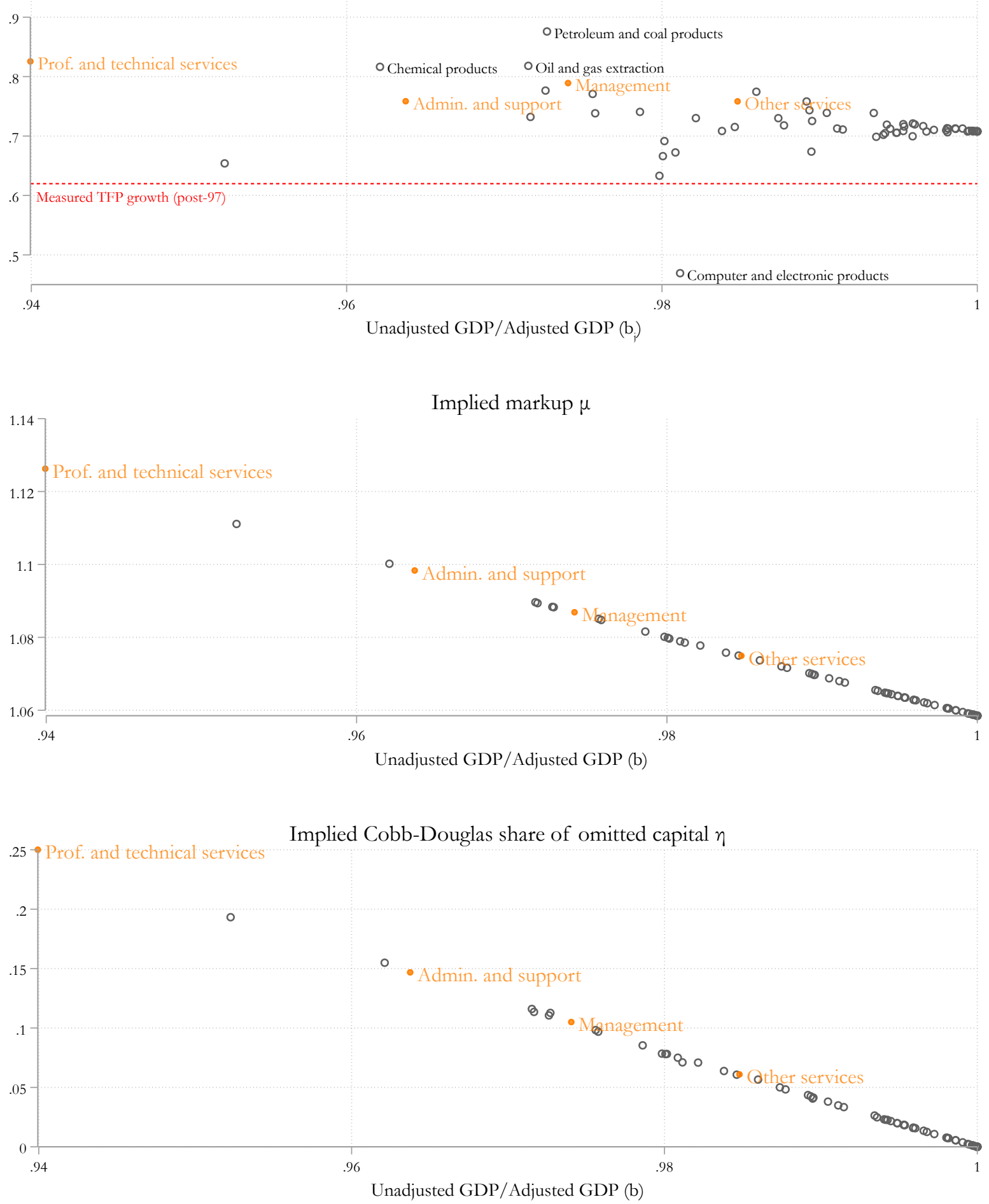

Figure 4: Implied moments when adjusting for individual commodity or sector groups. The moments in each panel are computed using second of the two approaches described in Section 3.1, applied to individual commodity or service groups among the 61 reported in the Input-Output tables. The top panel reports TFP growth adjusted for both intangibles and markups, the middle panel reports the implied markup, and the bottom panel reports the implied Cobb-Douglas share of omitted intangible capital in the production function. Key service sectors are highlighted in orange. 


\section{Supplementary Materials}

\section{A.1 Theory}

This appendix provides details for the theoretical results reported in Section 2.

\section{A.1.1 Main model}

We start by a describing and analyzing in more detail the balanced growth model described in Section 2 and used in Section 3 for empirical analysis. This model uses a value added production function.

\section{A.1.1.1 Description}

Firm The representative firm solves:

$$
T C_{t}=\min _{\mathbf{K}_{t}, L_{t}} \sum_{n=1}^{2} R_{n, t} K_{n, t}+W_{t} L_{t} \quad \text { s.t. } \quad Z_{t}\left(K_{1, t}^{1-\eta} K_{2, t}^{\eta}\right)^{\alpha} L_{t}^{1-\alpha} \geq Y_{t} \quad\left[M C_{t}\right]
$$

where $T C_{t}$ denotes total costs of production, $\mathbf{K}_{t}=\left\{K_{n, t}\right\}_{n=1}^{2}$ is a vector of capital inputs, with $K_{1, t}$ the measured capital input, and $K_{2, t}$ the omitted intangible input, $L_{t}$ is labor input, $\left\{R_{n, t}\right\}_{n=1}^{2}$ is a vector of user costs, $W_{t}$ is the wage rate, $Z_{t}$ is total factor productivity, $1-\alpha$ is the elasticity of output with respect to labor, and $\eta$ is the elasticity of the total capital input $K_{t}=K_{1, t}^{1-\eta} K_{2, t}^{\eta}$. Total factor productivity evolves exogenously, following:

$$
d Z_{t}=g_{Z} Z_{t} d t .
$$

The solution to this problem is:

$$
\begin{aligned}
T C_{t} & =M C_{t} Y_{t} \\
M C_{t} & =\frac{1}{Z_{t}}\left(\frac{W_{t}}{1-\alpha}\right)^{1-\alpha}\left(\frac{R_{t}}{\alpha}\right)^{\alpha} \\
L_{t} & =M C_{t} \frac{(1-\alpha) Y_{t}}{W_{t}} \\
K_{t} & =M C_{t} \frac{\alpha Y_{t}}{R_{t}}
\end{aligned}
$$




$$
\begin{aligned}
K_{t} & =K_{1, t}^{1-\eta} K_{2, t}^{\eta} \\
R_{t} & =\left(\frac{R_{1, t}}{1-\eta}\right)^{1-\eta}\left(\frac{R_{2, t}}{\eta}\right)^{\eta} \\
K_{1, t} & =(1-\eta) \frac{R_{t}}{R_{1, t}} K_{t} \\
K_{2, t} & =\eta \frac{R_{t}}{R_{2, t}} K_{t}
\end{aligned}
$$

The firm's revenue is $S_{t}=P_{t} Y_{t}$ and its profits are $\Pi_{t}=P_{t} Y_{t}-T C_{t}=\left(P_{t}-M C_{t}\right) Y_{t}$, where $P_{t}$ is the price of consumption goods. The labor share is:

$$
s_{L, t} \equiv \frac{W_{t} L_{t}}{P_{t} Y_{t}}=(1-\alpha) \frac{M C_{t}}{P_{t}} .
$$

Household The representative household solves:

$$
\begin{aligned}
U\left(\mathbf{K}_{t} ; \mathbf{X}_{t}\right)=\max _{\left\{C_{t+h}, \mathbf{I}_{t+h}\right\}_{h \geq 0}} & \int_{0}^{+\infty} e^{-\rho h} \frac{C_{t+h}^{1-\sigma}}{1-\sigma} d h \\
\text { s.t. } & d K_{n, t}=\left(I_{n, t}-\delta_{n} K_{n, t}\right) d t, \quad n=1,2 \\
& \sum_{n=1}^{2} R_{n, t} K_{n, t}+W_{t} L_{t}+\Pi_{t}=\sum_{n=1}^{2} Q_{n, t} I_{n, t}+C_{t}
\end{aligned}
$$

Here, $\rho$ is the household's discount factor, $\sigma \geq 1$ is the intertemporal elasticity of substitution in consumption, $\left\{\delta_{n}\right\}_{n=1}^{2}$ is the rate of depreciation of capital, and the vector $\mathbf{X}_{t}$ collects all variables that are either exogenous or taken as given by the household when making consumption plans: $\mathbf{X}_{t}=\left\{W_{t}, L_{t}, \Pi_{t}, R_{1, t}, R_{2, t}, Q_{1, t}, Q_{2, t}\right\}$. In particular, the prices of investment goods, $\left\{Q_{n, t}\right\}_{n=1}^{2}$, and labor supply, $L_{t}$, all evolve exogenously, following:

$$
\begin{aligned}
d Q_{n, t} & =g_{Q_{n}} Q_{n, t} d t, \quad n=1,2 \\
d L_{t} & =g_{L} L_{t} d t .
\end{aligned}
$$

Equilibrium An equilibrium is a set of deterministic sequences for all endogenous variables such that (1) given the exogenous processes for labor, productivity, and the prices of capital goods, the endogenous variables satisfy the solution to the firm's problem and solve the representative consumer's problem; and (2) the price of consumption goods and their 
marginal cost of production are related through:

$$
P_{t}=\mu M C_{t}
$$

where $\mu>1$ is the exogenous price-cost markup. Finally, in equilibrium, we normalize the price level to $P_{t}=1$, so that all other prices are expressed relative to consumption goods.

\section{A.1.1.2 Balanced growth path}

We next derive the unique stationary, or balanced growth, equilibrium of the model. Define an aggregate price index for capital goods $Q_{t}$ as:

$$
Q_{t}=Q_{1, t}^{1-\eta} Q_{2, t}^{\eta}
$$

Next, define the trend growth factor $X_{t}$ as:

$$
T_{X, t}=L_{t} Z_{t}^{\frac{1}{1-\alpha}} Q_{t}^{-\frac{\alpha}{1-\alpha}}
$$

and define the detrended variables:

$$
\begin{aligned}
c_{t} & \equiv \frac{C_{t}}{T_{X, t}} \\
w_{t} & \equiv \frac{W_{t} L_{t}}{T_{X, t}} \\
\pi_{t} & \equiv \frac{\Pi_{t}}{T_{X, t}} \\
i_{n, t} & \equiv \frac{Q_{n, t} I_{n, t}}{T_{X, t}}, \quad n=1,2 \\
k_{n, t} & \equiv \frac{Q_{n, t} K_{n, t}}{T_{X, t}}, \quad n=1,2 \\
R_{d, n, t} & \equiv \frac{R_{n, t}}{Q_{n, t}}, \quad n=1,2 \\
R_{d, t} & \equiv \frac{R_{t}}{Q_{t}} \\
y_{t} & \equiv \frac{Y_{t}}{T_{X, t}} \\
k_{t} & \equiv \frac{Q_{t} K_{t}}{T_{t}}
\end{aligned}
$$


Moreover, define the trend growth rate (the growth rate of $T_{X, t}$ ), the capital price growth rate (the growth rate of $Q_{t}$ ), and the discount rate $r$ as:

$$
\begin{aligned}
g & \equiv g_{L}+\frac{1}{1-\alpha} g_{Z}-\frac{\alpha}{1-\alpha} g_{Q} \\
g_{Q} & \equiv(1-\eta) g_{Q_{1}}+\eta g_{Q_{2}} \\
r & \equiv \rho+\sigma g .
\end{aligned}
$$

Using these detrended variables, the Hamilton-Jacobi-Bellman equation corresponding to the household's problem can be written as:

$$
\begin{aligned}
(r-g) u\left(\mathbf{k}_{t}, \mathbf{x}_{t}\right)=\max _{c_{t}, \mathbf{i}_{t}} \frac{c_{t}^{1-\sigma}}{1-\sigma} & +\sum_{n=1}^{2}\left(i_{n, t}-\left(g+\delta_{n}-g_{Q_{n}}\right) k_{n, t}\right) u_{k_{n}, t}\left(\mathbf{k}_{t}, \mathbf{x}_{t}\right) \\
& +\sum_{j}^{\dot{x}_{j, t}} u_{x_{j}, t}\left(\mathbf{k}_{t}, \mathbf{x}_{t}\right) \\
& \text { s.t. } \sum_{n=1}^{2} R_{d, n, t} k_{n, t}+w_{t}+\pi_{t}=\sum_{n=1}^{2} i_{n, t}+c_{t}
\end{aligned}
$$

where $\mathbf{i}_{t}=\left\{i_{n, t}\right\}_{n=1}^{2}, \mathbf{k}_{t}=\left\{k_{n, t}\right\}_{n=1}^{2}, \mathbf{x}_{t}=\left\{w_{t}, \pi_{t}, R_{d, 1, t}, R_{d, 2, t}\right\}, u\left(\mathbf{k}_{t}, \mathbf{x}_{t}\right)=U\left(\mathbf{K}_{t}, \mathbf{X}_{t}\right) / T_{X, t}^{1-\sigma}$, and $\dot{x}_{j, t} \equiv \frac{d x_{j, t}}{d t}$. After simplifications, the two Euler equations associated with this problem can be written as:

$$
\begin{gathered}
\left(\sum_{n=1}^{2} R_{d, n, t} k_{n, t}+w_{t}+\pi_{t}-c_{t}-\sum_{n=1}^{2}\left(\delta_{n}+g-g_{Q_{n}}\right) k_{n, t}\right) \frac{c_{k_{n}, t}}{c_{t}}= \\
\frac{R_{d, n, t}-\left(r+\delta_{n}-g_{Q_{n}}\right)+\sum_{j} \dot{x}_{j, t} u_{x_{j} k_{n}, t}}{\sigma}, \quad n=1,2 .
\end{gathered}
$$

A balanced growth path is defined as an equilibrium where detrended variables are constant: $\dot{x}_{j, t}=0$ for all $j, \dot{k}_{n, t}=0, n=1,2$, and so on. Detrended variables without a time index indicate these constant values.

Since $\dot{k}_{n, t}=i_{n, t}-\left(g+\delta_{n}-g_{Q_{n}}\right) k_{n, t}, n=1,2$, on the balanced growth path,

$$
i_{n, t}=i_{n}=\left(g+\delta_{n}-g_{Q_{n}}\right) k_{n}, \quad n=1,2 .
$$

Plugging this into the first-order condition, and using the budget constraint of the household and the fact that $\dot{x}_{j, t}=0$ for all $j$, we obtain that along the balanced growth path, detrended user costs must satisfy:

$$
R_{d, n, t}=R_{d, n}=r+\delta_{n}-g_{Q_{n}}, \quad n=1,2,
$$


the standard Hall-Jorgenson formula. rest of the balanced growth path is then given by:

$$
\begin{aligned}
M C & =\frac{1}{\mu} \\
R_{d} & =\left(\frac{R_{d, 1}}{1-\eta}\right)^{1-\eta}\left(\frac{R_{d, 2}}{\eta}\right)^{\eta} \\
y & =k^{\alpha} \\
k & =\left(\frac{\alpha}{\mu R_{d}}\right)^{\frac{1}{1-\alpha}} \\
w & =\frac{1-\alpha}{\mu} k^{\alpha} \\
\pi & =\frac{\mu-1}{\mu} k^{\alpha} \\
k_{1} & =(1-\eta) \frac{R_{d}}{R_{d, 1}} k \\
k_{2} & =\eta \frac{R_{d}}{R_{d, 2}} k \\
i_{n} & =\left(g+\delta_{n}-g_{Q_{n}}\right) k_{n}=\left(R_{d, n}-(r-g)\right) k_{n}, \quad n=1,2 .
\end{aligned}
$$

\section{A.1.1.3 Chained GDP growth vs. growth of output in consumption units}

Finally, we discuss the relationship between growth of output in consumption units, $\frac{d Y_{t}}{Y_{t}}$, and chained GDP growth, the usual empirical measures of real output. This discussion follows Oulton (2007).

First, note that we assume that measured nominal output is the sum of consumption expenditures, plus measured investment expenditures:

$$
P_{t} \hat{Y}_{t}=P_{t} C_{t}+Q_{1, t} I_{1, t}
$$

where $P_{t} \hat{Y}_{t}$ is measured nominal output (with $P_{t}$ referring to the price of consumption goods, and $\hat{Y}_{t}$ measured output in consumption units); $C_{t}$ is consumption; and $Q_{1, t} I_{1, t}$ are measured investment expenditures. In our model, measured chained GDP growth, $\frac{d \hat{Y}_{t}^{\text {ch }}}{\hat{Y}_{t}^{\text {ch }}}$, is defined as the share-weighted growth rate of real consumption and measured real investment:

$$
\frac{d \hat{Y}_{t}^{\mathrm{ch}}}{\hat{Y}_{t}^{\mathrm{ch}}} \equiv\left(1-s_{I_{1}, t}\right) \frac{d C_{t}}{C_{t}}+s_{I_{1}, t} \frac{d I_{1, t}}{I_{1, t}}
$$


where the share of investment in measured nominal GDP is:

$$
s_{I, t} \equiv \frac{Q_{1, t} I_{1, t}}{P_{t} \hat{Y}_{t}}
$$

where variables are defined as above. By contrast, since we have:

$$
\hat{Y}_{t}=C_{t}+\left(Q_{1, t} / P_{t}\right) I_{1, t}
$$

growth of measured output in consumption units is given by:

$$
\frac{d \hat{Y}_{t}}{\hat{Y}_{t}}=\left(1-s_{I_{1}, t}\right) \frac{d C_{t}}{C_{t}}+s_{I_{1}, t}\left(\frac{d I_{1, t}}{I_{1, t}}+\frac{d Q_{1, t}}{Q_{1, t}}-\frac{d P_{t}}{P_{t}}\right) .
$$

Therefore, chained GDP growth is not equal to the growth rate of measured output in consumption units. Instead:

$$
\frac{d \hat{Y}_{t}^{\mathrm{ch}}}{\hat{Y}_{t}^{\mathrm{ch}}}-\frac{d \hat{Y}_{t}}{\hat{Y}_{t}}=-s_{I_{1}, t}\left(\frac{d Q_{1, t}}{Q_{1, t}}-\frac{d P_{t}}{P_{t}}\right)
$$

It is straightforward to see that this bias remains nonzero even in the balanced growth path. (Note that in the balanced growth path, since we normalize $P_{t}=1$, the expression boils down to $-s_{I_{1}, t} \frac{d Q_{1, t}}{Q_{1, t}}$; however, $\frac{d Q_{1, t}}{Q_{1, t}}$ should then be interpreted as the change of the price of measured investment goods relative the price of consumption goods.)

Next, assume that, instead of measuring output growth using output in consumption units (as we do in our baseline approach), we were to measure it using chained GDP growth. Then, denoting by $\frac{d \hat{Z}_{t}^{c h}}{\hat{Z}_{t}^{c h}}$ the Solow residual obtained using chained GDP growth, since our other measures of input growth and input shares are unchanged, we have:

$$
\frac{d \hat{Z}_{t}^{c h}}{\hat{Z}_{t}^{c h}}=\frac{d \hat{Z}_{t}}{\hat{Z}_{t}}-s_{I_{1}, t}\left(\frac{d Q_{1, t}}{Q_{1, t}}-\frac{d P_{t}}{P_{t}}\right) .
$$

Note that, consistent with $\frac{d Q_{1, t}}{Q_{1, t}}<\frac{d P_{t}}{P_{t}}$, Table A2 shows that the Solow residual obtained using chained GDP growth is higher than the one obtained using growth of output in consumption units.

The rest of the derivations regarding the bias between the true rate of growth of neutral technology, $\frac{d Z_{t}}{Z_{t}}$, and the Solow residual $\frac{d \hat{Z}_{t}}{\hat{Z}_{t}}$, is unchanged. Therefore, we can express the bias between the chained GDP Solow residual, and the true growth rate of neutral technology, 
as:

$$
\frac{d \hat{Z}_{t}^{c h}}{\hat{Z}_{t}^{c h}}-\frac{d Z_{t}}{Z_{t}}=\Delta_{t}^{(1)}+\Delta_{t}^{(2)}+\Delta_{t}^{(3)}+\Delta_{t}^{(4)},
$$

where the terms $\Delta_{t}^{(1)}, \Delta_{t}^{(2)}$, and $\Delta_{t}^{(3)}$ are defined as in the baseline model, and:

$$
\Delta_{t}^{(4)} \equiv-s_{I_{1}, t}\left(\frac{d Q_{1, t}}{Q_{1, t}}-\frac{d P_{t}}{P_{t}}\right)
$$

In other words, with the chained GDP Solow residual, the analysis of the baseline text is unchanged, except that there is a fourth bias term. This term reflects the fact that with investment-specific technical change of the form assumed in our baseline model, the chained GDP Solow residual does not appropriately measure the growth rate of neutral technology. In our baseline approach, rather than adding the fourth bias terms $\Delta_{t}^{(4)}$, we instead measure the Solow residual using the growth rate of output in consumption units; as the previous discussion shows, the two approaches are equivalent, up to the additional bias term, $\Delta_{t}^{(4)}$.

\section{A.1.1.4 Additional results and proofs}

We next state the following result about the case of no markups $(\mu=1)$, and provide a proof below.

Result 5. Assume that $\mu=1, \sigma=1$, and that the stock of intangibles is growing $\left(d K_{2, t} / K_{2, t}>\right.$ 0 , or $\left.g>g_{Q_{2}}\right)$. Then, along the balanced growth path, TFP growth is biased downward $(\Delta<0)$, if and only if: $g_{Q_{2}} \geq \overline{\mathbf{g}}_{2}(\eta)$, where:

$$
\overline{\mathbf{g}}_{2}(\eta)=\frac{g_{L}+\delta_{2}}{\rho+\delta_{2}} g_{Z}+\frac{\rho}{\rho+g_{L}+\delta_{2}} g_{Q_{1}}+O(\eta)
$$

In particular, if $\delta_{2} \gg \rho$, measured TFP growth is biased downward, if and only if: $g_{Q_{2}}>g_{Z} \cdot{ }^{30}$

Proof. [Result 5] Along the balanced growth path, using the fact that $\sigma=1$, we have:

$$
\begin{array}{rlr}
\Delta & =\alpha \eta \frac{-(r-g)\left(g_{Q_{2}}-g_{Q_{1}}\right)+\left(g+\delta_{2}-g_{Q_{2}}\right)\left(g_{Z}-g_{Q_{1}}-(1+\alpha \eta)\left(g_{Q_{2}}-g_{Q_{1}}\right)\right)}{r-g+(1-\alpha \eta)\left(g+\delta_{2}-g_{Q_{2}}\right)} & \\
& =\alpha \eta \frac{-\rho\left(g_{Q_{2}}-g_{Q_{1}}\right)+\left(g+\delta_{2}-g_{Q_{2}}\right)\left(g_{Z}-g_{Q_{1}}-(1+\alpha \eta)\left(g_{Q_{2}}-g_{Q_{1}}\right)\right)}{\rho+(1-\alpha \eta)\left(g+\delta_{2}-g_{Q_{2}}\right)} & \text { when } \sigma=1
\end{array}
$$

\footnotetext{
${ }^{30}$ The proof is reported in Appendix A.1.1.4, and illustrated in Appendix Figure A1 illustrates the result.
} 
The stock of intangibles is growing if and only:

$$
\begin{aligned}
\frac{d K_{2, t}}{K_{2, t}}>0 & \Longleftrightarrow g-g_{Q_{2}}>0 \\
& \Longleftrightarrow g_{L}+\frac{1}{1-\alpha}\left(g_{Z}-g_{Q_{1}}\right)-\frac{1-\alpha+\alpha \eta}{1-\alpha}\left(g_{Q_{2}}-g_{Q_{1}}\right)>0
\end{aligned}
$$

Define $\quad x \equiv g_{Q_{2}}-g_{Q_{1}}$. Then:

$$
\begin{aligned}
g-g_{Q_{2}}>0 & \Longleftrightarrow g_{L}+\frac{1}{1-\alpha}\left(g_{Z}-g_{Q_{1}}\right)-\frac{1-\alpha+\alpha \eta}{1-\alpha} x>0 \\
& \Longleftrightarrow x \leq \overline{\bar{x}}(\eta) \equiv \frac{1-\alpha}{1-\alpha+\alpha \eta}\left[g_{L}+\frac{1}{1-\alpha}\left(g_{Z}-g_{Q_{1}}\right)\right]
\end{aligned}
$$

Thus intangible capital is growing so long as $x \leq \overline{\bar{x}}(\eta)$. In that case, note that the sign of the total bias only depends on the sign of its numerator. The sign of the numerator in $\Delta$ is the same as the sign of:

$$
\begin{aligned}
\Delta(x, \eta) & =(x-B(\eta))(x-C(\eta))-A(\eta) x \\
A(\eta) & \equiv \frac{(1-\alpha)(1+\alpha \eta)}{1-\alpha+\alpha \eta} \rho \\
B(\eta) & \equiv \frac{g_{Z}-g_{Q_{1}}}{1+\alpha \eta} \\
C(\eta) & \equiv \frac{1-\alpha}{1-\alpha+\alpha \eta}\left(g_{L}+\frac{1}{1-\alpha}\left(g_{Z}-g_{Q_{1}}\right)+\delta_{2}\right)
\end{aligned}
$$

The minimum of $\Delta(., \eta)$ is attained at $\hat{x}(\eta) \equiv \frac{1}{2}(A(\eta)+B(\eta)+C(\eta))$. Moreover, a sufficient condition for $\hat{x}(\eta)>\overline{\bar{x}}(\eta)$ for all $\eta$ is:

$$
\delta_{2}+\rho>\frac{\alpha}{(1-\alpha)(1+\alpha \eta)}\left(g_{Z}-g_{Q_{1}}\right)+g_{L}
$$

The discriminant of the polynomial $\Delta(., \eta)$ can be rewritten as:

$$
D(\eta)=(A(\eta)+B(\eta)+C(\eta))^{2}-4 B C(\eta)=(C(\eta)-B(\eta))^{2}+A(\eta)(A(\eta)+2(B(\eta)+C(\eta)))
$$

A sufficient condition for $D(\eta)>0$ for all $\eta$ is:

$$
g_{Z}-g_{Q 1}>0 .
$$


Assume conditions that (1) and (2) hold. Then, given that $D(., \eta)$ is a convex function with global minimum $\hat{x}(\eta)$,

$$
D(x, \eta)<0 \quad \text { and } \quad g>g_{Q_{2}} \quad \Longleftrightarrow \quad x_{1}(\eta) \leq x \leq \overline{\bar{x}}(\eta)
$$

where $x_{1}$ is the smallest root of the polynominal $\Delta(x)$ :

$$
x_{1}(\eta)=\frac{1}{2}(A(\eta)+B(\eta)+C(\eta))\left(1-\sqrt{1-\frac{4 B(\eta) C(\eta)}{(A(\eta)+B(\eta)+C(\eta))^{2}}}\right)
$$

The threshold reported in the Result is therefore given by:

$$
\overline{\mathbf{g}}_{2}(\eta) \equiv g_{Q_{1}}+x_{1}(\eta)
$$

For the expansion, assume that $C(\eta), A(\eta) \gg B(\eta)$. Then:

$$
\begin{aligned}
x_{1}(\eta) & =\frac{1}{2}(A(\eta)+B(\eta)+C(\eta))\left(1-\sqrt{1-\frac{4 B(\eta) C(\eta)}{(A(\eta)+B(\eta)+C(\eta))^{2}}}\right) \\
& =\frac{1}{2}(A(\eta)+B(\eta)+C(\eta)) 2 \frac{B(\eta) C(\eta)}{(A(\eta)+B(\eta)+C(\eta))^{2}}+O(\eta) \\
& =\frac{B(\eta) C(\eta)}{A(\eta)+B(\eta)+C(\eta)}+O(\eta) \\
& =\frac{g_{L}+\delta_{2}}{\rho+g_{L}+\delta_{2}}\left(g_{Z}-g_{Q_{1}}\right)+O(\eta) .
\end{aligned}
$$

Appendix Figure A1 illustrates this result. In a first parameter region (highlighted in blue), the price of omitted capital is growing too slowly to generate negative measurement error in TFP growth, while in the second one (highlighted in green), the price of omitted capital is growing sufficiently fast so as to generate negative measurement bias. The frontier between the two regions - corresponding to the threshold $\overline{\mathbf{g}}_{2}(\eta)$ in Result 5 - depends on $\eta$, the Cobb-Douglas intangible share, but, as indicated by Result 5 , its slope is small.

\section{A.1.2 Gross output model}

This appendix provides more details on the results relating to gross-output production functions. The main difference is that gross output is not mismeasured, but its components are, which will contribute to mismeasured productivity growth as in the value-added approach. 


\section{A.1.2.1 General results}

Assume that gross output is given by $X_{t}=Z_{X, t} G\left(M_{t}, L_{t}, K_{t}\right)$, where $G$ is homogeneous of degree $1, M_{t}$ are intermediate inputs, and $Z_{X, t}$ is "gross output" total factor productivity. ${ }^{31}$ Define the "gross output" Solow residual as:

$$
\frac{d \widehat{Z}_{X, t}}{\widehat{Z}_{X, t}}=\frac{d \hat{X}_{t}}{\hat{X}_{t}}-\widehat{s}_{X, M, t} \frac{d \widehat{M}_{t}}{\widehat{M}_{t}}-\widehat{s}_{X, L, t} \frac{d \widehat{L}_{t}}{\widehat{L}_{t}}-\left(1-\widehat{s}_{X, M, t}-\widehat{s}_{X, L, t}\right) \frac{d \widehat{K}_{t}}{\widehat{K}_{t}} .
$$

Here, $\widehat{s}_{X, M, t}$ and $\widehat{s}_{X, L, t}$ are the shares of intermediate input and labor in gross output:

$$
\widehat{s}_{X, M, t} \equiv \frac{\widehat{P}_{M, t} \widehat{M}_{t}}{P_{t} X_{t}}, \quad \widehat{s}_{X, L, t} \equiv \frac{W_{t} L_{t}}{P_{t} X_{t}}
$$

and $\widehat{P}_{M, t} \widehat{M}_{t}$ is nominal expenditure on intermediate inputs.

Analogous to the value added case, we are interested in whether the gross-output Solow residual is a biased measure of gross-output TFP growth when there are markups and omitted intangibles. Markups are defined as the wedge between the price of consumption goods, $P_{t}$, and the marginal cost of gross output, $\mu_{X, t} \equiv \frac{P_{t}}{M C_{X, t}} .32$ With omitted intangibles, gross output is always correctly measured. Omitting intangibles only affects its distribution between purchases of intermediates and purchases of investment goods.

As before, denoting by $B_{t}$ misclassified purchases of intangibles, we have: $\widehat{P}_{M, t} \widehat{M}_{t}=$ $P_{M, t} M_{t}-B_{t}$, where $P_{M, t} M_{t}$ are actual purchases of intermediate inputs. Similar to the ratio $b_{t}$ in the value added case, the ratio $c_{t}=\frac{P_{M, t} M_{t}}{\widehat{P}_{M, t} \widehat{M}_{t}} \leq 1$ captures the amount of mismeasurement due to omitted intangibles; in particular, when $c_{t}=1$, there is no mismeasurement.

Result 6. Assume that labor and intermediate inputs are chosen to minimize total variable cost $P_{M, t} M_{t}+W_{t} L_{t}$. Then, the bias in the gross-output Solow residual, relative to gross-output TFP growth, can be written as:

$$
\frac{d \hat{Z}_{X, t}}{\hat{Z}_{X, t}}-\frac{d Z_{X, t}}{Z_{X, t}} \equiv \Delta_{X, t}=\Delta_{X, t}^{(1)}+\Delta_{X, t}^{(2, L)}+\Delta_{X, t}^{(2, M)}+\Delta_{X, t}^{(3)}
$$

The components of the bias in the gross-output Solow residual, relative to gross-output TFP

\footnotetext{
${ }^{31}$ The terminology "multi-factor productivity" is sometimes used to refer to $Z_{X, t}$, but we use "gross output" TFP in order to distinguish it from the notion of productivity in our value-added approach.

${ }^{32}$ Note that $\mu_{X, t}$ is a gross-output, or a sales, markup. Under cost minimization and constant returns, we have $\mu_{t}=\left(\mu_{X, t}-\epsilon_{X, M, t}\right) /\left(1-\epsilon_{X, M, t}\right) \geq \mu_{X, t}$, where $\epsilon_{X, M, t}$ is the elasticity of gross output with respect to intermediate inputs. This can also be written as $\mu_{t}=\mu_{X, t}\left(1-c_{t} \hat{s}_{X, M, t}\right) /\left(1-c_{t} \mu_{X, t} \hat{s}_{X, M, t}\right)$. Additionally, as in the case of the value-added approach, we assume that $X_{t}$ is expressed in units of consumption goods.
} 
growth, are given by:

$$
\begin{aligned}
\Delta_{X, t}^{(1)} & =\hat{s}_{X, M, t}\left(\frac{d M_{t}}{M_{t}}-\frac{d \hat{M}_{t}}{\hat{M}_{t}}\right) & \text { (intermediate growth bias) } \\
\Delta_{X, t}^{(2, L)} & =-\hat{s}_{X, L, t}\left(\mu_{X, t}-1\right)\left(\frac{d \hat{K}_{t}}{\hat{K}_{t}}-\frac{d L_{t}}{L_{t}}\right) & \text { (labor share bias) } \\
\Delta_{X, t}^{(2, M)} & =-\hat{s}_{X, M, t}\left(\mu_{X, t} c_{t}-1\right)\left(\frac{d \hat{K}_{t}}{\hat{K}_{t}}-\frac{d M_{t}}{M_{t}}\right) & \text { (intermediate share bias) } \\
\Delta_{X, t}^{(3)} & =\left(1-\left(\epsilon_{X, L, t}+\epsilon_{X, M, t}\right)\right)\left(\frac{d K_{t}}{K_{t}}-\frac{d \hat{K}_{t}}{\hat{K}_{t}}\right) & \text { (capital growth bias) }
\end{aligned}
$$

and $\epsilon_{X, L, t}$ and $\epsilon_{X, M, t}$ are the elasticities of gross output with respect to labor and intermediate input, respectively.

The similarities and differences with respect to the value added case are the following.

First, there is no mis-measurement in gross output growth (whereas, in the value-added approach, output growth is potentially mismeasured). The term $\Delta_{X, t}^{(1)}$ instead reflects mismeasurement in the growth rate of intermediate inputs.

Second, the labor share of gross output $\hat{s}_{X, L, t}$ is not affected by the omission of intangibles, because gross output and the wage bill are correctly measured (whereas, in the value-added approach, the omission of intangibles can affect the measurement of the labor share). Thus, the labor share bias $\Delta_{X, t}^{(2, L)}$ only reflects markups.

Third, the intermediate share of gross output $\hat{s}_{X, M, t}$ is affected by the omission of intangibles. This creates an "intermediate share" bias, $\Delta_{X, t}^{(2, M)}$, the expression of which is closely analogous to the "labor share bias" in Result 3.

Finally, the mismeasurement of capital growth rates also creates a bias, $\Delta_{X, t}^{(3)}$, with the same intuition as in the value added case.

\section{A.1.2.2 Model}

Next, we describe a version of our model in which firms use a gross output production function. We then derive results on measurement bias in this model along the balanced growth path.

Firm The representative firm solves:

$$
T C_{X, t}=\min _{\mathbf{K}_{t}, L_{t}} \sum_{n=1}^{2} R_{n, t} K_{n, t}+W_{t} L_{t}+P_{M, t} M_{t} \quad \text { s.t. } \quad Z_{X, t}\left(\left(K_{1, t}^{1-\eta} K_{2, t}^{\eta}\right)^{\alpha} L_{t}^{1-\alpha}\right)^{1-\beta} M_{t}^{\beta} \geq X_{t}
$$


where $T C_{X, t}$ denotes total costs of production, $\mathbf{K}_{t}=\left\{K_{n, t}\right\}_{n=1}^{2}$ is a vector of capital inputs, with $K_{1, t}$ the measured capital input, and $K_{2, t}$ the omitted intangible input, $L_{t}$ is labor input, $\left\{R_{n, t}\right\}_{n=1}^{2}$ is a vector of user costs, $W_{t}$ is the wage rate, $M_{t}$ are intermediate inputs, $Z_{X, t}$ is total factor productivity (over all factors), $\beta$ is the elasticity of output with respect to intermediate inputs, $(1-\alpha)(1-\beta)$ is the elasticity of output with respect to labor, $\eta$ is the elasticity of the total capital input $K_{t}=K_{1, t}^{1-\eta} K_{2, t}^{\eta}$ with respect to intangibles. Total factor productivity (over all factors, including gross output) evolves exogenously, following:

$$
d Z_{X, t}=g_{Z_{X}} Z_{X, t} d t
$$

The price of intermediate goods also evolves exogenously, following:

$$
d P_{M, t}=g_{M} P_{M, t} d t
$$

Define $M C_{X, t}$, the marginal cost of capital, labor, and intermediates, to be the Lagrange multiplier on the constraint. The solution to this problem is:

$$
\begin{aligned}
T C_{t} & =M C_{X, t} Y_{t} \\
M C_{X, t} & =\frac{1}{Z_{X, t}}\left(\frac{P_{M, t}}{\beta}\right)^{\beta}\left(\frac{W_{t}}{(1-\beta)(1-\alpha)}\right)^{(1-\beta)(1-\alpha)}\left(\frac{R_{t}}{(1-\beta) \alpha}\right)^{(1-\beta) \alpha} \\
M_{t} & =M C_{X, t} \frac{\beta X_{t}}{P_{M, t}} \\
L_{t} & =M C_{X, t} \frac{(1-\beta)(1-\alpha) X_{t}}{W_{t}} \\
K_{t} & =M C_{X, t} \frac{(1-\beta) \alpha X_{t}}{R_{t}} \\
K_{t} & =K_{1, t}^{1-\eta} K_{2, t}^{\eta} \\
R_{t} & =\left(\frac{R_{1, t}}{1-\eta}\right)^{1-\eta}\left(\frac{R_{2, t}}{\eta}\right)^{\eta} \\
K_{1, t} & =(1-\eta) \frac{R_{t}}{R_{1, t}} K_{t} \\
K_{2, t} & =\eta \frac{R_{t}}{R_{2, t}} K_{t}
\end{aligned}
$$


The firm's revenue is $S_{t}=P_{t} X_{t}$ and its profits are $\Pi_{t}=P_{t} X_{t}-T C_{X, t}=\left(P_{t}-M C_{X, t}\right) X_{t}$, where $P_{t}$ is the price of consumption goods.

Household The representative household solves the same problem as in the model with a value added production function, so we do not re-state it here.

Equilibrium An equilibrium is a set of deterministic sequences for all endogenous variables such that (1) given the exogenous processes for labor, productivity, the price of intermediate goods, and the prices of capital goods, the endogenous variables satisfy the solution to the firm's problem and solve the representative consumer's problem; and (2) the price of consumption goods and their marginal cost of production are related through:

$$
P_{t}=\mu_{X} M C_{X, t}
$$

where $\mu_{X}>1$ is the exogenous price-cost markup of price over the marginal cost of labor, capital, and intermediate inputs - the gross output markup, for short. Finally, in equilibrium, we normalize the price level to $P_{t}=1$, so that all other prices are expressed relative to consumption goods.

\section{A.1.2.3 Equivalence with the value added model}

Aggregate accounting Intermediate output was introduced above assuming a "roundabout" production function, where the representative firm both produces consumption goods, and uses consumption goods as intermediate input (converting them to intermediate output at rate $\left.P_{t} / P_{M, t}\right)$ within the same period, while still behaving as though it were purchasing consumption goods from a perfectly competitive market.

Using the normalization $P_{t}=1$, gross output is given by:

$$
\begin{aligned}
X_{t} & =Z_{X, t}\left(\left(K_{1, t}^{1-\eta} K_{2, t}^{\eta}\right)^{\alpha} L_{t}^{1-\alpha}\right)^{1-\beta} M_{t}^{\beta} \\
& =W_{t} L_{t}+R_{1, t} K_{1, t}+R_{2, t} K_{2, t}+P_{M, t} M_{t}+\Pi_{t} \\
& =C_{t}+Q_{1, t} I_{1, t}+Q_{2, t} I_{2, t}+P_{M, t} M_{t}
\end{aligned}
$$

The first relationship uses the definition of the production function (the output approach), the second uses the definition firm profits (the income approach), and the third relationship uses the budget constraint of the household (the expenditure approach). Value added is 
defined as:

$$
\begin{aligned}
Y_{t} & \equiv X_{t}-P_{M, t} M_{t} \\
& =W_{t} L_{t}+R_{1, t} K_{1, t}+R_{2, t} K_{2, t} \\
& =C_{t}+Q_{1, t} I_{1, t}+Q_{2, t} I_{2, t} .
\end{aligned}
$$

The second line is the income approach definition of GDP, and the third line is the expenditure approach to GDP.

Value added representation The following result describes the equivalence between the value added and gross output models.

Result 7. Define:

$$
\begin{aligned}
Z_{t} & =\frac{\mu_{X}-\beta}{1-\beta}\left(\frac{Z_{X, t}}{\mu_{X}}\left(\frac{P_{M, t}}{\beta}\right)^{-\beta}\right)^{\frac{1}{1-\beta}} \\
\mu & =\frac{\mu_{X}-\beta}{1-\beta}
\end{aligned}
$$

Then, all quantities and prices in the gross output model are the same as in a value added model where total factor productivity $Z_{t}$ and markups $\mu$ are given by Equation (28). ${ }^{33}$

This equivalence result says that one can think of the value-added model as being derived from an underlying gross output model. The expressions in (28) then highlights two points. First, the link between the (value-added) markup $\mu$ in the value added model and the (gross output) markup $\mu_{X}$ in the gross output model depends on the intermediate share $\beta$. Second, value-added TFP growth $g_{Z}$ in the value-added model is related to gross-output TFP growth $g_{Z_{X}}$ through: $g_{Z}=\frac{1}{1-\beta}\left(g_{\tilde{Z}}-\beta g_{P_{M}}\right)$. Value-added TFP in the value-added model should therefore be thought of as reflecting a combination of technical change and change in the price of intermediate products. This equivalence result implies that all the result results regarding how the simple value-added Solow residual $d \hat{Z} / \hat{Z}_{t}$ potentially mis-measures valueadded TFP, $g_{Z}$, follow through in the gross output model.

Proof. [Result 7] Since the household's problem is the same in both models, we only need to show (1) that the first-order conditions of the firm's problem are the same as in the valueadded model, under the definitions of value-added TFP $Z_{t}$ and markups $\mu$ given above; and (2) that $Y_{t}$ and $M C_{t}$ defined as:

$$
Y_{t}=Z_{t} L_{t}^{1-\alpha}\left(K_{1, t}^{1-\eta} K_{2, t}^{\eta}\right)^{\alpha}
$$

\footnotetext{
${ }^{33}$ This is with the exception of intermediate inputs $M_{t}$, gross output marginal cost $M C_{X, t}$, and gross output $X_{t}$, which are undefined in the value-added model.
} 


$$
M C_{t}=\frac{1}{Z_{t}}\left(\frac{W_{t}}{1-\alpha}\right)^{1-\alpha}\left(\frac{R_{t}}{\alpha}\right)^{\alpha} .
$$

indeed measure value added and its marginal cost in the gross output model.

Combining the first-order conditions for capital and labor from the firm's problem in the gross output model, (26), we obtain (for any $Z_{t}$ ):

$$
Z_{t} K_{t}^{\alpha} L_{t}^{1-\alpha}=\frac{M C_{X, t}}{M C_{t}}(1-\beta) X_{t}
$$

where we defined $M C_{t}$ as in Equation (30). Plugging this back into the first-order conditions for capital and labor, this implies that they are the same as in the value added model:

$$
\begin{aligned}
W_{t} & =\frac{(1-\alpha) M C_{t} Y_{t}}{L_{t}} \\
R_{t} & =\frac{\alpha M C_{t} Y_{t}}{L_{t}}
\end{aligned}
$$

where $Y_{t}$ is defined as in equation (29). Note, additionally, that equation (31) implies:

$$
M C_{t} Y_{t}=(1-\beta) M C_{X, t} X_{t}
$$

In the equilibrium of the gross output model, $M C_{X, t}=\mu_{X}^{-1}$. Therefore:

$$
\left(\frac{L_{t}}{1-\alpha}\right)^{1-\alpha}\left(\frac{K_{t}}{\alpha}\right)^{\alpha}=\left(\frac{Z_{X, t}}{\mu_{X}}\left(\frac{P_{M, t}}{\beta}\right)^{-\beta}\right)^{\frac{1}{1-\beta}}
$$

Therefore, using the definitions of $Z_{t}$ and $\mu$

$$
\begin{aligned}
M C_{t} & =\frac{1}{Z_{t}}\left(\frac{L_{t}}{1-\alpha}\right)^{1-\alpha}\left(\frac{K_{t}}{\alpha}\right)^{\alpha} \\
& =\frac{1-\beta}{\mu_{X}-\beta}=\frac{1}{\mu} .
\end{aligned}
$$

This proves that $1=P_{t}=\mu M C_{t}$, as in the value-added model. Additionally, it implies that:

$$
\frac{M C_{X, t}}{M C_{t}}=\frac{\mu_{X}-\beta}{1-\beta} \frac{1}{\mu_{X}} .
$$


Therefore:

$$
\begin{aligned}
X_{t}-P_{M, t} M_{t} & =\left(1-\frac{\beta}{\mu_{X}}\right) X_{t} \\
& =\frac{\mu_{X}-\beta}{\mu_{X}} \frac{M C_{t}}{M C_{X, t}}(1-\beta) Y_{t} \\
& =\frac{\mu_{X}-\beta}{\mu_{X}} \frac{\mu_{X}(1-\beta)}{\mu_{X}-\beta}(1-\beta) Y_{t} \\
& =Y_{t},
\end{aligned}
$$

where to go from the first to the second line, we used equation (32). So $Y_{t}$ indeed measures value added. Moreover:

$$
M C_{t} Y_{t}=M C_{X, t} X_{t}-\beta M C_{X, t} X_{t}=T C_{X, t}-P_{M, t} M_{t}=T C_{t}
$$

where $T C_{t}$ is the total cost of production of output minus intermediate costs. So $M C_{t}$ measures the marginal cost of value added.

\section{A.1.2.4 Balanced growth}

For completeness, we next report the balanced growth expressions for the solution of the gross output model. The steps are the same as for the value added model, so we do not detail them. Define the aggregate price index for capital goods $Q_{t}$ as:

$$
Q_{t}=Q_{1, t}^{1-\eta} Q_{2, t}^{\eta}
$$

Next, define the trend growth factor $T_{X, t}$ as:

$$
T_{X, t}=L_{t} Z_{X, t}^{\frac{1}{(1-\beta)(1-\alpha)}} Q_{t}^{-\frac{\alpha}{1-\alpha}} P_{M, t}^{-\frac{\beta}{(1-\beta)(1-\alpha)}}
$$

and define the detrended variables:

$$
\begin{aligned}
c_{t} & \equiv \frac{C_{t}}{T_{X, t}} \\
w_{t} & \equiv \frac{W_{t} L_{t}}{T_{X, t}} \\
m_{t} & \equiv \frac{P_{M, t} M_{t}}{T_{X, t}}
\end{aligned}
$$




$$
\begin{aligned}
\pi_{t} & \equiv \frac{\Pi_{t}}{T_{X, t}} \\
i_{n, t} & \equiv \frac{Q_{n, t} I_{n, t}}{T_{X, t}}, \quad n=1,2 \\
k_{n, t} & \equiv \frac{Q_{n, t} K_{n, t}}{T_{X, t}}, \quad n=1,2 \\
R_{d, n, t} & \equiv \frac{R_{n, t}}{Q_{n, t}}, \quad n=1,2 \\
R_{d, t} & \equiv \frac{R_{t}}{Q_{t}} \\
x_{t} & \equiv \frac{X_{t}}{T_{X, t}} \\
k_{t} & \equiv \frac{Q_{t} K_{t}}{T_{X, t}}
\end{aligned}
$$

Moreover, define the trend growth rate (the growth rate of $T_{X, t}$ ), the capital price growth rate (the growth rate of $Q_{t}$ ), and the discount rate $r$ as:

$$
\begin{aligned}
g & \equiv g_{L}+\frac{1}{1-\alpha}\left(g_{Z_{X}}-\frac{\beta}{1-\beta} g_{P_{M}}\right)-\frac{\alpha}{1-\alpha} g_{Q}, \\
g_{Q} & \equiv(1-\eta) g_{Q_{1}}+\eta g_{Q_{2}} \\
r & \equiv \rho+\sigma g .
\end{aligned}
$$

Note that $g_{Z}=g_{Z_{X}}-\frac{\beta}{1-\beta} g_{P_{M}}$, where $Z_{t}$ is defined in Equation (28). Detrended user costs must satisfy:

$$
R_{d, n, t}=R_{d, n}=r+\delta_{n}-g_{Q_{n}}, \quad n=1,2,
$$

the standard Hall-Jorgenson formula. The balanced growth path is then given by:

$$
\begin{aligned}
M C & =\frac{1}{\mu_{X}} \\
R_{d} & =\left(\frac{R_{d, 1}}{1-\eta}\right)^{1-\eta}\left(\frac{R_{d, 2}}{\eta}\right)^{\eta} \\
x & =\left(\frac{\beta}{\mu_{X}}\right)^{\frac{\beta}{(1-\beta)(1-\alpha)}}\left(\frac{(1-\beta) \alpha}{\mu_{X} R_{d}}\right)^{\frac{\alpha}{1-\alpha}}
\end{aligned}
$$




$$
\begin{aligned}
k & =\frac{(1-\beta) \alpha}{\mu_{X} R_{d}} x \\
m & =\frac{\beta}{\mu_{X}} x \\
w & =\frac{(1-\alpha)(1-\beta)}{\mu_{X}} x \\
\pi & =\frac{\mu_{X}-1}{\mu_{X}} x \\
k_{1} & =(1-\eta) \frac{R_{d}}{R_{d, 1}} k \\
k_{2} & =\eta \frac{R_{d}}{R_{d, 2}} k \\
i_{n} & =\left(g+\delta_{n}-g_{Q_{n}}\right) k_{n}=\left(R_{d, n}-(r-g)\right) k_{n}, \quad n=1,2 .
\end{aligned}
$$

\section{A.1.2.5 TFP measurement on the balanced growth path}

Assumptions We make the same assumptions about (mis)measurement in aggregate accounts as we do in the analysis of Section 2. First, gross output $X_{t}$ is correctly measured. Second, measured value added excludes $Q_{2, t} I_{2, t}$. We have:

$$
\begin{aligned}
\widehat{Y}_{t} & =Y_{t}-Q_{2, t} I_{2, t} \\
& =X_{t}-{\widehat{P_{M, t} M_{t}}}^{{\widehat{P_{M, t} M_{t}}}}=P_{M, t} M_{t}+Q_{2, t} I_{2, t}
\end{aligned}
$$

Here, ${\widehat{P_{M, t} M}}_{t}$ is measured nominal purchases of intermediates (which are too large, because $Q_{2, t} I_{2, t}$ is misclassified). In what follows, we use the following two ratios (the first of which is also the one we use in the analysis of the value-added model):

$$
\begin{aligned}
b_{t} & =\frac{\widehat{Y}_{t}}{Y_{t}} \\
c_{t} & =\frac{P_{M, t} M_{t}}{P_{M, t} M_{t}+Q_{2, t} I_{2, t}}
\end{aligned}
$$


The case of no omitted intangibles corresponds to $\eta=0$. Using the expressions from Section A.1.2.4, we obtain that along the balanced growth path:

$$
\begin{aligned}
& b_{t}=b=1-\frac{1-\beta}{\mu_{X}-\beta} \frac{g+\delta_{2}-g_{Q_{2}}}{\rho+g+\delta_{2}-g_{Q_{2}}} \alpha \eta \\
& c_{t}=c=1-\frac{1-\beta}{\beta} \frac{g+\delta_{2}-g_{Q_{2}}}{\rho+g+\delta_{2}-g_{Q_{2}}} \alpha \eta
\end{aligned}
$$

The expression for $b_{t}$ is the same as Equation (14), for the value-added model, when $\mu=$ $\frac{\mu_{X}-\beta}{1-\beta}$. These expressions indicate that there are no omitted intangibles $(\eta=0)$, if and only if, $b=1$ and $c=0$.

Mis-measurement of value-added TFP growth $\left(g_{Z}\right)$ Recall that in the gross output model, value-added TFP (in levels) is defined as:

$$
Z_{t}=\frac{\mu_{X}-\beta}{1-\beta}\left(\frac{Z_{X, t}}{\mu_{X}}\left(\frac{P_{M, t}}{\beta}\right)^{-\beta}\right)^{\frac{1}{1-\beta}}
$$

so that, in growth rates.

$$
g_{Z}=\frac{1}{1-\beta}\left(g_{Z_{X}}-\beta g_{P_{M}}\right) .
$$

Given the equivalence between the gross output and value added approaches developed in Result (7), all the results of Section 2 on the mis-measurement of value-added TFP growth go through. Define the (value-added) Solow residual as:

$$
\frac{d \hat{Z}_{t}}{\hat{Z}_{t}}=\frac{d \hat{Y}_{t}}{\hat{Y}_{t}}-\hat{s}_{L, t} \frac{d \hat{L}_{t}}{\hat{L}_{t}}-\left(1-\hat{s}_{L, t}\right) \frac{d \hat{K}_{t}}{\hat{K}_{t}}
$$

where $\hat{s}_{L, t}$ is the labor share of value added, which, on the balanced growth path, is given by:

$$
\hat{s}_{L, t}=\hat{s}_{L}=\frac{W_{t} L_{t}}{\hat{Y}_{t}}=\frac{(1-\beta)\left(1 / \mu_{X}\right)}{b\left(1-\beta / \mu_{X}\right)}(1-\alpha)=\frac{1-\alpha}{b \mu} .
$$

Then $d \hat{Z}_{t} / \hat{Z}_{t}$ is a biased measure of $g_{Z}$, and the bias can be decomposed into a capital growth bias (which is zero whenever there are no omitted intangibles), and a labor share bias (which is driven by markups, but can amplify the omitted capital bias), and their expressions are given as in (4). 
Mis-measurement of gross output TFP growth $\left(g_{Z_{X}}\right)$ This model also has predictions for the bias between the gross-output Solow residual $d \hat{Z}_{X, t} / \hat{Z}_{X, t}$, and gross-output TFP growth $g_{Z_{X}}$, in the presence of markups and omitted intangibles, analogous to Result 6 . These predictions are summarized in the follow result.

Result 8. Assume that the growth rate of intermediate goods prices is correctly measured. Then, along the balanced growth path:

$$
\Delta_{X, t}=\Delta_{X}=\Delta_{X}^{(1)}+\Delta_{X}^{(2, M)}+\Delta_{X}^{(2, L)}+\Delta_{X}^{(3)}
$$

where $\Delta_{X}^{(1)}=0$, and:

$$
\begin{aligned}
& \Delta_{X}^{(2, L)}=-(1-\beta) \frac{\mu_{X}-1}{\mu_{X}}\left(g_{Z}-g_{Q_{1}}-\alpha \eta\left(g_{Q_{2}}-g_{Q_{1}}\right)\right) \quad \text { (labor share bias) } \\
& \Delta_{X}^{(2, M)}=-\beta \frac{\mu_{X} c-1}{\mu_{X} c}\left(g_{P_{M}}-g_{Q_{1}}\right) \quad \text { (intermediate share bias) } \\
& \Delta_{X}^{(3)}=-(1-\beta) \alpha \eta\left(g_{Q_{2}}-g_{Q_{1}}\right) \quad \text { (capital growth bias), }
\end{aligned}
$$

where along the balanced growth path, $c=1-\frac{1-\beta}{\beta} \frac{g+\delta_{2}-g_{Q_{2}}}{r+\delta_{2}-g_{Q_{2}}} \alpha \eta$.

Result (8) reports expressions for the components of the bias between the gross output Solow residual and gross output TFP growth, derived from applying to balanced growth solution to Result (6). In this result, we have assumed that the real growth rate of actual intermediate inputs, which is equal to $g-g_{P_{M}}$ in the balanced growth path, is the same as the real growth rate of measured intermediate inputs. The latter growth rates depends on the measured growth rate for intermediate inputs, $g_{\hat{P}_{M}}$. If this growth rate is correctly measured, the contribution of mismeasurement of intermediate input growth along the balanced growth path (the term $\left.\Delta_{X, 1, t}\right)$ is zero; otherwise, the contribution of this term is equal to $-\frac{\beta}{\mu_{X}}\left(g_{P_{M}}-\right.$ $\left.g_{\hat{P}_{M}}\right)$.

An important difference with the value-added case is that, so long as $d \hat{K}_{t} / \hat{K}_{t}>d L_{t} / L_{t}$ (the empirically relevant case), the labor share bias will be (weakly) negative. Thus, a sufficient condition for the overall bias to be negative is $g_{Q_{2}}>g_{P_{M}}>g_{Q_{1}}$. As discussed in Section 3, this condition is empirically plausible, as the types of intangible investments most likely to be misclassified as omitted intangibles are also among the intermediate goods with highest relative price growth.

In the empirical applications, we focus on quantifying mis-measurement of value-added TFP growth $g_{Z}$ by the value-added Solow residual $d \hat{Z}_{t} / \hat{Z}_{t}$, and not on mismeasurement of $g_{Z_{X}}$ using the gross-output Solow residual $d \hat{Z}_{X, t} / \hat{Z}_{X, t}$. We make this choice because we are 
interested in understanding trends in value-added TFP growth which can be compared with the relevant literature, but, in principle, the analysis could be extended to gross-output TFP growth.

\section{A.2 Empirics}

This section of the appendix provides more details on the empirical analysis.

\section{A.2.1 The decline in measured TFP growth}

In order to document the decline in measured TFP growth, we use the time series constructed by Fernald (2014). This data covers the period 1947q1-2020q1, and provides measures of the growth rate of real output, labor input, capital input, and the labor share, for the business sector. This comprises all corporate and non-corporate for-profit businesses, as well as other business entities, such as non-profits and certain government agencies; see Bureau of Economic Analysis (2017).

We make one main modification to the data of Fernald (2014): in Solow residual computations, we use the growth rate of GDP in consumption units. In computing the Solow residual, Fernald (2014) use the quarterly growth rate of real value added by businesses in chained dollars (NIPA table 1.3.6; FRED series A195RX1Q020SBEA). Instead, we use the quarterly growth rate in the ratio of nominal value added by businesses (NIPA Table 1.3.5; FRED series A195RC1Q027SBEA) to the implicit price deflator for personal consumption expenditures (NIPA Table 1.1.9; FRED series DPCERD3Q086SBEA).

We choose to do this because, in our balanced growth model, the notion of output we consider, $Y_{t}$, is directly defined in consumption units, and is not necessarily equal to chained GDP growth. We explain this point, which is explained more generally in Oulton 2007, in Appendix A.1.1.3. We compare below the results of the simple growth accounting decom-

position when chained GDP growth is used instead of the growth of output in consumption units.

Other than this difference, three points about these data are worth noting. First, the data on capital input growth are constructed from estimated stocks for nine types of capital, including specific estimated stocks for R\&D capital and software. These stocks are themselves derived from NIPA series on investment capitalized using perpetual inventory methods. The nine types of capital are: land; business inventory; business residential real estate; information processing equipment; other equipment; structures; software; R\&D; artistic originals. Investment in different capital goods is deflated using capital-specific price indices, so that 
the resulting growth rates in stocks are real. Aggregate capital growth is obtained by weighting these series by their estimated user cost shares. Second, the labor share is measured as the ratio of total labor payments to total value added; the capital share is obtained as the residual (one minus the labor share), as opposed to being directly imputed from estimates of the user cost of capital. Proprietor's income, in particular, is allocated so as to ensure that the aggregate labor share is equal to the labor share of non-financial corporations. Third, the data also contain an adjustment for variable capacity utilization; we compare trends with and without this adjustment below.

Figure 1 reports the time-series for TFP growth without adjustments for capacity utilization, defined as the simple Solow residual:

$$
\frac{d \hat{Z}_{t}}{\hat{Z}_{t}}=\frac{d \hat{Y}_{t}}{\hat{Y}_{t}}-\hat{s}_{L, t} \frac{d \hat{L}_{t}}{\hat{L}_{t}}-\left(1-\hat{s}_{L, t}\right) \frac{d \hat{K}_{t}}{\hat{K}_{t}}
$$

where $d \hat{Y}_{t} / \hat{Y}_{t}$ denotes the growth rate of output in consumption units,

$$
\hat{s}_{L, t}=\frac{W_{t} L_{t}}{N_{t}}
$$

denotes the labor share in nominal business value added, $N_{t}, d \hat{L}_{t} / \hat{L}_{t}$ denotes the growth rate of labor, and $d \hat{K}_{t} / \hat{K}_{t}$ denotes the measured growth rate of capital. The series show that, after a period of rapid increase in the early to mid-1990's, TFP growth reach a plateau, and then declined. This decline lasted until late 2007, but was not followed by a persistent rebound; instead, productivity growth has remained subdued since 2010.

Table 1 reports simple averages on the decline in TFP growth, comparing the 1947-1996 period, to the 1997-2018 period. Before 1997, TFP growth in the US had been, on average, $1.11 \%$ per year; after 1995 , it fell to $0.62 \%$ per year, a $0.49 \%$ decline. By contrast, between the two periods, growth of output in consumption units fell by $0.92 \% ; 0.43 \%$ of that decline is therefore attributable to a decline in input growth, and the rest to the TFP growth decline. Additionally, the labor share of income fell by 4 p.p. over the period. Finally, the last line in the table highlights the fact that the utilization adjustment constructed by Fernald (2014) using the methodology of Basu et al. (2013) only leads to a very small difference in the decline of measured TFP growth.

Table A2 compares output growth and the Solow residuals obtained using output in consumption units (our baseline approach), to the values obtained using chained GDP (the data provided in Fernald (2014)). The table shows that the growth rate of GDP in consumption units is lower than the growth rate of chained GDP by approximately $0.25 \%$ in both the 1947-1996 and 1997-2018 periods. As a result the Solow residual obtained using chained 
GDP is higher than in our baseline approach (by 0.25\%) in both periods. However, the change in both GDP growth and the Solow residual is the almost identical under the two approaches. This indicates that the bias created by the fact that $Y_{t}$, in the model, does not correspond to chained GDP in the data is stable across periods and does not affect our measurement of the decline in the the Solow residual.

\section{A.2.2 Methodology using only expenditure data}

The value of the growth rate $g_{Q_{2}}$ such that all of the gap between true TFP growth and the Solow residual $\hat{g}_{Z}$ is due to mismeasurement is given by:

$$
\begin{aligned}
g_{Q_{2}} & =\frac{1}{2}\left(\hat{r}+\delta_{2}+\hat{g}-\hat{g}_{K}+\hat{\xi}-\sqrt{\left(\hat{\xi}+\left(\hat{r}-\hat{g}-\left(\hat{g}_{K}+\delta_{2}\right)\right)\right)^{2}+4(\hat{r}-\hat{g})\left(\hat{g}_{K}+\delta_{2}\right)}\right), \\
\hat{\xi} & =\frac{\hat{s}_{L} \hat{b}}{(1-\hat{b})(1-\alpha)}\left[\tilde{g}_{Z}-\left(\hat{g}-(1-\alpha) \hat{g}_{L}-\alpha \hat{g}_{K}\right)\right],
\end{aligned}
$$

where $\hat{r}=\rho+\sigma \hat{g}$. This result is derived as follows.

Replacing $g_{Q_{2}}$ with $x$, and omitting the hat notation for measured variables, the conditions from the balanced growth model are:

$$
\begin{aligned}
g_{Z} & =g-(1-\alpha) g_{L}-\alpha g_{K}+\alpha \eta\left(x-\left(g-g_{K}\right)\right) \\
\mu & =\frac{1-\alpha}{s b} \\
\eta & =\mu \frac{1-b}{\alpha} \frac{r+\delta_{2}-x}{g+\delta_{2}-x}
\end{aligned}
$$

Substituting the expression for the markup,

$$
\begin{aligned}
g_{Z} & =g-(1-\alpha) g_{L}-\alpha g_{K}+\alpha \eta\left(x-\left(g-g_{K}\right)\right) \\
\eta & =\frac{(1-b)(1-\alpha)}{\alpha s b} \frac{r+\delta_{2}-x}{g+\delta_{2}-x}
\end{aligned}
$$

Substituting the expression for $\eta$ into the expression for the production function,

$$
g_{Z}=g-(1-\alpha) g_{L}-\alpha g_{K}+\frac{(1-b)(1-\alpha)}{s b} \frac{r+\delta_{2}-x}{g+\delta_{2}-x}\left(x-\left(g-g_{K}\right)\right)
$$

Let:

$$
\xi \equiv \frac{s b}{(1-b)(1-\alpha)}\left[g_{Z}-\left(g-(1-\alpha) g_{L}-\alpha g_{K}\right)\right]
$$


then we can write this as:

$$
\left(\left(r+\delta_{2}\right)-x\right)\left(x-\left(g-g_{K}\right)\right)-\xi\left(g+\delta_{2}-x\right)=0
$$

Let:

$$
\begin{aligned}
a & \equiv r+\delta_{2} \\
b & \equiv g-g_{K} \\
c & \equiv g+\delta_{2}<a
\end{aligned}
$$

The solution must satisfy:

$$
b<x<c<a .
$$

Indeed, the condition $b<x$ ensures that the implied growth rate of prices of omitted intangible capital is higher than than the growth rate of prices of measured capital. The condition $x<c$ ensures that the detrended user cost of omitted intangible capital is strictly positive. The equation for $x$ can be rewritten as:

$$
(a-x)(x-b)-\xi(c-x)=0
$$

or:

$$
\frac{(a-x)(x-b)}{c-x}=\xi
$$

Using the fact that $b<c<a$, it can be shown that the left-hand side in this equation is a strictly increasing mapping from $] b, c[$ to $] 0,+\infty[$, so there is always a unique solution to this equation in $] b, c[$. The unique solution in this interval is given by:

$$
x=\frac{1}{2}\left(a+b+\xi-\sqrt{(\xi+(a+b-2 c))^{2}+4(a-c)(c-b)}\right) .
$$

In terms of the original variables, the solution can be written as:

$$
\begin{aligned}
& x=\frac{1}{2}\left(r+\delta_{2}+g-g_{K}+\xi-\sqrt{\left(\xi+\left(r-g-\left(g_{K}+\delta_{2}\right)\right)\right)^{2}+4(r-g)\left(g_{K}+\delta_{2}\right)}\right) \\
& \xi=\frac{s b}{(1-b)(1-\alpha)}\left[g_{Z}-\left(g-(1-\alpha) g_{L}-\alpha g_{K}\right)\right] .
\end{aligned}
$$




\section{A.2.3 Other data sources}

BLS price indices In Section 3.4, as an alternative empirical proxy for $g_{Q_{2}}$, we use the BLS' Producer Price Indices for commodities. ${ }^{34}$ There are a number of challenges in mapping these data to the Input-Output tables. The main one is that the level of aggregation differs from that of the IO tables. Information on the producer prices for commodities are substantially more granular than in the Input-Output tables; but it tends to be less granular for service prices. We focus on BLS price indices reported at the 3- and 4-NAICS levels, and match them, based on names, to the IO table classification. This matching is available from the authors on request. Not all IO commodity and service groups are matched (for instance, Data processing, in the IO tables, does not have a clear match to the BLS commodity groups), and for the IO groups with several more granular matches in the BLS PPI tables, we take the simple average of prices across matches.

Table A5 reports results from a simple regression using the matched BEA-BLS sample. In all specifications, the dependent variable is $g_{Q_{2}}^{(B E A)}$, the empirical proxy for $g_{Q_{2}}$ constructed using the BEA GDP-by-industry data and described in Section 3.2, and the independent variable is the equivalent empirical proxy constructed using the BLS price deflators. The results of the table indicate that there is a robust correlation between the two variables, even within industry and year, though there remains independent variation between the two sets of price indices, with $R^{2} \mathrm{~S}$ in the order of $65 \%$ across specifications.

Non-financial public firms We obtain data on spending on organization capital from the sample of Compustat non-financial firms, for the 1997-2018 period. We use standard selection criteria in order to obtain the sample of domestically incorporated, publicly tradedfirms not in the utility or financial sector. ${ }^{35}$ The sample we obtain covers approximately $70 \%$ of aggregate investment and gross operating surplus in the corporate non-financial sector, as documented in Crouzet and Eberly (2020).

Our objective is to use this sample to construct an alternative measure of adjusted to unadjusted GDP, after reclassifying expenditures on organization capital, $M$ as investment:

$$
\hat{b}_{C S}=\frac{\hat{Y}_{C S}}{\hat{Y}_{C S}+\hat{M}_{C S}},
$$

where $\hat{Y}_{C S}$ is total value added in the Compustat sample, and $\hat{M}_{C S}$ are expenditures on organization capital. As discussed in the main text, intermediate expenditures on the three

\footnotetext{
${ }^{34}$ The PPI commodity tables are available at https://download.bls.gov/pub/time.series/wp/.

${ }^{35}$ We use the same sample selection criteria as Crouzet and Eberly (2020); see the appendix of that paper for more details.
} 
key service groups closely relate to the notion of organization capital developed in the macro and finance literature on intangible capital (Atkeson and Kehoe, 2005; Eisfeldt and Papanikolaou, 2013). As an empirical proxy for $\hat{M}_{C S}$, we use the measure developed by Eisfeldt and Papanikolaou (2013), who propose to measure organization capital spending as $0.3 \times(\mathrm{xsga}-\mathrm{xrd})$, where xsga denotes spending on sales and general and administrative expenses, and xrd denotes $R \& D$ spending.

Measuring value added, $\hat{Y}_{C S}$, is more challenging, because Compustat firms do not report separate line items for wage payments. In order to address this issue, we map the Compustat data to the 61 sectors of Make tables of the Input-Output accounts. This match uses the NAICS-3 and NAICS-4 classification of firms in Compustat, and is available from the authors on request. For each sector $s$, we then impute Compustat wages using:

$$
W_{s}^{(C S)}=\frac{S_{s}^{(I O)}}{S_{s}^{(C S)}} W_{s}^{(I O)},
$$

where $S_{s}^{(I O)}$ is sector gross output at producer prices from the IO tables, $S_{s}^{(C S)}$ is total revenue for the sector from Compsutat, and $W_{s}^{(I O)}$ are total wage payments for the sector from the IO tables. Given imputed wages for the sector, we then compute:

$$
\hat{Y}_{s}^{(C S)}=\Pi_{s}^{(C S)}+W_{s}^{(C S)}+R D_{s}^{(C S)},
$$

where $\Pi_{s}^{(C S)}$ is total EBITDA in the sector, and $R D_{s}^{(C S)}$ are total $R \& D$ expenditures in the sector. The former is the closest firm accounting counterpart to gross operating surplus, so that adding back wages provides an estimate of value added. The main difference with national accounting definitions of gross operating surplus is that $R \& D$ expenditures as treated as intermediate expenditures (operating costs) in firm accounting data, so that they need to be added back to EBITDA in order to obtain a measure of value added consistent with the national accounts definition. Finally, we define the Compustat proxy for the ratio of unadjusted to adjusted value added as:

$$
\hat{b}^{(C S)}=\frac{\sum_{s} \hat{Y}_{s}^{(C S)}}{\sum_{s} \hat{Y}_{s}^{(C S)}+\hat{M}_{s}^{(C S)}} .
$$

Figure A4 reports the resulting time series for $\hat{b}^{(C S)}$, along with the ratio of nominal investment to value added, with and without adjustment for investment in organization capital. 


\section{A.2.4 Robustness}

Other measures of relative price growth We use the Producer Price Indices for commodities from the Bureau of Labor Statistics as an alternative empirical proxy for $g_{Q_{2}}$. Appendix A.2.3 discusses the differences between BLS and BEA data, and shows that there is independent variation between the two sets of price measures, though they are highly correlated. Appendix Table A6 reports results obtained using this alternative empirical proxy for $g_{Q_{2}}$. For two of the three key service groups, $g_{Q_{2}}$ is lower than in our baseline analysis. ${ }^{36}$ As a result, the implied adjustments for TFP growth are lower than in the baseline; the total adjustment is approximately $21 \mathrm{bps}$, instead of $32 \mathrm{bps}$ in the baseline. However, the adjustment remains positive, because even the BLS proxies for $g_{Q_{2}}$ are higher than our estimate of $g_{Q_{1}}$, which is negative throughout the 1997-2018 period.

Estimating organization capital spending from firm data We use firm accounting data in order to construct an alternative proxy for $\hat{b}$. Our adjustment builds on the empirical measures of investment in organization capital proposed by Eisfeldt and Papanikolaou (2013). Conceptually, this form of intangible investment corresponds most closely to what might be misclassified as intermediate expenditures on the three key service groups highlighted in our baseline analysis. Appendix A.2.3 explains in detail how the empirical proxy for $\hat{b}$ is constructed in Compustat data, and Appendix Figure A4 reports the resulting time-series.

The most important point to note about this empirical proxy for $\hat{b}$ is that it contains both externally purchased investments in organization capital (which is also what our baseline approach estimates from the Use tables), and, potentially, own-account intangibles. Ownaccount intangibles could include, for instance, worker training, in-house investments in logistics, or expenditures on product management and branding, so long as they are not externally contracted or purchased. Because these expenditures would not correspond to service or commodity purchase in the Use tables, our baseline approach would not capture them. $^{37}$

The inclusion of own-account intangibles in this alternative measure of $\hat{b}$ suggests that its resulting values could be lower (i.e. the intangible adjustment larger) than those obtained from the Use tables. On the other hand, the estimates of $\hat{b}$ measure organization capital investment as a constant fraction $\gamma=30 \%$ of sales, general and administrative expenses (SG\&A), but there is evidence that this fraction may vary across industries, and could be as high as 50\% in industries such as Healthcare and High-tech (Ewens et al., 2019). This

\footnotetext{
${ }^{36}$ Price information in the BLS data is missing for the third key service group, Management.

${ }^{37}$ The exception to this is managerial time spent on organization capital, as this may be as use of intermediate inputs produced by the Management of Companies and Enterprises sector in the Use tables.
} 
could lead the values of $\hat{b}$ estimated from Compustat data to be lower than in the Use tables. Appendix Figure A4 (top panel) reports the time series for the ratio of $\hat{b}$ obtained from Compustat data; it is generally close to our most extensive adjustments from the Use tables (using Professional Services, Management, and Administrative Services), suggesting both of the effects described (the higher estimates due to own-account spending on organization capital, and the lower estimates due to the value of $\gamma$ used) potentially affect estimates of $\hat{b}$.

The magnitude of the adjustment is similar to what we obtained in our baseline analysis when reclassifying expenditures on PSTS and Management services in the Use tables. Table 4 then reports the implied TFP growth rates when using estimates for $\hat{b}$ from Compustat data. $^{38}$ Our mechanisms explain $29 \mathrm{bps}$ of the $49 \mathrm{bps}$ TFP growth decline in that case.

Alternative breakpoints Our baseline analysis uses 1997 as the breakpoint relative to which we analyze the decline of the Solow residual compared to its historical values. We use this breakpoint as our baseline for two main reasons. First, after 1997, the ratio of unadjusted GDP to GDP adjusted for misclassified investment stabilizes, after a long period of decline that starts in the 1980s, as indicated by Figure 3. In other words, the size of potentially misclassified investment, relative to GDP is closer to being constant after 1997, consistent with the assumptions of our balanced growth in Section 2.2. Since our goal is to understand the effects of misclassification of intangibles on TFP growth measurement, it is natural to date our breakpoint using this change in the trend of the ratio of unadjusted to adjusted GDP. Second, papers focusing on the slowdown in productivity growth have noted that this slowdown in productivity growth in the US started some time between the late 1990s and the mid-2000s (Cette et al., 2016; Byrne et al., 2013; Fernald, 2015). ${ }^{39}$

However, as emphasized in other papers, the breaks in the data is not sharp, so we also consider results using alternative breakpoints. Following the literature, we look at breakpoints in 2000 and 2004. Additionally, we consider an earlier breakpoint, 1993, as further robustness check. In Appendix Table A3, we report key data moments (the growth rate of inputs, output, and the resulting Solow residuals) for these three breakpoints. Using the later breakpoints, the implied decline in TFP growth is higher, with the drop in measured TFP growth rising to $0.68 \%$ for the 2004 breakpoint (compared to $0.49 \%$ in our baseline), reflecting the brief acceleration of TFP growth in the late 1990s, also noted in Byrne et al. (2013) and Fernald (2015).

Table A4 then reports results analogous to those of Table 4 (the effect of adjusting

\footnotetext{
${ }^{38}$ Appendix Figure A3 reports year-by-year results from this exercise for the 1997-2018 period.

${ }^{39}$ Cette et al. (2016) dates the start of the slowdown in TFP growth relative to the US, in a sample of advanced economies, in 1997. Fernald (2015) dates the slowdown in productivity growth in most US industries to 2004 .
} 
for markups and misclassified intangible investment on measured TFP growth) for these alternative breakpoints. The earlier breakpoint (1994) makes no notable difference to the results. However, the results for the later breakpoints are more muted than in our baseline. For the 2000 breakpoint, markups and intangibles together account for half of the decline in TFP growth (or $0.29 \%$ out of the $0.58 \%$ ), while after 2004 , they account for one-third of the decline in TFP growth (or $0.22 \%$ out of $0.68 \%$ ). By contrast, in our baseline, they account for two-thirds (or $0.33 \%$ out of $0.49 \%$ ) of the decline in TFP growth. The key reason for this difference is that the growth rate of the relative price of potentially misclassified intangibles - $g_{Q_{2}}$ - fell somewhat during the 2004-207 period, though it remains larger than the growth rate of the price of measured capital (and positive overall, as indicated in Appendix Table A3). Thus, to the extent that the growth in the relative price of misclassified intangibles slowed down over time, the source of mismeasurement we highlight will also decline.

Values of $\delta_{2}$ Appendix Figure A5 reports comparative statics for the adjusted Solow residual obtained in Section 3.3.2, when changing the value of the rate of depreciation of omitted intangibles. Our estimates are relatively insensitive to this parameter: compared to our baseline estimate of $0.95 \%$ when adjusting for two of the three key service inputs, implied TFP growth (the adjusted Solow residual) declines from $0.96 \%$ to $0.89 \%$ as $\delta_{2}$ increases from 0.05 to 0.40 . The intuition for the sign of the effect is that with lower depreciation, the stock of omitted intangibles, and therefore its user cost share, is larger, magnifying the effect of the capital growth mismeasurement on TFP growth. ${ }^{40}$

\footnotetext{
${ }^{40} \mathrm{~A}$ potential alternative to calibrating the value of $\delta_{2}$ is to try to estimate it directly. This could in principle be done with data on the income share of omitted intangible capital and on the required rate of return to capital $r_{t}$. However, contrary to the measures of omitted intangible investment explored in this section, an empirical proxy for the intangible capital income share is more challenging to construct.
} 


\begin{tabular}{lccc} 
& $1947-1996$ & $1997-2018$ & Change \\
\hline Growth rate of $K / L$ ratio & 2.27 & 2.34 & 0.06 \\
Measured labor share & 0.68 & 0.64 & -0.04 \\
\hline Bias $\left(\epsilon_{L}=1.00\right)$ & -0.73 & -0.84 & -0.11 \\
Bias $\left(\epsilon_{L}=0.68\right)$ & 0.00 & -0.09 & -0.09 \\
\hline
\end{tabular}

Table A1: Potential size of the bias in measured TFP growth induced by markups. The first two lines report sample averages of the measured rate of change of the capital to labor ratio and of the labor income share). The last two lines report estimates of the bias in measured TFP growth; the third line is the absolute upper bound, when all measured capital income is pure profits; and the fourth line is the estimate obtained when setting the output elasticity of labor equal to the 1947-1996 sample average of the measured labor income share, $\overline{\hat{s}}_{L}=0.68$. 


\begin{tabular}{lcccccc} 
& \multicolumn{2}{c}{$1947-1996$} & \multicolumn{2}{c}{$1997-2018$} & \multicolumn{2}{c}{ Change } \\
& $\begin{array}{c}\text { GDP in } \\
\text { cons. units }\end{array}$ & $\begin{array}{c}\text { Chained } \\
\text { GDP }\end{array}$ & $\begin{array}{c}\text { GDP in } \\
\text { cons. units }\end{array}$ & $\begin{array}{c}\text { Chained } \\
\text { GDP }\end{array}$ & $\begin{array}{c}\text { GDP in } \\
\text { cons. units }\end{array}$ & $\begin{array}{c}\text { Chained } \\
\text { GDP }\end{array}$ \\
\hline GDP growth (p.p.) & 3.36 & 3.62 & 2.44 & 2.68 & -0.92 & -0.93 \\
\hline TFP growth (p.p.) & 1.11 & 1.36 & 0.62 & 0.86 & -0.49 & -0.50 \\
\hline TFP growth (util.-adj.; p.p.) & 1.13 & 1.39 & 0.66 & 0.91 & -0.47 & -0.49 \\
\hline
\end{tabular}

Table A2: Differences in output growth and Solow residual using GDP in consumption units and chained GDP growth. The data are the same as in Table 1, except that in the columns marked "Chained GDP", the measure of GDP growth is the growth of business value added in chained dollars; see Appendix A.2.1 for more details on data sources. TFP growth (the Solow residual) is constructed as $\hat{g}_{Z}=\hat{g}-\hat{s}_{L} \hat{g}_{L}-\left(1-\hat{s}_{L}\right) \hat{g}_{K}$, where $\hat{g}$ is either the growth rate of output in consumption units (as defined in Appendix A.2.1), or chained output growth; $\hat{s}_{L}$ is the average measured labor income share; $\hat{g}_{L}$ is the average growth rate of labor input; and $\hat{g}_{K}$ is the average growth rate of capital. Utilization-adjusted TFP growth is constructed as $\hat{g}_{Z}=\hat{g}-\hat{s}_{L} \hat{g}_{L}-\left(1-\hat{s}_{L}\right) \hat{g}_{K}-\hat{g}_{u}$, where $\hat{g}_{u}$ is the average growth rate of utilization. 


\begin{tabular}{lcccc} 
& \multicolumn{4}{c}{ Average change } \\
(after minus before breakpoint) \\
Breakpoint & $\mathbf{1 9 9 7}$ & $\mathbf{2 0 0 0}$ & $\mathbf{2 0 0 4}$ & $\mathbf{1 9 9 4}$ \\
\hline GDP growth (p.p.) & -0.92 & -1.34 & -1.22 & -0.75 \\
Labor growth (p.p.) & -0.54 & -0.80 & -0.31 & -0.15 \\
Capital growth (p.p.) & -0.48 & -0.96 & -1.30 & -0.39 \\
Labor share of income & -0.04 & -0.04 & -0.05 & -0.04 \\
\hline TFP growth (p.p.) & -0.49 & -0.58 & -0.68 & -0.59 \\
\hline TFP growth (util.-adj.; p.p.) & -0.47 & -0.57 & -0.87 & -0.58 \\
\hline
\end{tabular}

Table A3: Data moments with alternative breakpoints. This table reports the change average output growth (with output measured in consumption units), labor growth, capital growth, the labor share of income, TFP growth, and utilization-adjusted TFP growth, for alternative breakpoints between the two samples we consider: 1997 (our baseline breakpoint); 2001; 2005; and 1993. The data are the same as in Tables 1 and A2. 


\begin{tabular}{lccccc} 
& $\hat{b}$ & $\hat{g}_{Q_{2}}(\%)$ & $g_{Z}(\%)$ & $\mu$ & $\eta$ \\
\hline $\mathbf{1 9 4 7 - 1 9 9 6}$ & 0 & 0 & 1.11 & 1.00 & 0 \\
\hline $\mathbf{1 9 9 7 - 2 0 1 8}$ & & & & & \\
$\quad$ No adj., no markups & 0 & 0 & 0.62 & 1.00 & 0 \\
No adj., markups & 0 & 0 & 0.71 & 1.06 & 0 \\
$\quad$ Intan. adj., markups & 0.89 & 0.65 & 0.95 & 1.19 & 0.50 \\
\hline
\end{tabular}

(a) Breakpoint: 1997

\begin{tabular}{lccccc} 
& $\hat{b}$ & $\hat{g}_{Q_{2}}(\%)$ & $g_{Z}(\%)$ & $\mu$ & $\eta$ \\
\cline { 2 - 6 } & 0 & 0 & 1.11 & 1.00 & 0 \\
\hline $\mathbf{1 9 4 7 - 2 0 0 3}$ & & & & & \\
$\mathbf{2 0 0 4 - 2 0 1 8}$ & 0 & 0 & 0.43 & 1.00 & 0 \\
No adj., no markups & 0 & 0 & 0.51 & 1.09 & 0 \\
No adj., markups & 0.88 & 0.28 & 0.65 & 1.23 & 0.53 \\
$\quad$ Intan. adj., markups & 0.88 & &
\end{tabular}

(c) Breakpoint: 2004

\begin{tabular}{lccccc} 
& $\hat{b}$ & $\hat{g}_{Q_{2}(\%)}$ & $g_{Z}(\%)$ & $\mu$ & $\eta$ \\
\hline $\mathbf{1 9 4 7 - 2 0 0 0}$ & 0 & 0 & 1.11 & 1.00 & 0 \\
\hline $\mathbf{2 0 0 1 - 2 0 1 8}$ & & & & & \\
No adj., no markups & 0 & 0 & 0.53 & 1.00 & 0 \\
No adj., markups & 0 & 0 & 0.63 & 1.07 & 0 \\
Intan. adj., markups & 0.89 & 0.36 & 0.82 & 1.20 & 0.51 \\
\hline
\end{tabular}

(b) Breakpoint: 2000

\begin{tabular}{lccccc} 
& $\hat{b}$ & $\hat{g}_{Q_{2}(\%)}$ & $g_{Z}(\%)$ & $\mu$ & $\eta$ \\
\hline $\mathbf{1 9 4 7 - 1 9 9 3}$ & 0 & 0 & 1.17 & 1.00 & 0 \\
\hline $\mathbf{1 9 9 4 - 2 0 1 8}$ & & & & & \\
$\quad$ No adj., no markups & 0 & 0 & 0.62 & 1.00 & 0 \\
$\quad$ No adj., markups & 0 & 0 & 0.71 & 1.06 & 0 \\
$\quad$ Intan. adj., markups & 0.89 & 0.65 & 0.95 & 1.19 & 0.50 \\
\hline
\end{tabular}

(d) Breakpoint: 1994

Table A4: Results with alternative breakpoints. Each panel reports the effects of adjusting for markups and for intangibles when the breakpoints used are 1997 (our baseline); 2001; 2005; and 1993. The intangible adjustment used is for Professional Services, Management, and Administrative services (corresponding to the penultimate line of Table 4). The adjustments are made following the second of the two approaches described in Section 3.1, which uses data on both expenditures and prices of intangibles. 


\begin{tabular}{lcccc}
\hline \hline & $(1)$ & $(2)$ & $(3)$ & $(4)$ \\
\hline$g_{Q_{2}}^{(B L S)}$ & $0.97^{* * *}$ & $0.97^{* * *}$ & $1.04^{* * *}$ & $1.05^{* * *}$ \\
& $(0.18)$ & $(0.18)$ & $(0.17)$ & $(0.18)$ \\
\hline Commodity/service FE & no & yes & no & yes \\
Year FE & no & no & yes & yes \\
Clustering of s.e. & commodity + & commodity + & commodity + & commodity + \\
$R^{2}$ & year & year & year & year \\
$N$ & 0.603 & 0.633 & 0.643 & 0.673 \\
\hline \hline
\end{tabular}

Table A5: Simple correlations in proxies for $g_{Q_{2}}$, for BEA and PPI price indices. The sample is the set of year and commodity or service gorups for which the BEA GDP-by-industry and the BLS PPI commodity price indices can be matched. In all specification, the dependent variable is $g_{Q_{2}}^{(B E A)}$, the empirical proxy for $g_{Q_{2}}$ derived from the BEA's GDP-by-industry tables and described in Section 3.2. 
$\underline{\text { Services }}$

Professional, scientific, and technical services

Other real estate

$\begin{array}{lll}0.940 & 0.59 & 0.25\end{array}$

Administrative and support services

$0.952-1.75$

n.a.

Insurance carriers and related activities

$\begin{array}{lll}0.964 & 0.20 \quad 0.33\end{array}$

Credit intermediation and related activities

$0.972 \quad-0.21$

0.28

Management of companies and enterprises

0.973

1.06

1.59

Commodities

Chemical products

$0.974 \quad 1.54 \mathrm{w}$

n.a.

Oil and gas extraction

0.962

1.31

1.26

Petroleum and coal products

$0.972 \quad 2.09$

1.38

Food and beverage and tobacco products

0.973

3.78

3.36

Food and beverage and tobacco products

(a) Individual commodity and service groups

\begin{tabular}{cccccccc} 
& \multicolumn{2}{c}{ BEA } & \multicolumn{3}{c}{ BLS } \\
& $g_{Z}(\%)$ & $\mu$ & $\eta$ & $g_{Z}(\%)$ & $\mu$ & $\eta$ \\
\hline $\mathbf{1 9 4 7 - 1 9 9 6}$ & 1.11 & 1.00 & 0 & 1.11 & 1.00 & 0
\end{tabular}

\section{7-2018}

No adjustment, no markups

No adjustment, markups

Adjusted for Prof. services

Adjusted for Prof. services + Admin.

Adjusted for Org. capital (Compustat)

$\begin{array}{cccccc}0.62 & 1.00 & 0 & 0.62 & 1.00 & 0 \\ 0.71 & 1.06 & 0 & 0.71 & 1.06 & 0 \\ 0.83 & 1.13 & 0.25 & 0.80 & 1.13 & 0.25 \\ 0.88 & 1.17 & 0.40 & 0.83 & 1.17 & 0.40 \\ 0.88 & 1.16 & 0.38 & 0.83 & 1.16 & 0.38\end{array}$

(b) Aggregated service groups

Table A6: Comparison of results using BEA and BLS price indices for mismeasured investment goods. The top panel reports the 10 commodity or service groups with the smallest value of unadjusted GDP to adjusted GDP, as in Table 2. The average is computed over the 1997-2018 period, for each commodity or service group. The second column reports average values for the relative price growth of omitted capital, computed using price deflators from the BEA GDP-byindustry tables, as described in Section 3.2. The third column reports price indices obtained from the BLS, as described in Section 3.4. The bottom panel reports results from adjusting TFP growth measures for intangibles and markups, as in Table 4. 


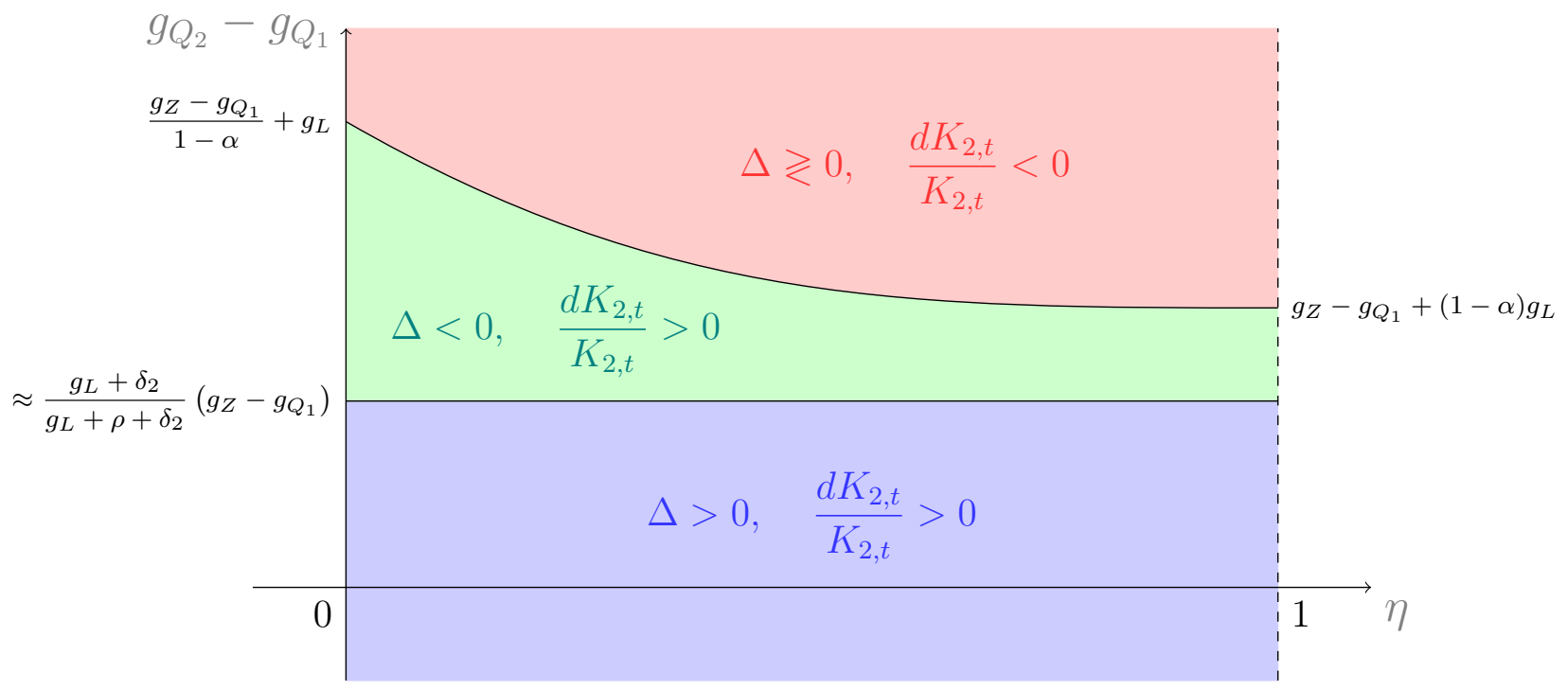

Figure A1: Sign of the total bias in measured TFP growth on the balanced growth path, depending on model parameters. The total bias is $\Delta=d \hat{Z}_{t} / Z_{t}-d Z_{t} / Z_{t}=d \hat{Z}_{t} / Z_{t}-g_{Z}$, where $d \hat{Z}_{t} / \hat{Z}_{t}$ is measured TFP on the balanced growth path, and $d Z_{t} / Z_{t}=g_{Z}$ is actual TFP growth. The horizontal axis corresponds to different values of $\eta$, the Cobb-Douglas share of omitted capital in production, and the vertical axis corresponds to different values of $g_{Q_{2}}-g_{Q_{1}}$, the difference between the growth rate of prices of omitted and measured capital. 
Ratio of unadjusted to adjusted GDP
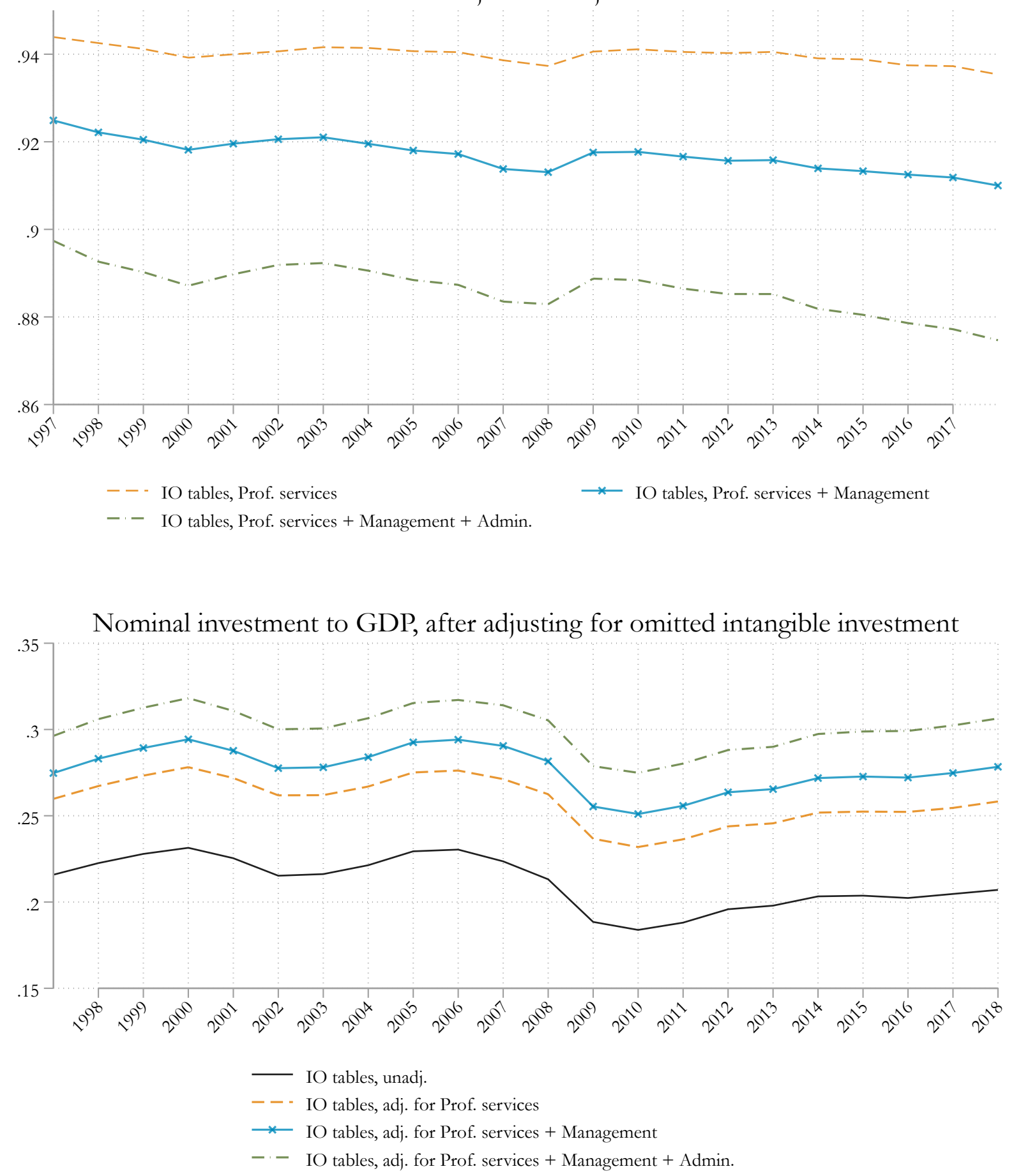

Figure A2: Time series for the ratio of unadjusted GDP to GDP adjusted for omitted intangibles (top panel), and for the ratio of investment to GDP without and with adjustments for omitted intangibles (bottom panel). The top panel reports the time series for $\hat{b}_{t}=P_{t} Y_{t} /\left(P_{t} Y_{t}+M_{t}\right)$, where $P_{t} Y_{t}$ is total GDP at producer prices, and $M_{t}$ is the nominal value of intermediate input use of a group of services, where the latter is obtained from the Use tables of the benchmark Input-Output accounts. Each line corresponds to the ratio obtained when treating a different group of services as misclassified intangible investment. The bottom panel reports the time series $\iota_{t}=\left(Q_{t} I_{t}+M_{t}\right) /\left(P_{t} Y_{t}+M_{t}\right)$, where $Q_{t} I_{t}$ is measured aggregate spending on investment goods, also obtained from the Input-Output accounts. 

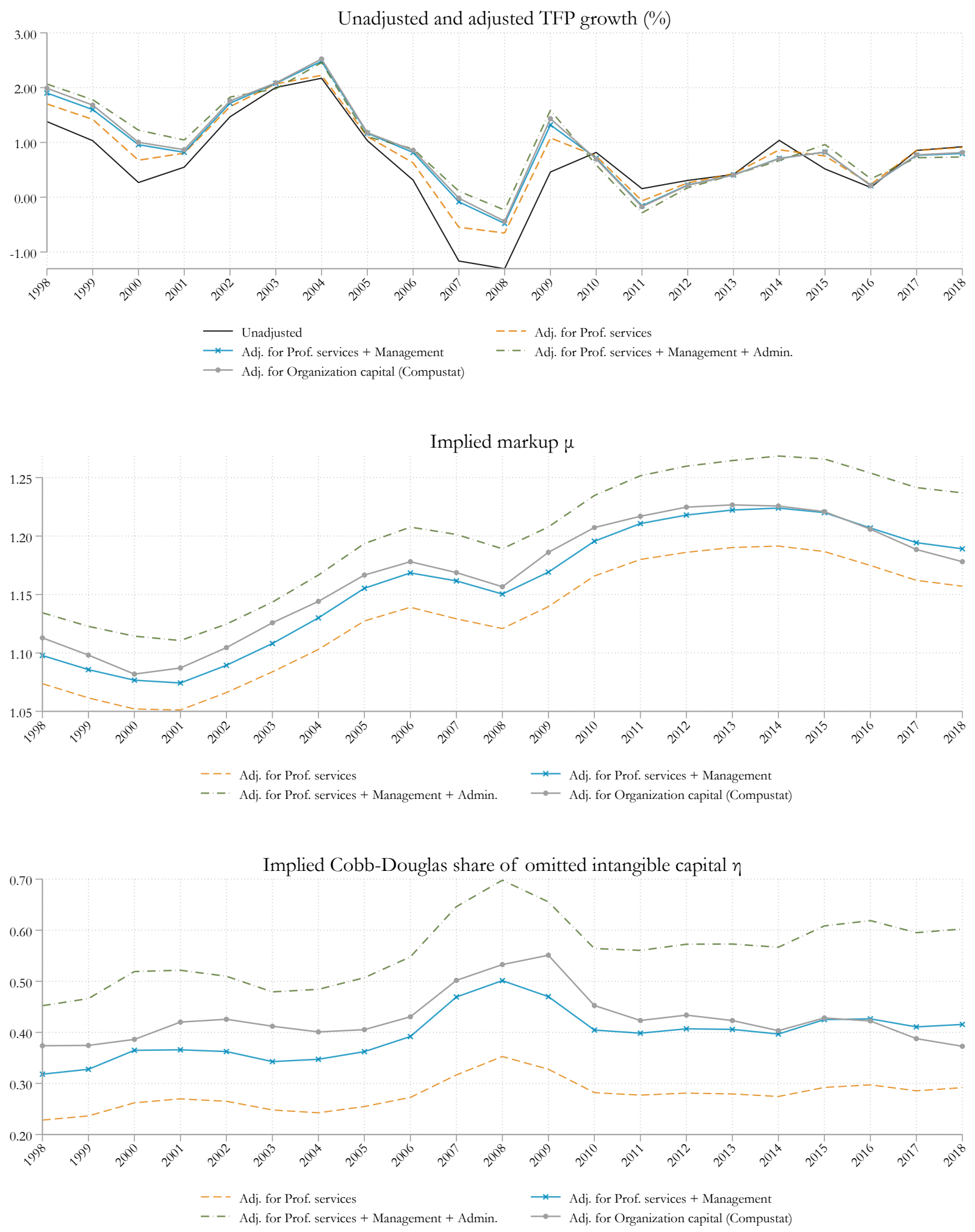

Figure A3: Time series for implied moments when adjusting for three key service groups. Adjusted TFP growth, markups, and the Cobb-Douglas share of omitted intangibles in the production function are computed following the second of the two approaches described in Section 3.1, which uses data on both expenditures and prices. The implied moments are constructed for each year separately. The series marked "unadjusted TFP growth" is the simple Solow residual. 

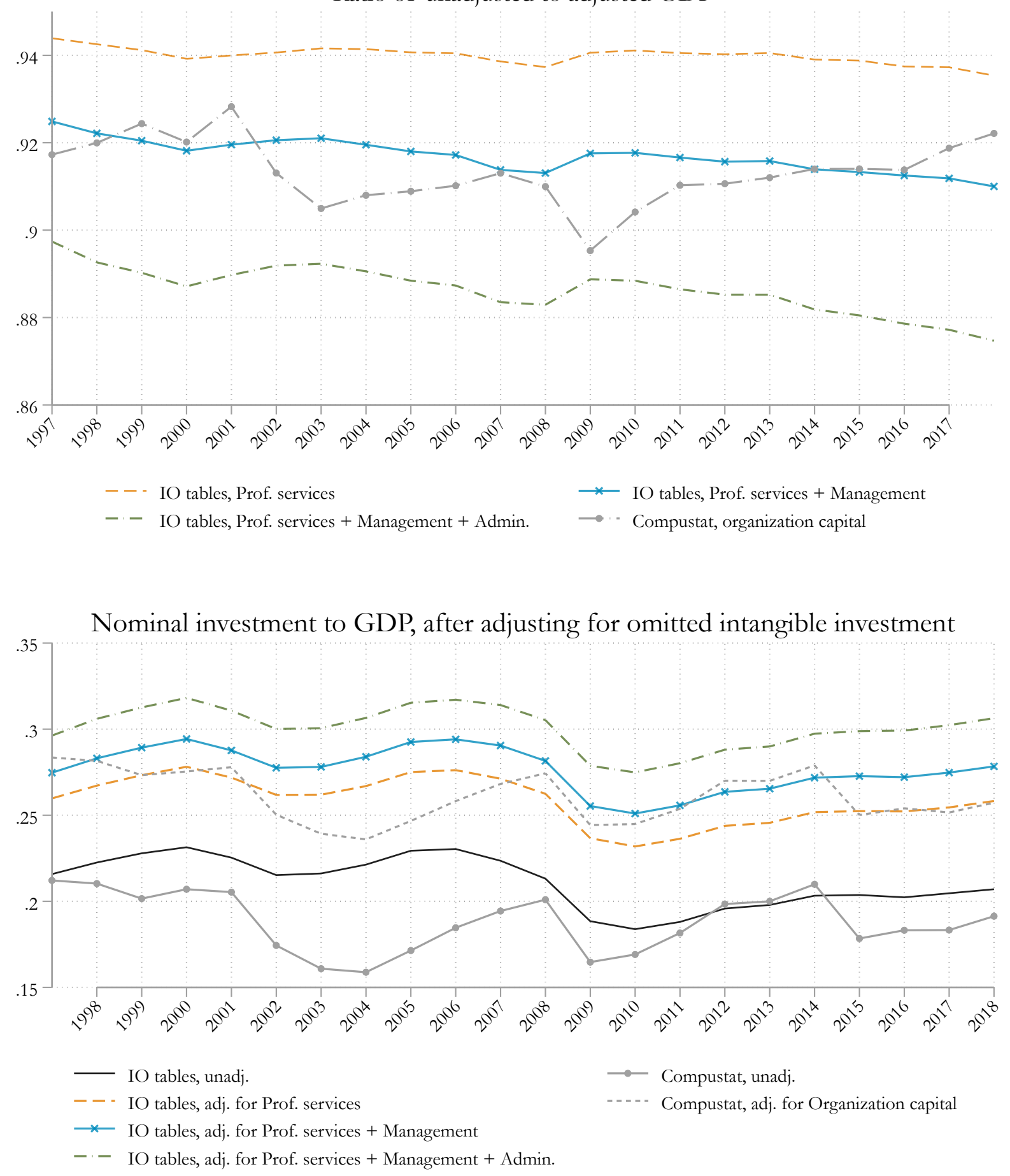

Figure A4: Compustat vs. IO tables: time series for unnadjusted GDP to GDP adjusted for ommited intangibles (top panel), and for the ratio of investment to GDP without and with adjustments for omitted intangibles (bottom panel). Relative to Figure A2, the only difference is the addition of the Compustat time series. The top panel reports the time series for $\hat{b}_{t}=P_{t} Y_{t} /\left(P_{t} Y_{t}+M_{t}\right)$, where $P_{t} Y_{t}$ is total GDP at producer prices, and $M_{t}$ is the nominal value of intermediate input use of a group of services, where the latter is obtained from the Use tables of the benchmark Input-Output accounts. The bottom panel reports the time series $\iota_{t}=\left(Q_{t} I_{t}+M_{t}\right) /\left(P_{t} Y_{t}+M_{t}\right)$, where $Q_{t} I_{t}$ is measured aggregate spending on investment goods. See Section 3.2 for details on time series constructed from the IO tables, and A.2.3 for the time series constructed from Compustat. 

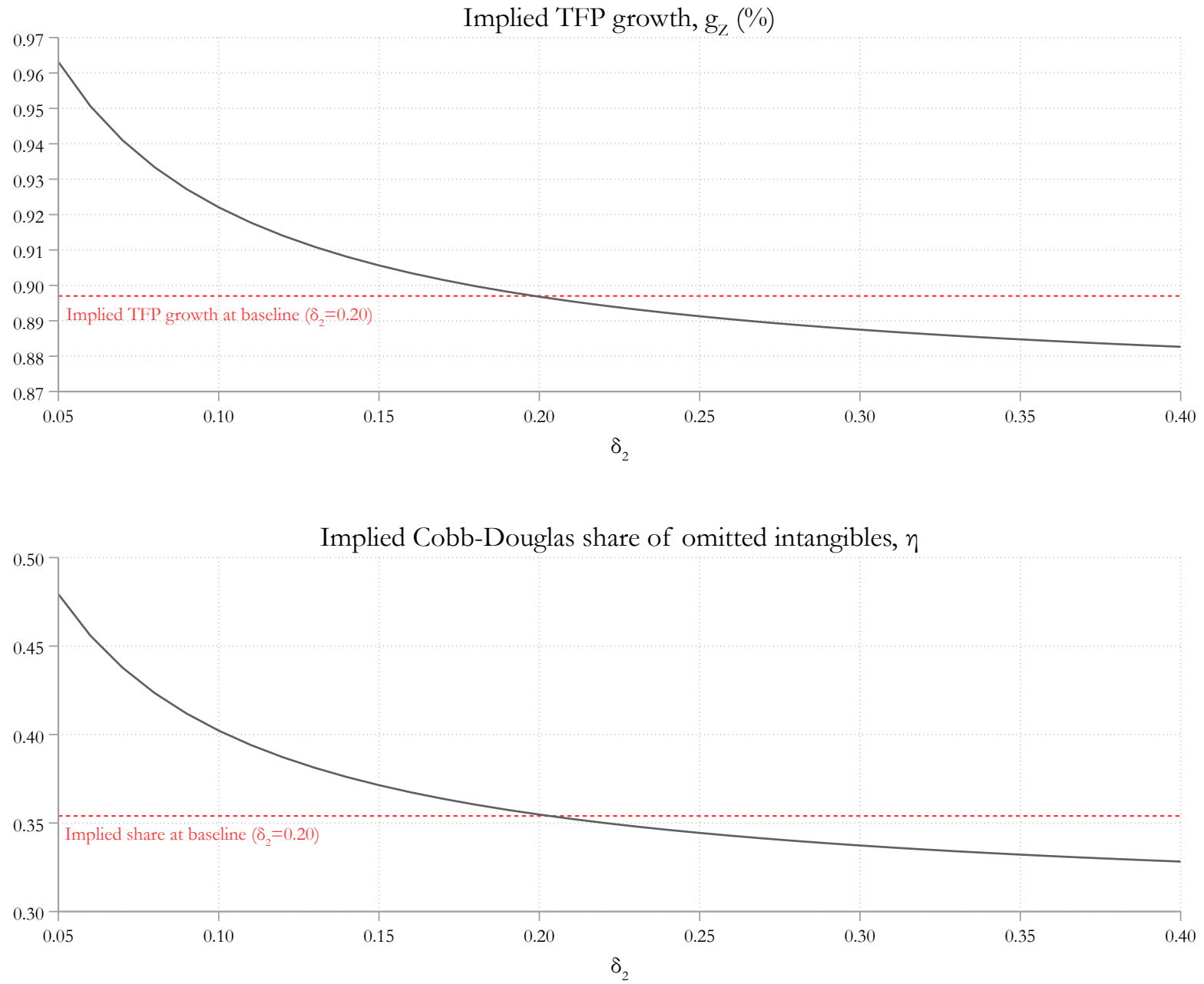

Figure A5: Implied moments for alternative values of the depreciation rate of omitted capital, $\delta_{2}$. The bottom graph reports implied productivity growth $g_{Z}$, and the bottom graph reports the implied value of the Cobb-Douglas share of intangible capital, $\eta$, obtained using the second of the two approaches describes in Section 3.1. For the values of $\hat{b}$ and $\hat{g}_{Q_{2}}$, we use those corresponding to the case when only intermediate expenditures on Professional, Technical and Scientific services (PSTS) and Management services are reclassified as intangibles. This corresponds to the fifth line in Table 4. 


\section{References}

Atkeson, A. and P. J. Kehoe (2005). Modeling and measuring organization capital. Journal of political Economy 113(5), 1026-1053.

Basu, S., J. Fernald, J. Fisher, and M. Kimball (2013). Sector-specific technical change. Manuscript, Federal Reserve Bank of San Francisco.

Bureau of Economic Analysis (2017). NIPA Handbook: Concepts and Methods of the US National Income and Product Accounts.

Byrne, D. M., S. D. Oliner, and D. E. Sichel (2013). Is the information technology revolution over?

Cette, G., J. Fernald, and B. Mojon (2016). The pre-great recession slowdown in productivity. European Economic Review 88, 3-20.

Crouzet, N. and J. Eberly (2020). Rents and Intangibles: a Q+ Framework. Working paper, Northwestern University.

Eisfeldt, A. L. and D. Papanikolaou (2013). Organization capital and the cross-section of expected returns. The Journal of Finance 68(4), 1365-1406.

Ewens, M., R. H. Peters, and S. Wang (2019). Measuring intangible capital with market prices. Technical report, National Bureau of Economic Research.

Fernald, J. (2014). A quarterly, utilization-adjusted series on total factor productivity. Federal Reserve Bank of San Francisco.

Fernald, J. G. (2015). Productivity and potential output before, during, and after the great recession. NBER macroeconomics annual 29(1), 1-51.

Oulton, N. (2007). Investment-specific technological change and growth accounting. Journal of Monetary Economics 54(4), 1290-1299. 